\title{
Proclus and Plotinus on Self-Constitution in the One
}

\author{
Jonathan Greig \\ 29,998 words \\ MSc by Research in Philosophy \\ The University of Edinburgh \\ August 20, 2014 \\ (With minor corrections made November 19, 2014)
}

This work is licensed under a Creative Commons Attribution 4.0 International License. http://creativecommons.org/licenses/by-nc-nd/4.0/ 


\begin{abstract}
The first principle, called the 'One', in Neoplatonism is typically asserted to be absolutely simple and beyond being, such that all positive attributes implying multiplicity are denied of it. With this in mind, in his Commentary on Parmenides, Proclus critiques the view that the One constitutes its own being. In making this critique, Proclus has his predecessor, Plotinus, in mind, who, although agreeing that the One is beyond being and absolutely simple, also holds the view criticized. At the same time, Plotinus' careful use of saying that the One is 'as if' (oiov) self-constituted ensures that he is not contradicting himself when he also denies that the One is divided or made dual in its constituting its own being. With this in mind, one could go with John Dillon's assessment that this disagreement is over semantics and that Proclus misunderstands Plotinus. However is Proclus misunderstanding Plotinus here, and are the differences between the two inconsequential on this count? In this dissertation, I wish to show that Proclus is accounting for Plotinus' 'as if' language through appropriating Plotinus' understanding of the One's causality, which is what makes possible Plotinus speaking of the One 'as if' causing itself. I focus on the two concepts of self-constitution in itself and the One's causality for both figures. Plotinus understands self-constitution such that, in the realm of being with Intellect and Soul, it represents each entity imperfectly realizing the One's perfect unity, which points to the One pre-containing perfect attributes that are imperfectly realized in Intellect. Likewise, the way Plotinus understands the One producing Intellect implies that the One anticipates Intellect in pre-containing its effects as a direct cause, albeit in a way that transcends literal description. This is what makes possible the language of the One 'as if' being self-constituted for Plotinus. Proclus rather understands the process differently: self-constitution in the realm of being indicates the respective perfection of each such entity (such as Being, Life, and Intellect), while simultaneously necessitating higher causes, eventually leading to the One as the first, uncaused cause. Proclus' One is rather an indirect cause through its production of beings by negation, starting with the two basic principles of the Limit and Unlimited as positive aspects of the One. Given these two factors of self-constitution in itself and the One's causality for Plotinus and Proclus, there is reason to see an underlying disagreement. I finally conclude that Proclus addresses and critiques Plotinus' causal model which supports the 'as if' language, which makes possible Plotinus' quasi-self-constitution in the One, so that insofar as Proclus requires the One to be absolutely simple in negating all sense of multiplicity, Proclus' critique is to this extent justified, where his own causal model is an attempt at improving on the inadequacy seen in Plotinus' system.
\end{abstract}




\section{Acknowledgements}

Special thanks to my supervisor, Dr. Inna Kupreeva, for all her support, insight, and advice in these past two years, and especially recently in the creation of this project.

I also wish to thank Prof. Carlos Steel for his recommendation for me to look into the metaphysics of self-constitution ( $\left.\alpha \dot{v} \theta v \pi \sigma_{\sigma} \sigma \alpha \tau o \nu\right)$ in Proclus, which was the inspiration for this project. As well, I must thank Prof. Peter Adamson, Dr. Gary Gabor, Dr. David Butorac, Evan King, and Alan Brown for all of their insights and suggestions with textual references and help with understanding the various concepts involved in this project between Plotinus and Proclus. 


\section{Contents}

1 Introduction $\quad 5$

2 Self-Constitution and Its Conceptual Origin in Self-Motion 9

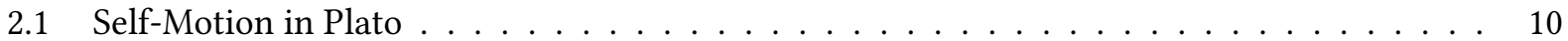

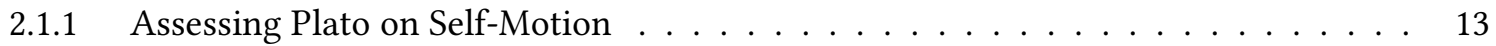

2.2 Aristotle on Self-Motion and the Unmoved Mover . . . . . . . . . . . . . . . . . . . . . 14

2.2.1 Self-Motion as Distinguished into Unmoved and Moved Movers . . . . . . . . . . . 15

2.2.2 Comparing Aristotle's Approach with Plato's on Self-Motion . . . . . . . . . . . 17

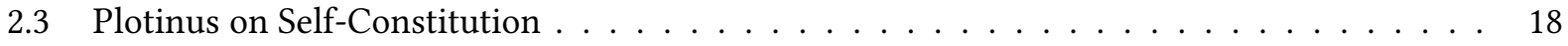

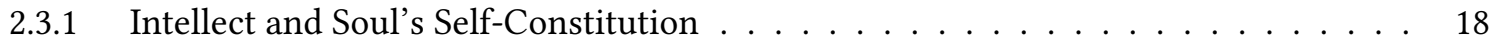

2.3.2 Answering the Aristotelian Objection to Self-Motion: Motion as an Aspect of Self-

Constitution . . . . . . . . . . . . . . . . . . . . 20

2.3.3 Conclusion: Self-Constitution in Plotinus' System . . . . . . . . . . . . . . . . 22

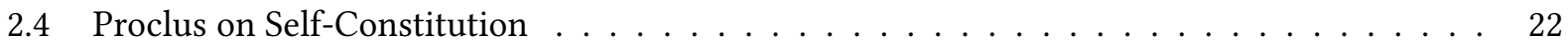

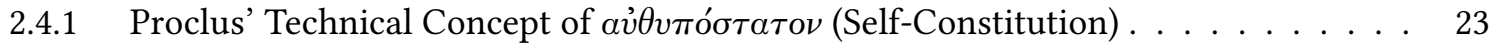

2.4.2 Self-Constitution in the General Structure of Causality . . . . . . . . . . . . . . 27

2.5 Conclusion: Comparing Plotinus and Proclus on the Concept of Self-Constitution . . . . . 28

3 Plotinus on the One and Its Causality 30

3.1 Plotinus' Principle of Simplicity and the Necessity for the One as First Principle . . . . . 30

3.1.1 The One as Beyond Being and Absolutely Simple . . . . . . . . . . . . . . . . . . . 32

3.2 The One's Causality of Being . . . . . . . . . . . . . . . . . . . 33

3.2.1 The One as Causing By What It Does Not Possess . . . . . . . . . . . . . . . . 34

3.2 .2 The Two-Act Theory . . . . . . . . . . . . . . . . . . . . 36

3.3 The oiov Principle: The One as Pre-Containing Multiplicity and Being . . . . . . . . . . 39

3.4 Conclusion: Plotinus' Conception of Simplicity and the Implications for Self-Constitution 40

4 Proclus on the One and Its Causality 42

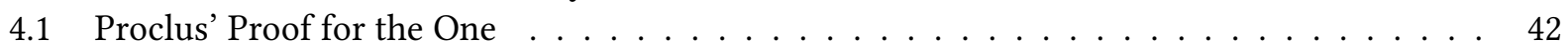

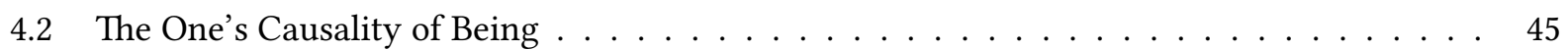

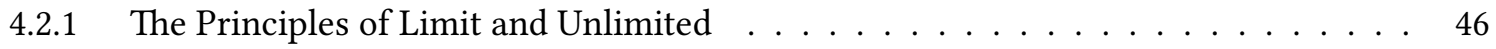

4.2 .2 The One's Causality via Negation . . . . . . . . . . . . . . . . . . . . 48

4.3 Conclusion: The One as Uncaused and Cause of Self-Constitution ～. . . . . . . . . . . 52

5 The One and Self-Constitution $\quad 54$

5.1 Enn. VI.8.13-14: Plotinus' Argument for the One as Cause of Its Own Being . . . . . . . 54

5.1.1 Contextualizing Plotinus' Argument for the One's Self-Constitution . . . . . . . . 55

5.1.2 Plotinus' Analogical Language as Corresponding with the One's Being . . . . . . . 57

5.2 Reviewing Proclus' Critique of Self-Constitution in the One . . . . . . . . . . . . 59

5.3 Objection: Is Proclus' Critique Justified? . . . . . . . . . . . . . . . . 61

5.4 Conclusion: Proclus' Causal Model as a Response to Plotinus . . . . . . . . . . . . . . . . 63

A The One and the Henads in Proclus $\quad 65$

B Some Conceptual Background on the Limit and Unlimited in Proclus $\quad 68$ 


\section{Introduction}

The nature of the first principle's causality is a major question for the Neoplatonists. From Plotinus onward, the Neoplatonic tradition has as its axiom that (1) all being is derived from a first principle that is an efficient cause, as well as final cause; and (2) that the first principle, the 'One', is absolutely simple and beyond being in itself. ${ }^{1}$ Where all being is characterized by some form of multiplicity, whether at the physical level or even the intelligible level, the One functions as the source of unity, and therefore existence, for all being. How the One is simple, and how the One functions as a cause of being, is at once a difficult, contested question for the Neoplatonists.

Given this background, in the Commentary on Parmenides, ${ }^{2}$ Proclus critiques the view that the One is self-constituted, saying that what is self-constituted, 'must necessarily be divisible into a superior and an inferior element; for it is superior in so far as it creates, and it is inferior in so far as it is created; the One, on the other hand, is entirely indivisible and non-multiple' (In Parm. 1150.6-9; trans. Morrow/Dillon). For Proclus, self-constitution implies a distinction of cause and effect, between a 'superior' and 'inferior' aspect of the same being, which implies a duality that the One, by definition, precludes. In giving this critique, Proclus appears to have Plotinus in mind, the latter of whom holds that the One in some sense constitutes its own being:

...for [the One] is the father of reason and cause and causative substance, which are certainly all far from chance, he would be the principle and in a way the exemplar ( $\pi \alpha \rho \alpha \dot{\delta} \epsilon \iota \gamma \mu \alpha)$ of all things which have no part in chance, truly and primarily, uncontaminated by chances and coincidence and happening, cause of himself and himself from himself and through himself. (Ennead VI.8.14.37-42; trans. Armstrong)

Plotinus asserts self-constitution in the One insofar as it is the source of being and Intellect, so that because of this, the One is most free and in control of itself such that it constitutes its being from itself and not from chance or any prior cause. ${ }^{3}$ In the background to this disagreement, Plotinus and Proclus equally hold that the One is absolutely simple and beyond all multiplicity, even to the point that all literal knowledge of the One is impossible. As a result, both Plotinus and Proclus negate all positive attributes applying to the One, insofar as any such attribute implies multiplicity. At one level, both philosophers agree that the One is beyond being a cause in any sense, even of having any activity or causation in relation to itself.

Given this picture, one could go along with John Dillon's assessment of Proclus' critique:

Proclus next turns to an attack on those Platonists who wish to make the One 'self-constitutive' ( $\alpha \dot{v} \theta v \pi$ ó $\tau \tau \alpha \tau o \nu)$.

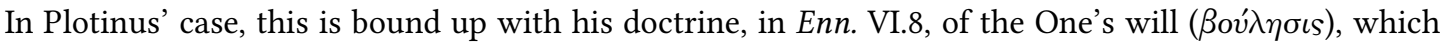
brings about its self-generation. For Proclus, self-constitution seems inevitably to involve a duality of creating and created aspects. Plotinus, however, is second to no man in his insistence on the complete

\footnotetext{
${ }^{1}$ A possible exception in this group is Porphyry, who is quoted by Damascius as holding that the first principle of all is

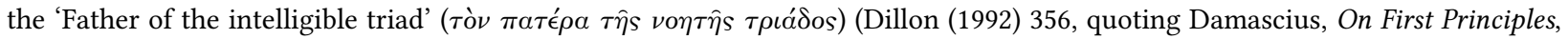
ch. 43). Although even with Porphyry, Dillon (1992) presents evidence to suggest that Porphyry keeps to an essentially similar understanding of the One as Plotinus-that is, that the One is absolutely simple, while as the source of Intellect, the One functions as the intelligible of Intellect's thinking, emphasized more so over Plotinus' description of the One as a kind of, but not literal, intelligible. Discussed further below.

${ }^{2}$ Here onward abbreviated as 'In Parm.'.

${ }^{3}$ Plotinus' emphatic response against the idea that the One comes about by chance begins in Enn. VI.8.7.11-13, with the 'rash statement' implying this latter view. Discussed further below in ch. 5.1.1.
} 
simplicity of the One, so the dispute here is really a matter of semantics, with, if anything, Proclus not appreciating the subtlety of Plotinus' reasoning. ${ }^{4}$

Dillon is initially right in pointing out the 'subtlety of Plotinus' reasoning': when Plotinus talks about the One's self-constitution, before he applies the concept to the One Plotinus lays out rather carefully that all positive language of the One can only be conditioned in 'as if' (oiov) phrases, in such a way that the One's unity is preserved. ${ }^{5}$ Put this way, Proclus' critique does seem a bit unfair, insofar as he does not explicitly address this linguistic distinction that Plotinus employs.

Despite this assessment, I believe there are other reasons to see that Dillon's conclusion may not be correct. While Plotinus and Proclus agree on the necessity for the One to be absolutely simple and beyond being, the criterion for the One's simplicity is construed differently between the two. For Plotinus, the One's direct production of Intellect implies that it must pre-contain the multiplicity of Intellect's being in a unified way, such that Plotinus will call Intellect an image of the One as a paradigm, or exemplar (as we just saw earlier). Proclus, by contrast, sees that the One's absolute simplicity necessitates a denial of even implicit multiplicity in the way Plotinus' One pre-contains this. The One for Proclus must be unparticipated as the first cause of being and multiplicity; instead of the One being a direct cause of multiplicity and being, Proclus relocates the cause of multiplicity to the principles of the Limit and Unlimited, which are positive manifestations of the One. As a consequence, Proclus holds that the One is a cause of all things sheerly through its negation of all positive attributes.

It is on the basis of this background that Plotinus affirms self-constitution in the One while Proclus denies this. For Plotinus, self-constitution in the lower entities of Intellect and Soul, below the One, are imperfect realizations of what the One is perfectly: although Plotinus denies the duality of self-thinking and, in this, self-constitution to the One, where these latter attributes properly apply to Intellect, Plotinus says that these apply in a certain way (in 'as if' terms) to the One as the source of Intellect, since it precontains perfectly what is imperfectly realized in multiplicity in Intellect. Proclus, by contrast, understands self-constitution differently to imply an entity's perfection in itself and simultaneous dependence on a higher cause: the highest entity, Being, for instance, is self-constituted as realizing its particular perfection as the principle of all beings, while on the other hand such self-constitution necessitates dependence on ultimately uncaused causes, such as the Limit and Unlimited in Being's case. In this sense, Proclus is conceiving of self-constitution as manifesting particular aspects of being from the basic combination of the Limit and Unlimited outside the One, so that the One is left free from being a direct cause of multiplicity in itself.

Given these two aspects of how the One's simplicity is conceived, in relation to its generation of being, and how self-constitution is conceived, I wish to show in this dissertation that Proclus is implicitly accounting for these differences in his critique of Plotinus on the One being self-constituted. Pace Dillon's assessment, Proclus' critique is accounting for the language Plotinus permits of the One, where Proclus rightly sees a tension in the admission of a quasi-multiplicity in the One, the latter of which is also otherwise asserted to be absolutely simple by Plotinus. Proclus' system of self-constitution and the One's

\footnotetext{
${ }^{4}$ Morrow/Dillon (trans.) 477.

${ }^{5}$ Enn. VI.8.13.46-50.
} 
simplicity, on his understanding, is an attempt to get around the tensions of making the One a direct cause of being.

In order to begin this inquiry, we should start with the more basic concept of self-constitution for Plotinus and Proclus, followed by an analysis of the One for both. By analyzing these two concepts separate, we can then see how Proclus accounts for Plotinus' approach to the One in the final chapter. Chapter 2, in particular, will begin with the conceptual origin of self-constitution with self-motion in Plato and Aristotle, who both try to explain physical motion as ultimately arising from immaterial causes. Plato holds that self-motion in itself is necessary to explain externally-caused motion, while Aristotle instead shows that proper motion can only reduce back to unmoved movers. Both Plotinus and Proclus end up adapting Plato's understanding of self-motion and Aristotle's framework of the unmoved mover into their systems, albeit in different ways. Plotinus' understanding of self-constitution in the entities of Intellect and Soul will be shown to imply each entity's imperfect realizing of the One's unity, which points to the One possessing in a unified, perfect way the self-constituting activity that each lower entity has. By contrast, Proclus' view of self-constitution follows on Proclus' understanding that there is a hierarchical multiplicity of entities in the realm of soul and intellect-rather than the single hypostases of Soul and Intellect, as in Plotinus' system-which are at once causally dependent on each other. Proclus' understanding of self-constitution in this approach is that each entity constitutes itself as a sign of its perfection, while each self-constituted entity is dependent on prior causes-which eventually leads to non-self-constituted causes like the One.

Chapters 3-4 will look at the One and its causality in Plotinus and Proclus. In Plotinus' case, the theory of two acts, with all things having an internal and external act, will play a factor in the One's production of Intellect, while at the same time we will also see how Plotinus characterizes the One as absolutely simple and beyond being while also pre-containing the causes of all being within itself. In contrast to this, Proclus will be shown to be looking at the One's causality of being through the dyad of the Limit and Unlimited arising as positive aspects of unity from the One. The outcome of this comparison will be to show how Plotinus conceives of the One as a direct cause of multiplicity, while Proclus understands the Limit and Unlimited as the direct causes of multiplicity, with the One acting as a purely negative cause. By understanding the One either implying in a 'hidden' way multiplicity (for Plotinus), or negating all implications of multiplicity (for Proclus), this will be the foundation on which self-constitution is either asserted or negated of the One.

Chapter 5 will finally review the passages where Plotinus asserts self-constitution in the One and also where Proclus critiques the view of self-constitution applying to the One. Particular focus will be given to the way Plotinus speaks about the One's self-constitution as part of his more general consideration of the One pre-containing in a hidden way attributes that are manifested in Intellect as an image of the One. Out of this analysis, it will be asserted that Proclus' denial of metaphorical language in relation to the One follows on understanding that the use of that metaphorical language is a natural side-effect of the way Plotinus understands the One to pre-contain its effects. From this, I will argue that Proclus' critique of Plotinus' argument for self-constitution in the One is justified insofar as Proclus wishes to hold to a consistent understanding of the One's simplicity implying the negation of all implications of multiplicity, even if 'hidden' and unified on Plotinus' account and use of metaphorical language. Plotinus' One, on 
this count, stands only on the premise that the simplicity of the One can be conceived to allow for an analogical sense of multiplicity that preserves its internal unity. If simplicity in the One is meant to have a full realist implication, Proclus' account does more justice to the reality of the One as absolutely simple, while self-constitution as relegated to entities of the realm of intellect and soul are those by which the multiple attributes of being come about, rather than being pre-contained in the One as with Plotinus. 


\section{Self-Constitution and Its Conceptual Origin in Self-Motion}

In order to begin an inquiry into Proclus' response to Plotinus, it will help for us to step back and ask what is being meant by self-constitution in itself-both as Proclus develops a systematic understanding of the

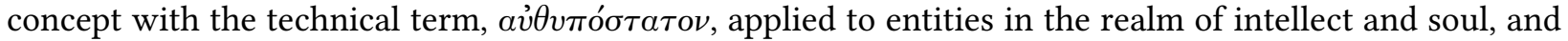
as Plotinus analogously understands the concept with his characterization of the One's self-constitution

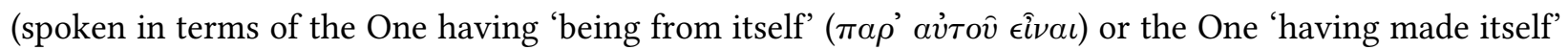

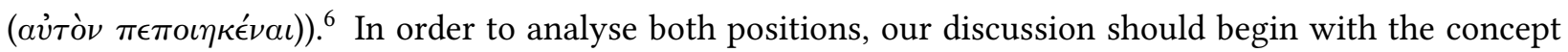
of self-motion in Plato and Aristotle. One reason to go back to the concept of self-motion can be found in Proclus directly relating the concept with self-constitution in his Commentary on the Parmenides, where he argues that the self-caused stands in the same relationship to what is caused by another as self-motion does for things that are externally moved:

For a start everything is said to be in itself which is cause of itself and which is self-constituted

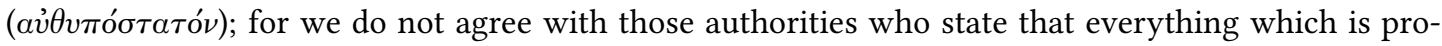
duced is produced by a cause other than itself, but even as we are accustomed to rank the self-motive

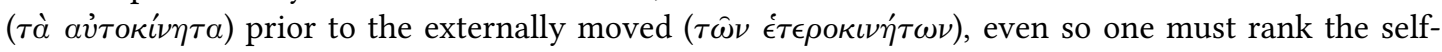
constituted as prior to what is produced by another agent. (In Parm. 1145.26-1146.1; trans. Morrow/Dillon)

In this case, Proclus is taking as a more general principle the view that all things which are caused by another must go back to self-caused entities, which follows on the same doctrine that the self-moved is the proper first cause of the externally moved. Proclus' reference to the 'authorities' with which he disagrees recalls Aristotle's position that everything which is in motion reduces back to an unmoved mover-which, in this case, Proclus thinks is not enough for caused beings, let alone moved things. ${ }^{7}$ The implicit reference to Aristotle also brings to mind Plato's view that self-motion is the proper first cause of all moved things, a position which Aristotle disagrees with and refines with the unmoved mover as the first, efficient cause of motion.

Because Proclus draws this connection between self-motion and self-constitution, it will be worthwhile to begin our analysis with Plato and Aristotle's positions on self-motion in order to see how the early consideration of this question will bear on the later concept of self-constitution. We will then look at Plotinus and Proclus on self-constitution and see how they adapt Plato and Aristotle's earlier positions to their own metaphysical structures. As we will eventually see, Plotinus implicitly ends up drawing on Plato's understanding of self-motion for his entities of Intellect and Soul posterior to the One, where each has a characteristic self-constitutive motion which is cause of its subsequent product. At the same time, Plotinus also wants to reconcile and combine Aristotle's concept of the unmoved mover with Plato's selfmover in the case of the One, so that Plotinus' attribution of self-constitution to the One is somewhat analogous to Plato's holding self-movers as the first efficient cause of motion. Proclus similarly re-adapts Plato's self-movers in the case of the intermediary entities of soul, while he develops a distinct notion of

\footnotetext{
${ }^{6}$ Enn. VI.8.13.54-55.

${ }^{7}$ Steel (ed., 2009) 139, n. 28, lists the 'Peripatetici' as the corresponding source for Proclus' authorities. Given the connection to Aristotle, cf. Physics VII.1, 241b34, 242a49-50; VIII.5, 256a13-18.
} 
self-constitution, analogous to self-motion, which also applies to entities in the realm of intellect as well as soul. Proclus ultimately wishes to keep a version of Aristotle's unmoved mover as distinct from Platonicadapted self-movers, and in doing so Proclus also carries this over by holding to a structure of uncaused cause and self-caused causes, unlike Plotinus. While Plotinus might be roughly characterized as keeping to a Platonic two-term structure of self-constituted and externally caused, Proclus sees the necessity to hold to an Aristotelian-adapted three-term structure of uncaused cause, self-caused cause, and externally caused.

\subsection{Self-Motion in Plato}

Plato discusses self-motion in Laws (894-895), Timaeus (88e-89a), and Phaedrus (245c-e), while the Laws passage provides a more in depth account of self-motion. In the Timaeus passage, Plato, by way of Timaeus, references self-motion as the best kind of motion among others when he talks about the relation of soul with body in the general context of the cosmos:

Now the best of the motions is one that occurs within oneself and is caused by oneself. This is the motion that bears the greatest kinship to understanding and to the motion of the universe. Motion that is caused by the agency of something else is less good. Worst of all is the motion that moves, part by part, a passive body in a state of rest, and does so by means of other things. (Timaeus 88e-89a; trans. Zeyl.)

Plato provides this hierarchy of motions in the general context of the good conditioning of the whole man with soul and body, where it is the right proportion between and in the two elements that is the foundation for being in a good or bad condition. ${ }^{8}$ Being in a good condition implies exercising both body and soul in the right proportion-exercising the body and not being entirely at rest, for instance, is modelled after 'foster-mother and nurse of the universe' (Timaeus $89 \mathrm{~d}$ ), where the internal and external motions of the body are in harmony. Likewise, one who simply exercises the body should also exercise the soul with the various pursuits of wisdom if such a man is 'to truly deserve the joint epithets of 'fine and good". Thus when Plato provides the three accounts of motion, self-motion is shown to be the best since it is tied with keeping the right balance of proportions which brings about the good condition of the whole $\operatorname{man}^{9}$ - where the internal and external motions of the body are in harmony. Likewise, one who simply exercises the body should also exercise the soul with the various pursuits of wisdom if such a man is 'to truly deserve the joint epithets of 'fine and good". Although in this context Plato speaks in terms of the body, Plato appears to have the principle of self-motion as the best in mind when he talks about the world soul 'revolving within itself' after it is 'woven together with the body from the center on out in every direction to the outermost limit of the universe'. ${ }^{10}$ The soul in this context is called the 'most excellent' of all things created by the Demiurge, since it shares in reason and harmony. ${ }^{11}$ Combined with the previous

\footnotetext{
${ }^{8}$ Timaeus $87 \mathrm{c}-\mathrm{d}$.

${ }^{9}$ Timaeus $87 \mathrm{~d}$ illustrates this well with the man who exercises himself in the proper balance: 'But if he models himself after what we have called the foster-mother and nurse of the universe and persistently refuses to allow his body any degree of rest but exercises and continually agitates it through its whole extent, he will keep in a state of natural equilibrium the internal and the external motions' (trans. Zeyl).

${ }^{10}$ Timaeus 36d9-e6; trans. Zeyl.

${ }^{11}$ Timaeus 37a1-3.
} 
observation of self-motion in relation to the body, it seems that Plato thinks of self-motion as best in this context, insofar as it, in one sense, embodies reason as a principle for external motions which originate from its own movement.

The second consideration of self-motion can be seen in Phaedrus 245c-e when Plato uses self-motion as part of the proof for saying that soul is immortal:

First, then, we must learn the truth about the soul divine and human by observing how it acts and is acted upon. And the beginning of our proof is as follows: (3) Every soul is immortal. (1a) For that which is ever moving is immortal but that which moves something else or is moved by something else, when it ceases to move, ceases to live. (1b) Only that which moves itself, since it does not leave itself, never ceases to move, and this is also the source and beginning of motion for all other things which have motion. But the beginning is ungenerated. For everything that is generated must be generated from a beginning. And since it is ungenerated, it must be also indestructible; for if the beginning were destroyed, it could never be generated from anything nor anything else from it, since all things must be generated from a beginning. Thus (1c/1) that which moves itself must be the beginning of motion. And this can be neither destroyed nor generated, otherwise all the heavens and all generation must fall in ruin and stop and never again have any source of motion or origin. But since that which is moved by itself has been seen to be immortal, one who says that this self-motion is the essence and the very idea of the soul, will not be disgraced. For every body which derives motion from without is soulless, but that which has its motion within itself has a soul (2), since that is the nature of the soul; but if this is true, that that which moves itself is nothing else than the soul-then (3) the soul would necessarily be ungenerated and immortal. Concerning the immortality of the soul this is enough.... (Phaedrus 245c5-246a1; trans. Fowler)

The structure of this passage has various parts worth analyzing. In this passage, Plato (through the character of Socrates) uses self-motion as a middle premise for showing the soul to be immortal, so that the following syllogism is implied:

1. All self-motion (B) is immortal (A).

(a) All that is ever-moving (1b) is immortal (1a).

(b) All that is self-moving (1c) is ever-moving (1b).

(c) Therefore, (1) all that is self-moving (1c) is immortal (1a).

2. All soul (C) is that which is self-moving (B).

3. Therefore, all soul (C) is immortal (A).

With the second, minor premise, (2), exactly how extensive 'all soul' is taken to be is somewhat ambiguous in the passage, as well as what kind of soul is meant. Plato specifies soul 'divine and human', which would appear to preclude other living things lower than a human level, however to what degree this implies soul as rational compared to soul as involving the incensive, or appetitive, parts is a question. In any case, what appears to matter most for our purposes, at (1b) in the passage, is the nature of self-motion as a necessary beginning for all motion with the first premise, where eternal motion self-evidently implies immortality. This is a fair start, although exactly how and why self-motion constitutes a necessary beginning for all motion is not immediately clear-could we not imagine a scenario (which Aristotle eventually brings up) 
of something that is unmoved in itself but causes motion and thus constitutes the beginning of motion? Yet this is not enough here: given the metaphysical options we are presented with, where else will motion come from except from something which is in motion itself? In other words, it seems for Plato there must be a paradigm of motion on which all other motions find their source and beginning-thus something which is self-moved and remains an eternal source of motion on which all temporal, corruptible motions return to as their beginning and generation. ${ }^{12}$

This brings us to the Laws X passage discussing self-motion, where Plato brings out more explicitly other reasons for considering self-motion as the best kind of motion. In the general context of this passage, Plato is seeking to show the existence of the gods as paradigms around which the city's constitution should be framed. An essential part of this proof for Plato involves showing that soul is the cause of all motion in the universe-and this is done so by way of showing that soul as self-moved is the cause, which implicitly leads to the existence of the gods as related to the nature of soul. ${ }^{13}$ Looking in detail where self-motion is discussed, at Laws 893b1-894b1 Plato lists what end up being eight kinds of natural motion ${ }^{14}$ that form the posterior kinds of motion dependent on two primary motions: what is moved by something else (or rather 'incapable of moving itself') and moves other things, and that which moves itself and other things. ${ }^{15}$ Plato eventually sets out to show that the motion which moves itself and others is the most primary form of motion, taking priority over that which is 'incapable of moving itself', which by implication seems to include all the other categories of motion. ${ }^{16}$ We see this further elaborated in the following:

Athenian Stranger: Let us speak further, in the following way, and again answer ourselves. If somehow everything were to come together and stand still, just as most of those men venture to say, which motion of the ones we spoke of would necessarily be the first to come to be among them? Surely the one that moves itself. For it would never be changed by another that is prior, since there is among them no prior change. So, as the source of all motions, and the first to come to be among what was standing still and to exist among what moves, we shall assert that the one that moves itself is necessarily the oldest and most powerful change of all, while the one that is altered by another and moves others is second. (Laws X 895a4-b8; trans. Mayhew)

The Athenian Stranger here sets up a situation where, assuming all things are at a stand-still, we should see that self-motion must necessarily be the first motion among the others to come into being. All the other motions end up being summed up in the motion that does not move itself, which implies that the motion which moves itself-self-motion-must come first as that which first brings about the other kinds

\footnotetext{
${ }^{12}$ Cf. Menn (2012a) 7-8, which considers further why Plato (among others like Democritus) is unable to conceive of an unmoved mover causing motion, since it would seem that to cause motion necessitates the entity being, itself, in motion. This is where the distinction between potentiality and actuality $\left(\dot{\epsilon}^{\prime} \nu \rho \gamma \epsilon^{\prime} \dot{\alpha} \alpha\right)$ is one essential element which makes possible Aristotle positing an unmoved mover in the way he does.

${ }^{13}$ Seen later at Laws 896e1-897b7, esp.: 'Athenian Stranger: Indeed, since soul manages and resides in all things that anywhere are in motion, isn't it necessary to assert that it also manages the heavens? Klineas: Indeed so. ... Athenian Stranger: So soul drives all things in the heavens and on earth and in the sea through its own motions... Soul uses all of these, and every time it joins with reason-'god' correctly for the gods-it guides all things toward what is correct and happy, but when it associates with lack-of-reason it produces in all things the opposite of these.'

${ }^{14}$ (1) Motion in one location-i.e. circular motion; (2) motion in many locations ('gliding' and 'rolling'); (3-4) separation and combination; (5-6) growth and decay; and (7-8) generation and corruption. See Mayhew 106-17 for a comprehensive discussion of these types of motion listed in 893b1-894b1. Proclus, at In Parm. 1155.15-27 and 1158.12-17, describes the motions listed in the Laws passage as natural motions; cf. Opsomer 226, n. 177.

${ }^{15}$ Laws $894 \mathrm{~b} 9-\mathrm{c} 1$.

${ }^{16}$ Mayhew (comm.) 118-9.
} 
of motion. Plato says that this is the 'oldest' motion, although it is initially unclear if he means 'oldest' in time absolutely. Insofar as the thought experiment takes all things at a stand-still, in relative terms we can take Plato to mean at least that which moves itself is the first motion which sets other, non-self-moved things in motion. Plato speaks abstractly at this point, we should bear in mind: we could imagine an animal, as a whole, moving itself. However we find Plato is not simply thinking of this: Plato goes on to link self-motion with life when he talks about 'earth or water or what has the form of fire' (Laws 895c4-7) which also moves itself-what in other words has the principle responsible for such self-movement, i.e. soul. While all bodies are, in themselves, lifeless and moved by another, Plato seems to have in mind soul as a distinct, separable attribute which applies to living bodies (like animals) by which such bodies are moved. Given this, Plato defines the essence of soul as 'self-motion', implying that soul is a first principle of motion by pre-containing motion imparted to other, moved entities below it in its moving itself. We can see the Laws passage as a variation of the argument offered in Phaedrus 245-246, where self-motion necessarily constitutes a beginning for all motion as a paradigm, since such a motion 'does not leave itself, [and] never ceases to move'.

\subsubsection{Assessing Plato on Self-Motion}

In all these passages, Plato ranks self-motion as the best, highest form of motion, presumably insofar as such a motion comes from itself instead of being dependent for its being from another. In both the Laws and Phaedrus passages, Plato links self-motion with soul as responsible for all physical motion in the cosmosimplicitly this would include the motion of the planets and stars, as well as the more proximate cases of plants and animals. One question that is perhaps not so clear is exactly how Plato conceives motion, particularly with the soul: is this a kind of physical motion, itself, or is this immaterial and distinct from physical motion? If the latter, how is this so? Earlier in the Timaeus the soul is implicitly distributed in bodies in its motion, which almost implies that it has a quasi-physical existence, even if it is not visible and like other physical motions. ${ }^{17}$ On the other hand, Plato's implication that self-motion implies immortality through perpetuity implies that it has a distinct existence compared to extraneous motion found in physical bodies.

In the Timaeus, soul functions as a bridge between the intelligible realm and the physical realm, bringing about ordered motions and forms in physical things. ${ }^{18}$ Given this bridge, one possible reason for the emphasis on self-motion, or soul, as implying immortality is the tie the latter has with the Forms as eternal paradigms. Self-motion, on this picture, could be characterized in a similar relationship of soul to the Forms insofar as it is a paradigm of motion from which all other externally-caused motions come about. Support for this might come in the form of Sophist 249a-d, where Plato introduces motion as a distinct Form into the intelligible realm of Being, since 'if no beings change then nothing anywhere possesses any intelligence about anything' (Sophist 249b4-5). At the same time, Plato characterizes motion as one among five other 'great kinds' ( $\mu \epsilon$ ' $\left.\iota \sigma \tau \alpha \gamma \epsilon \nu \eta^{\prime}\right)$ which define the intelligible realm: other than Motion, Being, Sameness, Dif-

\footnotetext{
${ }^{17}$ Timaeus 46d4-7. Cf. Broadie (2012) 179-80 on the question of the soul's ontological status; cf. Opsomer (2012) 263.

${ }^{18}$ Timaeus 36e-37a3; see earlier discussion.
} 
ference, and Rest are the other 'kinds'. ${ }^{19}$ Because of the introduction of motion into the intelligible realm, Plato may have in mind that the soul's self-motion is a kind of instantiation of motion in the intelligible realm as a middle point between the external motion of the physical world and intelligible form of motion among the other five 'great kinds'. This is, of course, one way to conceive of how Plato is envisioning self-motion as an intermediary between the intelligible and physical realms.

Ultimately, however, Plato does not address how self-motion is distinct from physical motion, if it is different. Another question is why Plato does not also consider the possibility that the first efficient cause of motion is an unmoved mover; although Plato locates motion as one of the highest Forms, if motion were to imply, for instance, a capacity being filled or potentiality being brought to act, would there not need to be something which is prior to this sense of motion? (A critique Aristotle has, as we next see.) Such questions Plato does not explicitly answer for us. At the least, we do see that there is a distinction between motion as it is manifested in externally moved things and the type of motion that exists in a higher entity like soul, with soul's self-motion, for instance, as the paradigm and cause of lower, externally-caused motion. We will eventually see Plotinus indirectly return to this causal structure with his understanding of Intellect and Soul's self-constitution. We will also see Proclus directly pick up on self-motion as a necessary step in the chain of causality as immediately responsible for external motion, while self-moved entities must rely on a prior, unmoved mover. This is where Aristotle's critique and modification of Plato's understanding of self-motion comes in next.

\subsection{Aristotle on Self-Motion and the Unmoved Mover}

Aristotle picks up on self-motion as a principle of movement from Plato, while he makes crucial refinements in the theory. Although Aristotle agrees that self-motion stands prior to things that are in motion, he brings out a distinction in all self-motion between two elements: the unmoved mover, and the moved mover. In doing so, self-motion is no longer seen as correlating with an entity that is unified in being at once that which moves and that which is moved, but rather self-motion is seen as involving two, distinct elements of (A) an unmoved mover and (B) a moved mover in an entity that moves itself. This kind of analysis of self-motion eventually makes possible Aristotle's positing of a first principle for all motion in the form of the first unmoved mover that is responsible for the eternal motion of the stars and planets, which are thereby causes of all corruptible motion in the sublunar region. ${ }^{20}$ Given this overview, it will help to analyze the reasons why and how Aristotle will distinguish these two elements in the mechanism of self-motion.

\footnotetext{
${ }^{19}$ Sophist 254d4-256e, where the first three kinds of Being, Motion, and Rest are placed together with Sameness and Difference.

${ }^{20}$ Implied at Physics VIII.10 with the proof that the first, unmoved mover of all motion is without magnitude and parts, and beyond the circumference of the world. This is elaborated in Metaphysics XII.6-10, where the unmoved mover (shown to be multiple unmoved movers in XII.8 for each star/planet, although there is some implication that there is a first unmoved mover among the many) is shown to be completely in act, intellect ( $\nu$ ov̂s) thinking itself, and the direct final cause for the eternal motion of the stars and planets, which in turn cause the generation and corruption of the sublunar world.
} 


\subsubsection{Self-Motion as Distinguished into Unmoved and Moved Movers}

Aristotle's analysis of self-motion starts in Physics VIII.4, where he shows that all things in motion have a distinct principle which is responsible for their motion, applying in the case of both externally moved things (e.g. hand moving stick) and internally, self-moved things (e.g. soul moving animal). Given this general premise, Physics VIII.4 finishes with a question of whether the principle itself is also in motion or not. At the beginning of Physics VIII.5, Aristotle takes up this question by considering the example of the man moving his hand, which moves the stick that moves the stone. ${ }^{21}$ In this series, Aristotle notes that each element is moved by something else beyond itself-except for the man who initiates the motion, and moves himself in moving his hand which moves the subsequent series. Each element in the series is dependent on a prior mover, which in the initial argument Aristotle shows must come to something which moves itself-in the latter example, the man. ${ }^{22}$

However, on another, closer examination, Aristotle starts to introduce a distinction in self-motion, eventually leading to the two elements of an unmoved mover and a moved mover. The distinction begins when Aristotle considers the agent which is moving something is either itself in motion accidentally or necessarily. If accidentally, then the mover need not itself be in motion in order to move. ${ }^{23}$ Aristotle further elaborates this in his discussion of three elements involved in motion:

Moreover, the conclusion to which we have been led is a reasonable one. For there must be three things - the moved, the mover, and the instrument of motion. Now the moved must be in motion, but it need not move anything else; the instrument of motion must both move something else and be itself in motion (for it changes together with the moved, with which it is in contact and continuous, as is clear in the case of things that move over things locally, in which case the two things must up to a certain point be in contact); and the mover-that is to say, that which causes motion in such a manner that it is not merely the instrument of motion-must be unmoved. Now we see the last things, which have the capacity of being in motion, but do not contain a motive principle, and also things which are in motion but are moved by themselves and not by anything else: it is reasonable, not to say necessary, to suppose the existence of the third term also, that which cause motion but is itself unmoved. So, too, Anaxagoras is right when he says that Mind (voús) is impassive and unmixed, since he makes it the principle of motion; for it could cause motion in this way only by being itself unmoved, and have control only by being unmixed. (Physics 256b13-27; trans. Hardie/Gaye)

In this case, Aristotle brings out the unmoved mover as distinct from the moved mover, insofar as the latter is an instrument of motion with the thing it moves. What makes the first mover distinct is that, definitionally, it is not an instrument but rather the agent of the motion-so that, necessarily, it could not move itself, or be moved, in the same way that the instrument is. The instrument which is moved and, itself, moves, is affected in its moving, insofar as it is in continuous contact with what it moves. In our earlier example, the stick pushing the stone can be described as the moved mover while, in this immediate series, the man is unmoved in causing the motion of the stick with his hand. This is, however, a crude description, since we would have to say that even the man himself, as moving the stick through his

\footnotetext{
${ }^{21}$ Physics VIII.156a4-13.

${ }^{22}$ Premised on the necessity that there must be a first mover and not an infinity of movers. See Physics VII.1, esp. 242a17-243a2, where Aristotle shows this by a reductio argument of the impossibility of infinite motion in a finite time.

${ }^{23}$ Physics 256b8-10: 'If, then, it is an accidental attribute, it is not necessary that that which cause motion should be in motion ...' (trans. Hardie/Gaye).
} 
hand, is also moving his body in moving the stick-so we would have to say that, within the man, there is an unmoved component which moves his bodily hand, and so on. One might see this by implication with Aristotle's commendation of Anaxagoras describing vov̂s (Intellect) as a principle of motion by being 'impassive and unmixed'. We should also keep in mind, by this point, that Aristotle is speaking in terms of the mover which is accidentally in motion-it need not, itself, be in motion. This could be like the human soul, for instance, which is only accidentally in motion and not, itself, in motion ${ }^{24}$-or this could also be the absolutely separate, unmoved mover we find later shown in Physics VIII.9-10 and Metaphysics $\Lambda .6-10{ }^{25}$

Remembering Aristotle's distinction of the first mover considered as either accidentally or necessarily in motion, ${ }^{26}$ what about the latter alternative? This eventually bears problems: if motion in itself implies a capacity that is being brought to a terminus, and if the first mover moves itself with this definition of motion in mind, this implies an impossibility. Aristotle develops this difficulty through a number of examples, ${ }^{27}$ summing up with the example of the teacher:

(A-1) But this is of course impossible; for it involves the consequence that one who is teaching is learning whereas teaching necessarily implies possessing knowledge, and learning not possessing it. (A-2) Still more unreasonable is the consequence that, since everything that is moved is moved by something that is itself moved, everything that has a capacity for causing motion is capable of being moved in the sense in which one might say that everything that has a capacity for making healthy has a capacity for being made healthy, and that which has a capacity for building has a capacity for being built ... (B) It is not necessary, therefore, that that which is moved should always be moved by something else that is itself moved: so there will be an end to the series. Consequently the first thing that is in motion will derive its motion either from something that is at rest or from itself. (Physics 257a12-17, 25-27; trans. Hardie/Gaye)

In the first two parts of the argument (A-1, A-2), Aristotle presents the absurdity of the first mover being moved while simultaneously moving another, where this implies a form of infinite regress: the teacher (A1), who is educating the student, is also learning at the same time-and then how can the teacher be first in bringing about knowledge in the student? The absurdity is that the teacher as such possesses knowledge, so that he should not have the potentiality (or capacity) to learn more if he is a proper teacher in relation to the student he is educating. In this sense, the teacher is analogous to the unmoved mover, whereas the student is analogous to that which is being moved. Aristotle lists further examples that follow this absurdity of attributing motion to the primary thing causing motion (A-2) (what causes health becoming healthy; what builds also being built). These considerations ultimately lead Aristotle to rule out the first mover of a series being itself necessarily moved, so it must be in one form or another unmoved (C).

Does this mean that Aristotle has totally denied the notion of self-movement? Strictly speaking, he has in the case of a continuous, indivisible entity that is one, but not necessarily so if self-motion is conceived in terms of a divisible whole which contains an unmoved, and a moved, moving part. Aristotle finishes his refutation of the first mover of a series being self-moved by saying, 'Consequently the first thing that is in motion will derive its motion either from something that is at rest or from itself' (Physics 257a27;

\footnotetext{
${ }^{24}$ De Anima 406a2-12, 408b30-34. Cf. Menn (2002) 94.

${ }^{25}$ See n. 20.

${ }^{26}$ See n. 23.

${ }^{27}$ Physics 256a28-256b3, with this particular example: 'we must say that if someone is teaching some lesson in geometry, he is also being taught that same lesson in geometry' (trans. Hardie/Gaye).
} 
trans. Hardie/Gaye). With the former case, Aristotle is implicitly leaving open his later discussion of a distinct, separate unmoved mover which is 'at rest', ${ }^{28}$ while the rest of the discussion goes back to those like animals which still have motion from themselves. In this particular case, Aristotle says that such things which move themselves in this sense must have some form of divisibility in them, so they can not be simply continuous and whole, as we saw earlier, but infinitely divisible in a way that distinguishes between the unmoved and moved moving elements. ${ }^{29}$ Aristotle puts this in terms of analyzing a self-moved entity in terms of two components: (A) that which is already in act and unmoved, and (B) the element that is both moved and moves something else, where both together make the whole compound that moves itself $(\mathrm{AB}){ }^{30}$ The unmoved element $(\mathrm{A})$ is only moved accidentally, as a result, and so by implication it does not move itself but is the proper efficient cause of motion in self-moved entities. ${ }^{31}$ Thus, Aristotle cements the unmoved mover as the first, efficient cause of all motion, even in self-moved entities like animals.

\subsubsection{Comparing Aristotle’s Approach with Plato's on Self-Motion}

Having seen Aristotle's proof for the existence of the unmoved mover as the more proper cause of motion over self-motion, we should look back to Plato's own theory of self-motion and compare. We should first note that Aristotle still retains a concept of self-motion, although in a derivative sense, but the ultimate causes of motion are effectively unmoved. Even in self-moved composites, like animals, the proper final and efficient cause of movement has to come from the unmoved element-the soul, for instance. This seems to be a break from Plato, where he does not make the distinction between potentiality and actuality in self-motion as Aristotle does. As we concluded in our earlier discussion, for Plato self-motion seems to be the proper paradigm of motion by which all the things after it derive their motion. In the way Plato conceives of the series of motions, it would be impossible to pose an unmoved mover as Aristotle sets up his understanding-conceptually it would be a problem to talk about how an unmoved mover could start motion without itself being in motion. ${ }^{32}$ In this sense, Aristotle's introduction of actuality ( $\left.\dot{\epsilon}^{\prime} \epsilon^{\prime} \rho \gamma \epsilon \iota \alpha\right)$ in contrast to potentiality ( $\left.\delta v_{v a \mu \iota s}\right)$ is what makes possible the introduction of an unmoved element that is the first cause of motion.

\footnotetext{
${ }^{28}$ Physics VIII.10, esp. 267b18-26, where Aristotle is considering that the first unmoved mover, being responsible for the first motion that is eternal and over an infinite time, must be without magnitude, without parts and indivisible. See further Metaphysics

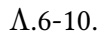

${ }^{29}$ Physics 257a29-257b1.

${ }^{30}$ Physics 258a1-9.

${ }^{31}$ Physics 257b20-23.

${ }^{32}$ Menn (2002) 93, commenting on Aristotle's reasons for seeing that the soul is not moved, notes some reasons to see why it is conceptually difficult to imagine soul causing motion without being moved in itself: 'But first it is worth recalling why the thesis that the soul is not moved was so far out of the mainstream of Greek philosophy. All philosophers before Aristotle, and most philosophers after him, assume that when $\mathrm{X} \epsilon \dot{\epsilon} \epsilon \rho \epsilon \hat{\imath}$, when it is doing something, there must be some process going on in $\mathrm{X}$, it must be moving or changing in some way; things that are incapable of motion, like numbers or Platonic Forms, are also incapable of acting or doing anything. Since the soul, when it thinks or senses, is doing something, it seems that the soul is moved. Furthermore, the case seems especially strong that when X moves another thing, and is thus acting on another thing, then X cannot be static; and everyone agrees that the soul moves the body.' See also Ibid., n. 13: 'Before Aristotle I know only one possible exception: Plato in the Sophist may think that Form F acts on soul S in bringing it about that S knows F, without Form F thereby being moved or changed (this seems to be the only option not excluded at Soph. 248d4-e5). But if this is Plato's view, he leaves it to be inferred indirectly, and does not actually state it. ... After Aristotle and before the Aristotelian and Platonist revivals of the 1st-2nd cents. ad, Theophrastus may be the only philosopher who thinks that something can $\epsilon^{\prime} \nu \rho \gamma \epsilon \hat{\imath} \nu$ without

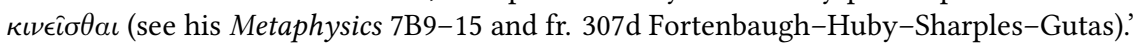


As we will see, Plotinus and Proclus both adapt Aristotle's framework to their own structures, while at the same time they also want to retain some form of Plato's self-motion as a basis for their basic concept of self-constitution. We should next see how each accomplishes this. Specifically, we must first look at Plotinus' description of the generation of Intellect, Soul, and physical entities from the One and see how he comes to provide an implicit answer to Aristotle's challenge for Platonic self-motion as part of explaining each entity constituting itself. Proclus, by contrast, will be seen to mirror more directly Aristotle's division between the three elements of an unmoved mover, moved mover, and that which is moved, while also retaining some version of Plato's doctrine of self-motion for the second element of the moved mover. This will ultimately mirror Proclus' conception of the chain of causation with the analogous elements of an uncaused cause (the One), that which self-constituted, and that which is externally caused.

\subsection{Plotinus on Self-Constitution}

In his metaphysical system, Plotinus ends up adapting Aristotle's approach to positing an unmoved mover with the One, although he directly disagrees with Aristotle that the first principle is a divine intellect. Plotinus rather posits that the first principle, the 'One', is absolutely simple and the source of the hypostasis of Intellect, and therefore the realm of being. ${ }^{33}$ In this, the One is both an efficient and a final cause of all of reality through its generation of Intellect, with Intellect generating in turn Soul, and Soul generating the physical world. ${ }^{34}$ Intellect and Soul constitute their own being through their desire for, and attempt to attain, absolute unity which is the One itself. As a result, self-constitution in the realm of being with Intellect and Soul is a deficient realization of each entity attempting to reach and imitate the One. Although the One is analogous to Aristotle's unmoved mover in being absolutely unmoved and uncaused in relation to Intellect, later on we will see that Plotinus also makes the One's internal 'being' a paradigm for Intellect's own being by the One mirroring the latter's attributes in a unified, simple way. ${ }^{35}$ The latter will be the foundation on which Plotinus eventually ascribes self-constitution to the One.

\subsubsection{Intellect and Soul's Self-Constitution}

In Enn. V.2.1, Plotinus describes the generation of Intellect, Soul, and the physical world following on the One, where each subsequent being's production is hypostasized in its attempt to attain unity and return to its prior cause:

This, we may say, is the first act of generation: (A) the One, perfect because it seeks nothing, has

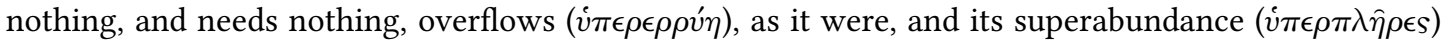
makes something other than itself. This, when it has come into being, (A1) turns back upon the One

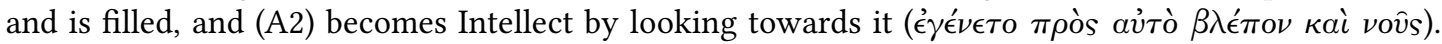

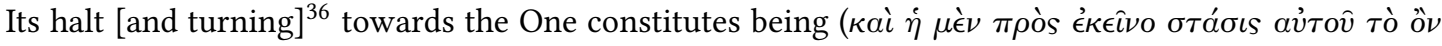

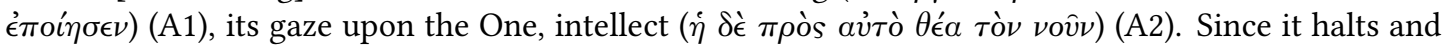
turns towards the One that it may see, it becomes at once Intellect and being. (B) Resembling the One thus, Intellect produces in the same way, pouring forth a multiple power-this is a likeness of it-just

\footnotetext{
${ }^{33}$ Discussed further in ch. 3.1 .

${ }^{34}$ On the One as an efficient cause, cf. ch. 3.2, esp. 3.2.2.

${ }^{35}$ Discussed in detail at ch. 3.3 .

${ }^{36}$ Armstrong adds this to fit the prior context of $\epsilon \pi \epsilon \sigma \tau \rho \alpha \dot{\phi} \eta$, although the sense can still stand without the addition.
} 
as that which was before it poured it forth. This activity springing from the substance of Intellect is Soul while Intellect abides unchanged: for Intellect too comes into being while that which is before it abides unchanged. (C) But Soul does not abide unchanged when it produces: it is moved and so brings forth an image. It looks to its source and is filled, and going forth to another opposed movement generates its own image, which is sensation and the principle of growth in plants. (Enn. V.2.1.8-22; trans. Armstrong)

The process of hypostatization for Intellect and all lower entities begins with the One subsiding in itself as the focal point from which and towards which Intellect has its being. Each subsequent stage (Intellect to Soul, and to a certain degree Soul to physical beings) follows the same pattern of procession and return from its prior cause. The One subsides in itself while it has a secondary activity-its 'superabundance' ( $(\pi \pi \epsilon \pi \lambda \hat{\eta} \rho \epsilon s)$-following on its primary being from which the first, pre-actualized stage of Intellect comes about (A). ${ }^{37}$ The resulting activity which proceeds from the One is not Intellect actualized until the entity which proceeds 'turns back' towards the One and attempts to see it. At this stage, Plotinus distinguishes between (A1) the turn towards the One, and (A2) the sight towards the One. Each stage constitutes a distinct position in the hypostatization of Intellect: (A1) is what constitutes being ( $\tau \grave{o}$ òv), while (A2) constitutes Intellect as a faculty ( $\tau \grave{\partial} \nu \nu o \hat{\nu} \nu)$ with its seeing. By implication we can see three stages described: (1) the procession from the One that is pre-Intellect; (2) pre-Intellect's stop and turn towards the One, and (3) pre-Intellect's seeing towards the One which is where Intellect proper becomes actualized as itself. Plotinus thus sees this pattern of procession, stopping, and returning as a pattern which is repeated on the lower level between Intellect and Soul, where Soul is an even more multiple manifestation of Intellect as a 'one-many' ( $\left(\hat{\epsilon} \nu \pi o \lambda \lambda \alpha\right.$ ) ${ }^{38}$ Soul's subsequent production of material beings, however, does not have the same relationship: it does not remain forever in itself in the way Intellect does in its production, but it is also affected and moved in its organizing and producing material beings. This is why seeing plants' growth, Plotinus' example, is able to happen in the first place, since Soul is present as an immanent principle in shaping and producing the external, physical effect of growth and development-and more so for sensation.

At this point, we should note that one immediate problem for Intellect's attempt to see the One is that the One, as such, is beyond being and thought. ${ }^{39}$ If Intellect could see the One, it would try to be the One rather than remain itself. ${ }^{40}$ Conceptually this is impossible, since sight already implies a duality between subject and object, which is implied in Intellect's activity, while the One as pure unity and simplicity is beyond such duality. ${ }^{41}$ Instead, Intellect attempts to grasp the One through itself as a product of the One, which is how the duality of subject and object comes about in Intellect seeing itself. It is in this 'turning' (A1) and 'sight' (A2) that a duality between object (A1) and subject (A2) comes about. ${ }^{42}$ Seeing the process of self-constitution for Intellect (and by implication Soul) in this way, self-constitution can be described as

\footnotetext{
${ }^{37}$ The distinction between the One and its superabundance implies Plotinus' theory of two acts. Cf. ch. 3.2.2.

${ }^{38}$ See further discussion on p. 34.

${ }^{39}$ See Enn. V.3.13. Discussed further below, p. 32.

${ }^{40}$ Cf. Enn. VI.8.13.12-13.

${ }^{41}$ On Intellect's activity of thought implying a distinction between subject and object, see Enn. V.3.10.20-27, esp.: 'But if a thing is not going to go forth to something else, it will be immobile; but when it is altogether immobile, it will not think. The thinking principle, then, when it thinks, must be in two parts, and either one must be external to the other or both must be in the same...' (trans. Armstrong).

${ }^{42}$ Plotinus provides a further elaboration in Enn. V.3.11.1-16, where pre-actualized Intellect has an indefinite vision which becomes defined in its turning to itself and thinking itself. Cf. Bussanich (1988) 221-36, Emilsson (2007) 76-7.
} 
a deficient realization of each hypostasis attempting to realize its higher, more unified cause. As we will see, this account is distinct from Proclus' approach to self-constitution happening as the result of an entity realizing its own perfection from its higher causes: whereas self-constitution is a sign of deficiency, for Proclus self-constitution is a sign of the relative autonomy of an entity. ${ }^{43}$

\subsubsection{Answering the Aristotelian Objection to Self-Motion: Motion as an Aspect of Self-Constitution}

So far we have seen the process that Plotinus has described with self-constitution for Intellect and Soul, however it is not yet clear how Plotinus can explain the motion inherent in the description of the process. In his description of Intellect, Plotinus directly ascribes motion to Intellect's activity, so that it is by motion in Intellect that Intellect has its existence-fitting the picture of Intellect constituting itself through its turning and subsequent seeing and thinking itself. ${ }^{44}$ We should also note that Plotinus follows Aristotle in making Intellect, like Aristotle's unmoved mover, completely in act and lacking in any potentiality. ${ }^{45}$ However from Aristotle's account of activity and motion, this is a problem since both concepts stand opposed to each other: actuality, or activity (é $\nu \epsilon ́ \rho \epsilon \epsilon \alpha)$, implies completion at every point along a given trajectory,

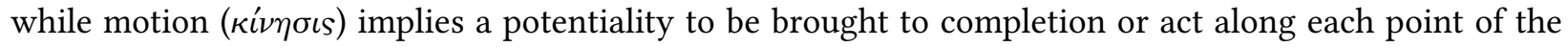
same trajectory up to a given terminus. ${ }^{46}$ For instance, building a house is an activity that would be called a motion on Aristotle's account, since the construction is part of bringing about the completion of the house; seeing or thinking, on the other hand, is a perfect activity for Aristotle, where the activity does not imply imperfection at any point but is already completed at each point in time. ${ }^{47}$ We can also recall that this was one reason Aristotle rejected the concept of a simple entity being a self-mover, since it would involve the same entity undergoing and acting at once, implying the necessity for a prior, unmoved mover.

Plotinus is implicitly aware of this objection to self-motion, and he offers a partial response to this in

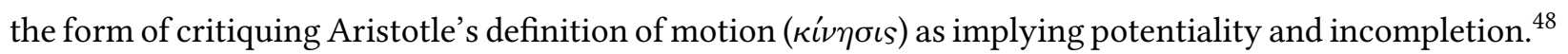
Plotinus rather reworks motion to imply not simply an incomplete activity but also complete activity itself:

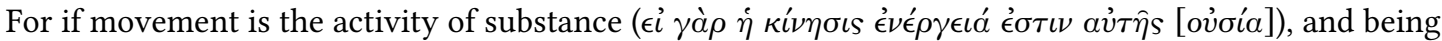
and the primary genera altogether are actively actual, movement could not be something incidental,

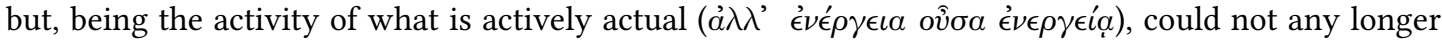
be called something which contributes to the completion of substance, but is substance itself. (Enn. VI.2.15.8-10; trans. Armstrong)

At the beginning of this passage, Plotinus takes as a conditional that we see movement in substance's

\footnotetext{
${ }^{43}$ See ch. 2.4.1.

${ }^{44}$ Enn. VI.7.13.38-42: '...but if [Intellect] was not in every way and for ever varied, in so far as it was not varied, Intellect would stand still. But if it stands still, it does not think; so that if it came to a standstill, it has not thought; but if this is so, it does not even exist. It is, then, thought; that is, all movement filling all substance...' (trans. Armstrong).

${ }^{45}$ Enn. V.3.5.39-43, esp.: '...for this Intellect (o vov̂s) is not potential, nor is it one and its intellection another: for in this way

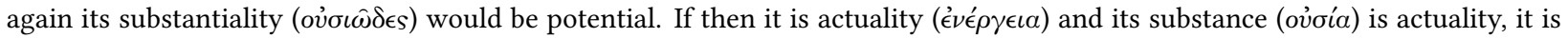
one and the same with its actuality...' (trans. Armstrong).

${ }^{46}$ Physics III.2, 201b31-33.

${ }^{47}$ See Emilsson (2007) 34-5.

${ }^{48}$ Plotinus does not offer a direct refutation of Aristotle's critique of self-motion, but Proclus (picking up from Iamblichus) does in the form of a more conscious appraisal of Aristotle's triad of unmoved mover, moved mover, and the externally moved. The middle term of the latter series, for Proclus, becomes directly responsible (via soul) as an efficient cause for motion, while Proclus preserves the unmoved mover as an efficient cause for both the self-moved mover and the externally moved. Cf. n. 51 .
} 
activity: if such movement exists in a thing, it could not be something incidental but rather essential in some sense to that thing's being. Plotinus uses the example of walking as one example to support this idea: although I may be walking to the store, and the activity taken in that respect is incomplete, the activity of walking in itself, taken abstractly from the process, can be considered to be complete at any one time or another for Plotinus. ${ }^{49}$ On this count, motion need not be a time-conditioned activity but can be, and Plotinus argues is, timeless just as activity ( $\left.\epsilon^{\prime} \nu \epsilon^{\prime} \rho \gamma \epsilon \iota\right)$ is.

One consequence is that Plotinus appears to link activity with motion as such, so that Intellect, as what is most in act, is also entirely in motion as well. ${ }^{50}$ In making this link, Plotinus seems to be supplying an indirect answer to Aristotle's challenge to Platonic self-motion: Plotinus agrees that the first mover must be in complete actuality to cause motion, while he also holds that this does not interfere with ascribing motion to the first mover in such a way that potentiality is implied-the essential problem for Platonic self-motion on Aristotle's account. ${ }^{51}$ In Plotinus' walking example, the activity of walking in itself-motion as pure actuality-is what makes possible the temporal motion from point $\mathrm{A}$ to point $\mathrm{B}$-motion as actualization of a potential. This is an implicit match with Plato's understanding of self-motion as that by which external motions can be brought about, like Soul as the self-moving entity responsible for physical motion, only here in the case of the physical example of walking. ${ }^{52}$ So also in the case of Intellect, Intellect's selfconstitutive activity is that which makes possible its production of Soul, as well as by analogy Soul in relation to physical things. Plotinus explains this phenomenon of each entity producing its lower effect in terms of his theory of two acts, where each thing possesses an internal activity which is that by which it has a distinct, external activity following on that thing. ${ }^{53}$ Fire, for instance, has its own internal, constitutive activity which is that by which the external activity of heat is produced. Thus in the case of Intellect, Intellect's internal activity and movement in thinking itself, constituting its being, is that by which its external activity follows; the latter ends up becoming Soul when it attempts to turn back to its source in Intellect.

\footnotetext{
${ }^{49}$ Enn. VI.1.16.1-14.

${ }^{50}$ See Emilsson (2007) 37-8.

${ }^{51}$ Iamblichus picks up a parallel form of this counter-argument to Aristotle, as Opsomer (2012) 271-2 notes: 'Aristotle's solution is to get rid of (primary) self-movers and substitute unmoved movers for them. ... Iamblichus opts for a different solution: to retain self-motion, but to conceptualize it as corresponding to the middle voice of the verb [ $\kappa \iota \epsilon^{\prime} \omega$, 'to move'], as it were. If that entails the complete loss of any active causal sense, the risk of introducing an uncaused motion becomes very real. The only hope to avoid this, so it seems, would be to deny that this kind of motion involves the actualisation of a potentiality.' Opsomer in $272-3$ further notes that Iamblichus is likely reusing Plotinus' critique that motion necessitates distinction between potentiality and actuality in his own notion of self-motion, while Plotinus has a more general critique.

${ }^{52}$ See ch. 2.1. On relating Plotinus' concept of motion-as-activity with self-motion, cf. Emilsson (2007) 37: 'For as Chiaradonna (2002: 189) notes, even if Plotinus emphasizes that a kinêsis is complete in the sense that once it is enacted it does not require (more) time to be complete, he also makes the point that it is characterized by the feature of 'recurrence' (to palin kai palin). This feature of recurrence belongs to motions as such, not to the motion of a certain extent. For the latter is presented as what results from the recursive character of motion as such but different from it. That is to say, to have walked half a mile is the result of recurring motion which brought the walker from the one place to the other.' With the feature of 'recurrence', Emilsson cites Chiaradonna (2002) 189-90, esp. 190 n. 65, as a possible reflection of the Stoic position of the concept in Plotinus.

${ }^{53}$ Discussed in relation to the One's production of being in ch. 3.2.2.
} 


\subsubsection{Conclusion: Self-Constitution in Plotinus' System}

Plotinus' characterization of activity as also implying motion can be seen as a kind of reconciliation by Plotinus of Aristotle's unmoved mover with simple self-motion in Plato. On the one hand, the relationship between a thing's internal activity and external activity is analogous to Aristotle's relationship of the unmoved mover in relation to the moved mover. At the same time, given Plotinus' understanding of activity as implying motion, the unmoved mover is implicitly also itself in motion: Intellect, for instance, as unmoved in relation to its generation of Soul, is at the same time in motion as it constitutes its own being. In this sense Plotinus seems to be subsuming self-motion under the unmoved mover, in attempting to explain both how an entity constitutes its own being and how it also produces a lower being. So far our analysis has mostly focused on the causal chain between Intellect and Soul, but as we will eventually see, although the One is absolutely beyond being, even it also has a similar kind of internal activity and motion, including a kind of self-constitution, which brings about its external activity that is constitutive of Intellect.

\subsection{Proclus on Self-Constitution}

Proclus ends up following a similar path to Plotinus in retaining Plato's concept of self-motion as an efficient cause of motion, although in a more explicit way compared to Plotinus. Proclus holds that all motion involves an unmoved mover, self-mover, and that which is externally moved-markedly similar to Aristotle's triad of motion, except that in Proclus' case the middle term (instead of being called the 'moved mover', as with Aristotle) receives an autonomous role as efficient cause of external motion. In his Elements of Theology, proposition 14, Proclus proves that everything falls into two categories of either that which is moved or that which is not moved-and of the former, that which is self-moved comes first as the efficient cause of externally moved entities. ${ }^{54}$ Although he goes back to Plato in holding that selfmotion in its own right comes before the externally moved, Proclus also goes back to Aristotle and holds that the self-moved relies on an unmoved mover as its prior cause. ${ }^{55}$ While Plotinus in some sense blurs the distinction between self-motion and the unmoved mover in the relationship that his hypostases of Intellect and Soul have in their causality of lower entities, Proclus emphasizes the distinction between the self-moved and the unmoved mover. One reason for this is that Proclus sees motion implying divisibility, which is a characteristic of material bodies. ${ }^{56}$ Soul for Proclus therefore involves self-motion only insofar as it is an organizing principle of externally moved material bodies through its activity, while in essence

\footnotetext{
${ }^{54}$ Elem. Theol. prop. 14, 16.9-12: 'All that exists is either moved or unmoved; and if the former, either by itself or by another, that is, either intrinsically or extrinsically: so that everything is unmoved, intrinsically moved, or extrinsically moved ( $\pi \hat{\alpha} \nu \not \alpha \rho \alpha$

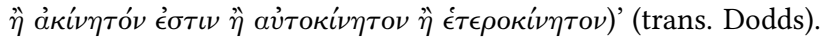

${ }^{55}$ Elem. Theol. prop. 14, 16.20-26. Cf. Opsomer (2009) 207-8, who says that, on the one hand, Proclus holds that the self-mover is relatively independent as a cause of motion, while at the same time, souls for Proclus are not technically the first efficient cause of motion but rather the unmoved mover, even implying that there is an unmoved mover internal to a self-mover (n. 4).

${ }^{56}$ Opsomer (2009) 208-9: 'Indivisibility precludes motion. To be more precise: it is incompatible with passive physical motion. Hence Proclus often associates indivisibility with being unmoved, for instance when he defines the essence of intellect as indivisible [cf. Elem. Theol. prop. 171, 150.1-3]. But not only that: indivisibility is also linked with the active power to move (to cause motion, that is). Hence both aspects of unmoved movers-their being unmoved as well as their being movers-are tied up with indivisibility. Divisibility, on the other hand, is linked with passibility.'
} 
it remains indivisible and implicitly unmoved. ${ }^{57}$ Given this distinction, however, Proclus adapts Plotinus' basic structure of self-constitution-with the basic concept of entities acting on themselves in a way that constitutes their being-with his own concept of the $\alpha \dot{v} \theta v \pi$ ó $\tau \tau \alpha \tau o \nu$ which applies to entities in both realms of intellect and soul. ${ }^{58}$

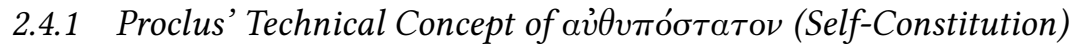

The central discussion of self-constitution happens in propositions 40-51 in the Elements of Theology, which come after Proclus' discussion of the triad of motion in prop. 14 and his relegating all things into the hierarchy of body, soul, intellect, and the One in prop. 20. In the latter proposition, intellect stood in the position of the unmoved in relation to soul as self-moved and body as the externally moved. However this is not enough: all things have unity as their principle, while intellect still implies multiplicity ${ }^{59}$-thus, the One must come before intellect as the principle of unity. Having described the structure of reality, Proclus needs to explain how intellect stands in its own relation between the One and soul, as well as the material realm, insofar as it holds an analogous intermediary position as soul did between the unmoved (intellect) and the extraneously moved (body). On this count, self-constitution is the general mechanism which Proclus uses to explain the intermediary position of the entities of the realm of both intellect and soul. ${ }^{60}$

The reasoning for this is worked out in prop. 40, which states: 'All that proceeds from another cause is subordinate to principles which get their substance from themselves ( $\tau \grave{\alpha} \pi \alpha \rho$ ' $\epsilon a v \tau \hat{\omega} \nu \dot{v} \phi \iota \tau \tau \alpha \dot{\mu} \mu \nu \alpha)$ and

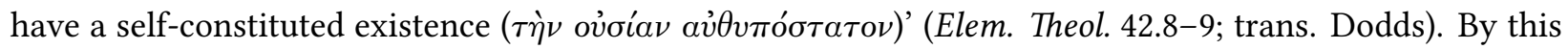
point, it has already been shown that there are self-sufficient ( $\alpha$ ข้ $\alpha \rho \kappa \epsilon s)$ principles which stand prior to subsequent entities that depend for their existence on these higher principles-soul, for instance, stands as a self-sufficient principle for all things that are moved externally and thus depend for their motion on the prior principle of soul. Proclus starts with this assumption in the proof, showing that self-sufficiency on this understanding is conceptually linked to a thing producing its own being instead of being produced by something else, so that these kinds of principles stand as prior to all subsequent beings which have their being derived from something else. ${ }^{61}$ Proclus then proceeds to show through an argument via negativa

\footnotetext{
${ }^{57}$ Elem. Theol. prop. 190-191; Opsomer (2009) 208: 'In prop. 15 [of Elem. Theol.], Proclus argues that immateriality and indivisibility are conditions of self-action, of which self-motion (in the sense of locomotion) is one type. He shows that it is indeed impossible for a body and in general for any divisible substance to 'revert upon itself' (Elem. Theol. prop. 15). This argument shows that he has understood the full force of Aristotle's argument and accepts it, but only for physical substances.'

${ }^{58}$ Given this general doctrine of causality, self-motion for Proclus ends up being one type of self-constitution, where soul particularly has the attribute of self-motion insofar as it is a principle of externally moved things, as mentioned earlier.

${ }^{59}$ Elem. Theol. prop. 14, 22.24-25: 'For intellect ( $\nu$ ov̂s), though unmoved, is yet not unity: in thinking itself, it is object to its

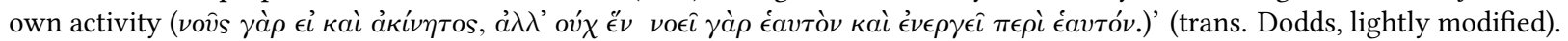

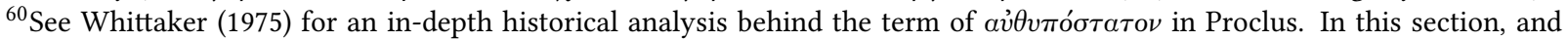
in this dissertation in general, I am mostly interested to draw out the concept in itself and trace the conceptual background to self-motion in Plato and Aristotle, on which Proclus is directly drawing, as has just been shown.

${ }^{61}$ Elem. Theol. 42.10-17: 'For if all that is self-sufficient in its existence orin its activity is superior to that which depends upon another cause (prop. 9); and if that which produces itself, having the power of furnishing its own being, is self-sufficient in respect of its existence, whereas that which is produced entirely by another is not self-sufficient; and if the self-sufficient is nearer akin to the Good; and if terms which have more kinship and likeness to their causes are generated from the cause before the unlike terms: then terms which are produced by themselves and self-constituted are senior to those which derive their being solely from another' (trans. Dodds).
} 
why the self-constituted must exist as distinct from the One and other extraneously caused things:

For either there is nothing self-constituted ( $\alpha \dot{\theta} \theta v \pi \sigma_{\sigma} \tau \alpha \tau o \nu$ ), or the Good is such, or else the principles which arise first from the Good $(\tau \grave{\alpha} \pi \rho \hat{\omega} \tau \alpha \grave{\epsilon} \kappa \tau \dot{\alpha} \gamma \alpha \theta \circ \hat{v} \dot{v} \pi \circ \sigma \tau \alpha \dot{\nu} \tau \alpha)$. But if there be nothing selfconstituted, there will be no true self-sufficiency ( $\tau \grave{o}$ av̌ $\tau \alpha \rho \kappa \epsilon s)$ in anything: neither in the Good, which is superior to self-sufficiency, since it is not a possessor of the Good, but is One and Good-absolute; nor in things posterior to the Good, since each will depend upon another, belonging not to itself but wholly to its prior. And if the Good be self-constituted, producing itself it will lose its unity, inasmuch as that which proceeds from the One is not-one (for if it be self-constituted it proceeds from itself ( $\dot{\alpha} \phi$ '

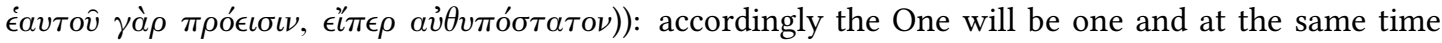
not-one. It follows, then, that the self-constituted must exist, but posterior to the First Principle ( $\tau \grave{o}$ $\pi \rho \hat{\omega} \tau o \nu)$. That it is prior to those terms which proceed wholly from another cause, is evident: for it is more autonomous than they, and nearer akin to the Good, as has been shown here. (Elem. Theol. 42.18-29; trans. Dodds)

Proclus sets up two alternative scenarios if one does not posit the existence of the self-constituted-either the Good is self-sufficient, or there are no self-sufficient principles. If the latter is the case, all externally caused things will be continually dependent on other prior, external causes, which seems to imply an infinite regress. In this scenario, a similar reasoning is being used from the case of the self-moved which is directly responsible for bringing about the motion of the extraneously moved. We earlier saw that it was not in the nature of the unmoved mover to bring about extraneous motion, which is what distinguished the unmoved mover from the self-moved which could bring about such motion. In the same way, the Good is analogous to the unmoved mover as being superior to self-sufficiency by its own nature, where all that is self-sufficient, although deriving being from itself, participates in and is fulfilled by goodness which is ultimately a derivation from the primary Good, or the One, itself. ${ }^{62}$ This leads to the other, alternative scenario of considering the Good as self-constituted, which would imply that it produces itself in some sense-and already this runs into the absurdity that the One, although hypothetically producing itself, duplicates itself as One and not-One. ${ }^{63}$ Thus, self-constituted entities distinct from the One are needed as the proximate cause for that which depends for its existence on another.

So far we have seen Proclus' demonstration that there should be self-constituted entities, yet we should still see what is entailed by self-constitution in itself, particularly in what sense a thing's constituting, or producing, itself is distinct from external production. Prop. 41 contextualizes this question with its proof

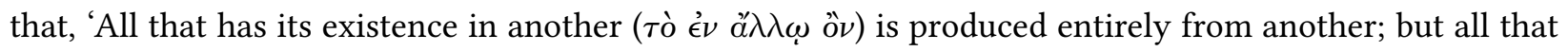

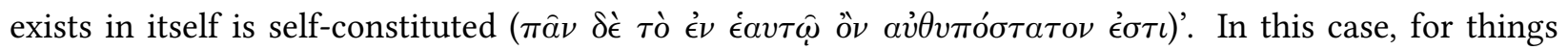
that have their cause in something else-for instance, body moving itself-their existence can only be in virtue of the cause externally bringing about the effect in another-thus, self-moving body is possible only in virtue of its participation in soul as an external cause to itself. ${ }^{64}$ On the other hand, self-constituted

\footnotetext{
${ }^{62}$ See Elem. Theol. prop. 13, which identifies the Good with the One. On the Good as superior to the self-sufficient, see Elem. Theol. prop. 8, 10.

${ }^{63}$ Elem. Theol. prop. 2. The question of why the One is not self-constituted is discussed further below in ch. 4 .

${ }^{64} \mathrm{Cf}$. Elem. Theol. prop. 80, 74.27-30: 'The proper nature of all bodies is to be acted upon, and of all incorporeals ( $\left.\alpha \sigma \omega \dot{\omega} \mu \tau o \nu\right)$ to be agents, the former being in themselves inactive ( $\alpha \dot{\delta} \rho \alpha \nu \grave{\epsilon} s)$ and the latter impassible ( $\left.\dot{\alpha} \pi \alpha \theta \dot{\epsilon}^{\prime}\right)$; but through association with the body the incorporeal too is acted upon, even as through partnership with incorporeals bodies too can act' (trans. Dodds). For a discussion of this essential principle from prop. 80 that only immaterial entities are proper causes in themselves, see Barnes (1983), although his dismissive conclusion is a tad unfair to the basic concepts Proclus has in mind and the real problem of causality in general.
} 
entities exist in themselves insofar as the effect is present with the cause, where there is no distinction between the latter two as otherwise exists for anything involving spatiality or a substrate. ${ }^{65}$ Soul, on this count, can exist separately from body, while intellect, or intellectual content, can also exist distinct from the soul. This sense of existing separately implies in some sense a thing existing 'in itself', distinct from other things. In the Commentary on the Parmenides, in commenting on Parmenides 138a6-b2 with the question of what is meant by being 'in itself', Proclus elaborates more on self-constitution implying an entity existing in itself as distinct from other entities:

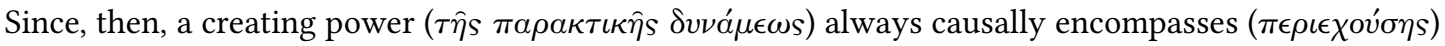

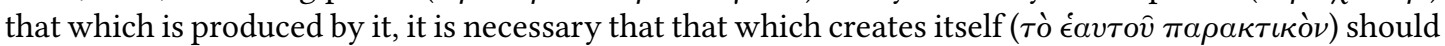

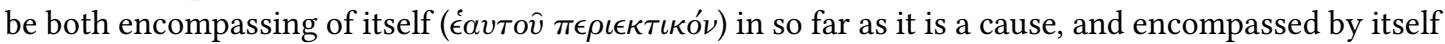

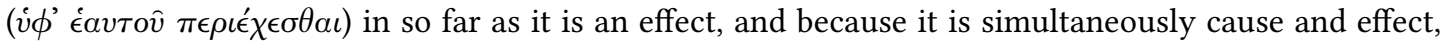
it is necessary for it to be encompassing and encompassed. If then, that which is 'in another' is that which is produced by another, superior cause, that which is 'in itself' must be declared to be that which is self-begotten and produced by itself; and even as the former was encompassed by its cause, so the latter will be encompassed by itself, and it will be encompassing and cohesive of itself, through the same thing being both agent and object of cohesion and encompassment; for in preserving itself it will encompass itself. (In Parm. 1146.10-21; trans. Morrow/Dillon, lightly modified)

Proclus here conceives of a thing's self-constitution in terms of its encompassing itself. The idea seems to be that, by a thing producing itself, its effect is not outside, or distinct from, itself, but rather the effect is also simultaneously itself. In speaking of the cause being 'in itself', Proclus appears to be reusing Aristotle's discussion of being 'in itself' with, for instance, the jar of wine which is 'in itself' insofar as the compound of each part, 'jar' and 'wine', are parts of the same whole compound of 'jar of wine'. . $^{\text {Al- }}$ though this is a physical analogy implying divisibility, Proclus applies this to the self-constituted entity distinguished between itself as cause, and itself as an effect, which are analogous 'parts' of itself as an otherwise indivisible entity. ${ }^{67}$ In one way, Proclus underlines the real sense in which there is a distinction in an entity's self-constitution between itself as a cause (or what is 'encompassing of itself', $\epsilon a v \tau o \hat{v}$

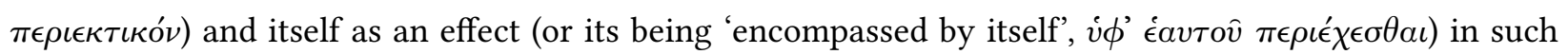
a way that implies some form of internal reduplication. ${ }^{68}$ As implied from prop. 40, this implies a kind of duality in self-constitution. At the same time, self-constitution still implies simplicity and partlessness insofar as the self-constituting entity 'reverts' upon itself entirely, where such reversion is impossible for

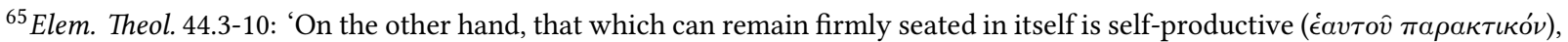
since it proceeds from itself to itself: it has the power of containing itself, and is in itself not spatially, nor as in a substrate, but as the effect is in the cause. For space and substrate are alike distinct from their content, whereas the principles in question are self-identical. Such a term, therefore, exists in itself by self-constitution, and as the consequent exists in the cause' (trans. Dodds). Cf. Dodds commentary, p. 224-5.

${ }^{66}$ Physics IV.3, 210a27-33, esp.: 'When there are parts of a whole-the one that in which a thing is, the other the thing which is in it-the whole will be described as being in itself. For a thing is described in terms of its parts, as well as in terms of the thing as a whole, e.g. a man is said to be white because the visible surface of him is white, or to be scientific because his thinking faculty is. The jar then will not be in itself and the wine will not be in itself. But the jar of wine will; for the contents and the container are both parts of the same whole' (trans. Hardie/Gaye). This is, of course, unlike speaking of being 'in another', which Aristotle speaks of earlier (210a14-24), with part being in whole, like, e.g., a finger in a hand.

${ }^{67}$ This is one implication of the doctrine that the effect is pre-contained in its cause; on this, see Elem. Theol. prop. 35, 38.9-10. On self-constituted entities being indivisible and without parts, see Elem. Theol. prop. 47, 46.29.

${ }^{68}$ Gersh (1978) 133, n. 44.
} 
an entity with parts and divisibility. ${ }^{69}$ Although self-constituted entities are thus 'simple' on this count, this is distinct from the One's absolute simplicity, where self-constitution still has the duality of cause and effect in its action upon itself. ${ }^{70}$

A final difficulty to address is the use of spatial metaphors implying motion and spatiality in selfconstitution with terms involving entities being 'in themselves' and 'encompassing themselves'. One problem is that production typically implies motion: fire produces as its effect heat, where the effect would be motion from not-hot (cold) to hot. Such a motion, however, can be divided into parts, where the motion can be divided at a point where the effect is halfway hot, or one-quarter hot, etc. Given this last question, Proclus' earlier language of self-constituted entities 'encompassing' and preserving themselves can be seen to imply circular locomotion, where the motion is a return back to the same starting position, implying both a potentially eternal motion and merely a relative sense of privation-to-form motion (e.g., one can walk once around a circular walkway from point A (not-B) to B, the latter of which is coincidentally also A). ${ }^{71}$ At least in this sense, self-constitution can imply a motion where the cause and effect overlap each other like circular locomotion, which negates the problem of motion typically implying starting from an absolute privation to the reception of a form. At the same time, since self-constitution implies entities that revert on themselves, divisibility is impossible by definition, where motion like physical locomotion necessitates divisibility. Even though a self-constituted entity produces itself, in 'encompassing' and being 'in' itself, such production happens in a simple and partless entity, while the same could also be said of an external production by such entities (e.g. the intelligible entity, Being, together with Life, is responsible for the production of Intellect as their effect). In these cases, such motion is a pre-figurement of motion seen in the physical realm, while it precludes divisibility into parts and separation. 'Spiritual motion' on this understanding is rather characterized in terms of procession and return between cause and effect, whether externally between entities in the realm of soul and/or intellect, or internally for such entities with self-constitution. ${ }^{72}$ As a result, such motion for entities in the realm of soul and intellect implies multiplicity, insofar as there is a distinction between cause and effect in each entity proceeding or reverting to itself or to its prior cause, while at the same time such activity negates divisibility into parts along a continuum as would otherwise exist in physical terms. One can characterize this as discrete 'motion' as opposed to being continuous, which implies divisibility insofar as this negates dividing such motion into parts. ${ }^{73}$ Speaking in these terms, one can make sense of why Proclus uses terms implying motion and spa-

\footnotetext{
${ }^{69}$ Elem. Theol. prop. 47, 46.30-48.4. On self-constitution implying self-reversion, see Elem. Theol. prop. 42; 43. On self-action, implicitly self-reversion, implying being partless, see Elem. Theol. prop. 15, 16.30, including the earlier discussion.

${ }^{70}$ Further discussion of 'simplicity' can be seen in ch. 5 .

${ }^{71} \mathrm{Cf}$. Aristotle's discussion of infinite, continuous motion with circular motion in Physics VIII.8.

${ }^{72}$ Opsomer (2009) 225-6: 'In intellect motion takes the form of procession and return. Since these are forms of being in motion, one could designate these motions as passive motions, inappropriate as it may be to speak of passivity in the spiritual realm. Yet this expression is warranted by Proclus' use of the passive verb forms of $\kappa \iota v \epsilon$ ć... Physical motion, however, is the image of a higher form of 'motion', one that is proper to intellective being. As was the case with intellective roundness and straightness, spiritual motion does not presuppose the structure of the mathematical continuum. The place of self-constituted entities is discussed further below.

${ }^{73}$ Opsomer (2009) 227-9, esp.: 'Spiritual motion is situated beyond the realms of space and time, yet requires some form of multiplicity. Multiplicity is indeed the necessary condition for motion in general. In the physical realm this multiplicity is continuous. Contrarily, multiplicity in the spiritual realm does not have the structure of a mathematical continuum, but is discrete, if we adopt the terminology of Aristotle's Categories.'
} 
tiality in talking about the production involved in self-constitution, but in a way that best suits the type of activity happening between cause and effect. ${ }^{74}$ This will ultimately help contextualize why Proclus looks at self-constituted entities as indivisible and in a sense simple, while being at once a duality-precluding its application to the One.

\subsubsection{Self-Constitution in the General Structure of Causality}

Before moving to our next chapter considering the One's causality for Proclus and Plotinus, we should briefly look at how Proclus conceives of self-constitution standing in his causal structure, particularly in how it only applies to entities in the realm of soul and intellect rather than to the One. A particular attribute of self-constitution for Proclus is that it is the manner by which each such entity distinguishes itself from its prior causes in the whole scheme of immaterial entities. We can see this illustrated in the realm of intellect with the highest entities, 'Being', 'Life', and 'Intellect'. Each stands in a descending hierarchy as causes of both each other and lower entities: Being, for instance, is responsible for the existence of all things, while Life is responsible for the class of beings which possess the attribute of life; Intellect, is then responsible for beings participating in intelligibility (e.g., soul). ${ }^{75}$ At the same time, each of these entities also has the same, descending relationship with each other: Being is a cause of Life and Intellect, while Life is an effect of Being and cause of Intellect; Intellect is thus an effect of both Being and Life. ${ }^{76}$ Each entity in this scheme implies each other, although relative to the causal relationship it holds with each: Being, for instance, pre-contains Life and Intellect as its effects, while Intellect to the contrary implies Being and Life as its prior causes.

A conceptual difficulty in this case is that, while each entity implies each other, one has to explain the mechanism by which each entity stands as distinct from the other, while there is the causal relationship each has with the other. ${ }^{77}$ On the one hand, there is a unity in the structure of Being, Life, and Intellect as aspects implying and reflecting each other in the same intelligible reality, while at the same time there is a distinction between each as representing distinct aspects of reality. Because of the need for this distinction, self-constitution enters the conceptual picture as explaining this distinction in each entity causing, and being an effect of, the other. An example of this lies with the highest entity, Being, which is composed of the primal elements of the Limit and Unlimited, ${ }^{78}$ while it realizes these combined together on its own level as pure being. By turning to itself and constituting itself, the hypostasis of Being returns to its prior causes of the Limit and Unlimited-both realizing the distinct perfection it has in itself while also

\footnotetext{
${ }^{74}$ On Proclus' use of physical metaphors in the intelligible/spiritual world, see Opsomer (2009) 226-7.

${ }^{75}$ Elem. Theol. prop. 101.

${ }^{76}$ Elem. Theol. prop. 103.

${ }^{77}$ Gersh (1973) 18 explains this relationship in commenting on Elem. Theol. prop. 103, which discusses the interpenetration of Being, Life, and Intellect: 'The interesting feature of this passage is that it emphasizes first, the unity of the three hypostases, secondly, the triadic structure of the configuration, and thirdly, the enneadic structure. The hypostases are a unity because each pervades the others, they form a triad because each predominates at a different point, and they are enneadic because each is analysable into a structure which mirrors the whole.' Dodds 254 also comments on this passage: 'Are Being, Life, and Intelligence to be regarded as three aspects of a single reality or as three successive stages in the unfolding of the cosmos from the One? Proclus characteristically answers that both views are true: they are aspects, for each of them implies the others as cause or as consequent; they are successive, not coordinate, for each is predominant (though not to the exclusion of the others) at a certain

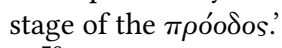

${ }^{78}$ Discussed in detail in ch. 4.2.1.
} 
simultaneously turning to its higher causes. ${ }^{79}$ We may also go further and note that Proclus' term used

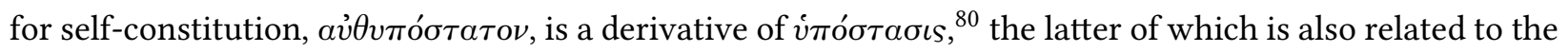

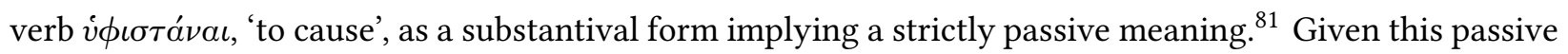
sense of being caused, $\alpha \dot{v} \theta v \pi$ ó $\tau \alpha \tau o \nu$ as derived from író $\tau \tau \alpha \sigma \iota s$ implies a dependence on a prior cause out of which an entity constitutes itself, whether from another self-caused cause or, ultimately, uncaused causes like the Limit/Unlimited or the One. ${ }^{82}$ As we have already seen, the etymological implications match the way Proclus sees self-constitution in his causal system as ultimately dependent on uncaused causes.

\subsection{Conclusion: Comparing Plotinus and Proclus on the Concept of Self-Constitution}

Looking back at Proclus, one main attribute of self-constitution that comes out is that such entities are dependent on higher causes in the process of constituting their being. The entity of Being in the realm of intellect, for instance, is able to constitute itself only insofar as it has the prior principles of the Limit and Unlimited as its causes. In this case, Being has a double-sided reversion both towards its prior causes and towards itself in its self-constitution. This so far matches Plotinus' idea of self-constitution with Intellect turning towards itself in its attempt to turn towards the One. A major difference between these two pictures is that, whereas Plotinus saw the self-constitution of each lower entity, like Intellect and Soul, as a deficient attempt by each to attain perfect unity with the One, Proclus appears to see self-constitution as a gradated level of perfection below the One (and implicitly the Limit and Unlimited, with Being). ${ }^{83}$ Going back to the example of Being, while it is lower than the principles of the Limit and the Unlimited, and as a consequence is receptive of these latter two as its causes, Being's self-constitution is representative of the perfection it contains as principle of all lower entities which derive their existence ultimately from Being.

\footnotetext{
${ }^{79}$ Gersh (1973) 134 elaborates on this idea: 'Thus, the relationship between an effect and its cause is one of identity combined with difference. In view of all this, it seems reasonable that the relationship which we should seek to establish between the two types of motion should also be one of identity combined with difference. To return to our earlier example, Intellect (the effect) can only contain being and life (its causes) when the latter are assimilated to the 'intellectual' level. In other words, Intellect is identical with its causes inasmuch as it contains them, but different from them inasmuch as it contains them in a fashion suitably modified in accordance with the hierarchical structure of the system. Moreover, inasmuch as Intellect is identical with its causes it proceeds and reverts upon itself, but inasmuch as it is different from its causes it may fairly be said to proceed and revert upon those causes.'

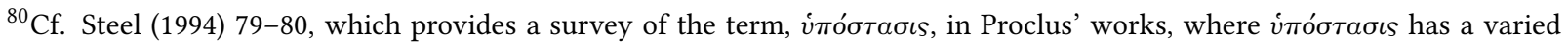

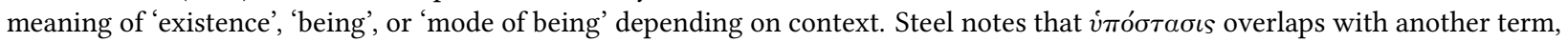

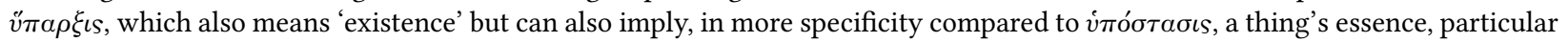

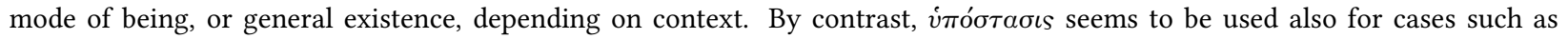
hypothetical non-existence or abstract existence in concept, for example, while $v \pi \alpha \rho \xi \iota$ implies existence more specifically in 'real life' rather than in these hypothetical, or abstract, cases. This is worth bearing in mind while balancing with the more

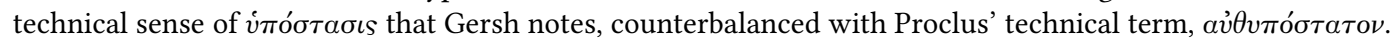

${ }^{81}$ Gersh (1973) 31. Gersh lists further on (p. 32) some examples of the technical use: In Tim. 297.18-19, which speaks of the

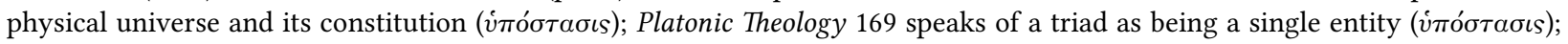
and Alcibiades Commentary 321.8-12, which speaks of the unity of being, life, and intellect in the human soul.

${ }^{82}$ Gersh (1973) 32-3: 'The notion of causal dependence in effect precludes the application of the term to anything above the

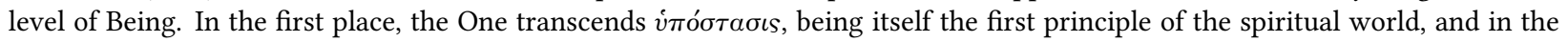
second place, since the One does not itself produce triadically, then neither the First Limit nor the First Infinity which follow immediately after it can be caused in this sense. Thus, the first three principles in the spiritual world are uncaused inasmuch as this term is not applied to them.' The discussion of the principles of Limit, Unlimited, and the One being uncaused are discussed in the next chapter (3).

${ }^{83}$ Cf. n. 106.
} 
Likewise, Life's self-constitution is indicative of itself being the perfection from which all lower entities with the attribute of life derive their being.

Under this picture, Proclus looks at self-constitution as the model by which different perfections are manifested in the realm of being, which eventually go back to the highest, simplest self-constituted perfection of Being. Because all self-constituted entities go back to higher, simpler principles on this picture, the first causes of self-constitution must be beyond self-constitution, as Proclus' system appears to imply. With Plotinus' system, on the other hand, since self-constitution is a sign of imperfection and incomplete unity for the lower entities of Intellect and Soul, self-constitution in the realm of being implies imperfect unity, which implies that the One must have this kind of activity in a more perfect way, albeit in terms that are beyond what is seen in the realm of being. It is with these two understandings of self-constitution in mind that we will next look at Plotinus and Proclus on the One, where each one's conception of the One's causality will either imply self-constitution or negate it. 


\section{Plotinus on the One and Its Causality}

Before looking at Proclus on his conception of the One's causality, we should first look at the foundation laid before him with Plotinus, particularly insofar as Plotinus' conception of the One's causality supports his statement of the One constituting its own being from Enn. VI.8.13. We should briefly begin with Plotinus' account explaining the One's existence as the first cause of all being, where he postulates unity as the basic first principle of all being. ${ }^{84}$ We must then see how Plotinus conceives of the One's transcendence and causality of Intellect, where we can see Plotinus trying to balance the tension between the One as absolutely simple, on the one hand, yet implying the multiplicity of Intellect's being, on the other, which facilitates the language Plotinus will use in talking about the One having a kind of self-causation.

\subsection{Plotinus' Principle of Simplicity and the Necessity for the One as First Principle}

As with the rest of the Neoplatonists, Plotinus' first principle for all being is that simplicity and unity underlies everything, such that a first principle of absolute simplicity is necessary as a grounding cause for unity in all things. ${ }^{85}$ Plotinus elucidates the specifics on this principle in Enn. V.4.1:

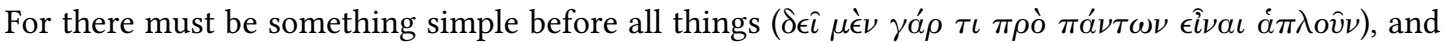
this must be other than all the things which come after it, existing by itself, not mixed with the things which derive from it, and all the same able to be present in a different way to these other things, being really one, and not a different being and then one; it is false even to say of it that it is one, and there is

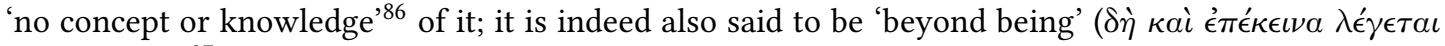

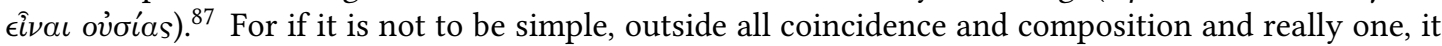

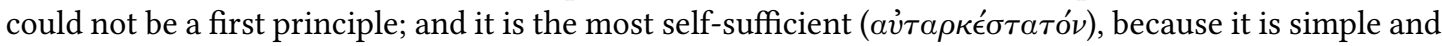
the first of all: for that which is not the first needs that which is before it, and what is not simple is in need of its simple components so that it can come into existence from them. (Enn. V.4.1.5-15; trans. Armstrong)

In this case, Plotinus looks at the principle of simplicity as a final cause, insofar as he mentions 'that which is not the first needs that which is before it', implicitly for its being. At the same time, this principle is an efficient cause as providing the 'simple components' by which each thing exists. The criterion laid down for simplicity is that such a principle must negate all implications of multiplicity to the radical degree that

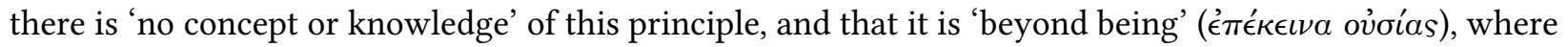
being implies multiplicity in some sense.

In Enn. VI.9 ('On the Good or the One'), Plotinus further elaborates on this principle of simplicity, which we eventually find is the 'One' beyond the hypostases of Soul and Intellect-each of which has a distinct role in producing reality. Enn. VI.9.1 provides some specific examples of what Plotinus has in mind with the basic principle he outlined in V.4.1:

It is by the one that all beings are beings, both those which are primarily beings and those which are in any sense said to be among beings. For what could anything be if it was not one? For if things are

\footnotetext{
${ }^{84}$ As was seen with Proclus in Elem. Theol. prop. 1-6.

${ }^{85} \mathrm{O}$ 'Meara 44 calls this the 'principle of prior simplicity': the idea that 'everything made up of parts, every composite thing, depends and derives in some way from what is not composite, what is simple'.

${ }^{86}$ Cf. Parmenides 142a3-4.

${ }^{87}$ Cf. Republic 509b9.
} 
deprived of the one which is predicated of them they are not those things. For an army does not exist if it is not one, nor a chorus or a flock if they are not one. But neither can a house or a ship exist if they do not have their one ( $\tau \grave{o}$ êv ov̉K é $\chi o v \tau \alpha$ ), since the house is one and so is the ship, and if they lose it the house is no longer a house nor the ship a ship. So then continuous magnitidues, if the one was not with them, would not exist; at any rate, if they are cut up they change their being in proportion

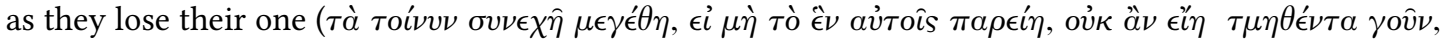

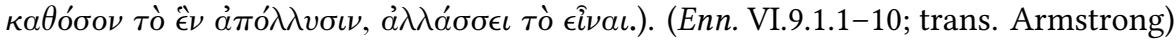

Plotinus starts with the example of the being of the army that is held together when various soldiers are collected together into one common grouping. The group's participants would otherwise disperse without the unity characteristic of the army which brings together the multiplicity of the soldiers into one. This is also the case with the examples of the house and the ship, which are even more characteristically one and united in their material compared to the army's looser unity as a collection of individuals. Although each collection is defined by its unique account as an army, house, or ship, Plotinus lays emphasis on unity as the common, underlying attribute explaining each kind of collection's existence, so that there must be some prior principle of unity which imparts each thing's existence.

Plotinus uses this latter example with artificial things to look at the various levels of reality. Natural bodies have their unity as a whole uniting parts, yet they depend for that unity on their prior source of soul for that unity. ${ }^{88}$ Soul with its various, distinct powers, in turn, depends on Intellect for its unity in receiving the various intelligible forms that it thinks and realizes discursively. ${ }^{89}$ Intellect, which contains the Forms in its thinking, is more one than Soul by pre-containing the principles of being in itself through which the latter partakes in forming physical bodies. ${ }^{90}$ Yet, however, even this is not enough for Plotinus: although Intellect is most at one with itself by possessing the Forms as part of its single activity of thinking, Intellect's thinking still implies a multiplicity-both in the duality of subject and object in its thinking on itself, and also the multiple Forms implied in its activity of thought. ${ }^{91}$ Plotinus sums up the problem of positing Intellect as the absolute first principle of simplicity:

At any rate 'man' and 'living being' and 'rational' are many parts and these many are bound together by the one. 'Man' and 'one' are therefore different, and one has parts and the other is partless. And, further, universal being, which has all the beings in it, will be still more many and different from the one, and will have the one only by sharing and participation. (Enn. VI.9.2.19-24; trans. Armstrong)

Although Intellect is the most simple being by pre-containing the Forms and being fully in act, ${ }^{92}$ even it still implies multiplicity insofar as each Form, taken by itself ('man' as an example), implies multiplicity as part of its definition (e.g., 'man' also implying 'living being' and 'rational'). Thus, even with Intellect as 'universal being', and thus most one compared to Soul and all lower entities in the material world, a

\footnotetext{
${ }^{88}$ Enn. VI.9.1.10-14.

${ }^{89}$ Enn. VI.9.1.15-44. Cf. O’Meara 18-9.

${ }^{90}$ Enn. VI.9.2.1-8, esp.: '.. for example if intellect is substance, intellect is also the one since it is primarily being and primarily one, and as it gives the other things a share in being, so in the same measure it also gives them a share in the one' (trans. Armstrong).

${ }^{91}$ Enn. VI.9.2.25-29. Plotinus documents reasons for seeing Intellect's self-thinking as implying a multiplicity instead of a unity. See Enn. V.6.1.13-15 on the necessity for duality in all thinking, including Intellect's self-thinking; see Enn. V.3.5.36-49 for a technical discussion of Intellect thinking itself in such a way that implies distinction between itself as (1) subject, (2) object, and (3) activity of thought. On the Forms implying multiplicity, see Enn. VI.9.2.29-32.

${ }^{92}$ Cf. n. 45.
} 
prior principle of unity is responsible for uniting Intellect's being. By this point, we can see that Plotinus is a realist in his emphasis on the existence of a principle of unity behind all beings-what Plotinus calls the 'One'. ${ }^{93}$ We must then see how Plotinus characterizes the One as precluding multiplicity and its being absolutely simple in relation to Intellect, which comes after it.

\subsubsection{The One as Beyond Being and Absolutely Simple}

An immediate question to raise is this: what exactly does Plotinus have in mind in calling the One 'beyond being'-in fact, what is meant by 'beyond being'? Going further in Enn. VI.9, Plotinus provides a beginning of an answer:

[The One] is not therefore Intellect, but before Intellect. For Intellect is one of the beings, but that [i.e. the One] is not anything, but before each and every thing, and is not being; for being has a kind of

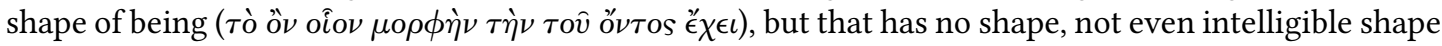
( $\mu \rho \rho \phi \hat{\eta} s \nu \eta \eta \tau \hat{\eta}$ ). For since the nature of the One is generative of all things it is not any one of them. It is not therefore something or qualified or quantitative or intellect or soul; it is not in movement or a

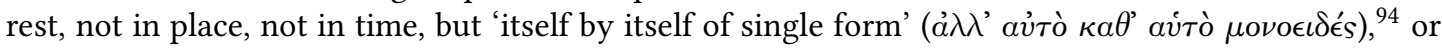
rather formless, being before all form, before movement and before rest; for these pertain to being and are what make it many. (Enn. VI.9.3.37-45; trans. Armstrong)

By this point, Plotinus has ruled out that the first principle is Soul or Intellect, as we saw earlier-but we are then left at a loss for description for the One, where language involves reasoning corresponding with being (or Intellect, as primary being) which comes after the One. ${ }^{95}$ Plotinus speaks in terms of 'shape' which gives a particular form and determination to a physical thing. By implication, we could also even apply this up to the very level of being having a kind of 'shape'. Yet even this is not enough with the One which transcends being-thus it is 'shapeless'. Plotinus similarly describes the One, following on this, as being without motion and rest, where the latter two are attributes of being and constitutive of multiplicity. ${ }^{96}$ In essence, the One for Plotinus transcends every category of being which is represented by Intellect, since it is the cause of Intellect's being as the prior source of unity.

Describing the One with these restrictions in mind is a difficulty. In terms of coming up with an alternative theory of speaking of the One, Plotinus describes language about the One as ultimately being relative to our vantage point in the realm of being:

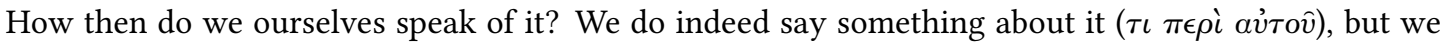

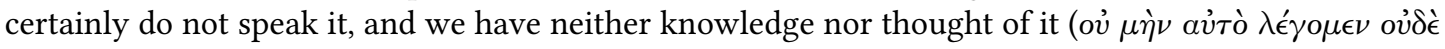

\footnotetext{
${ }^{93}$ Enn. VI.9.2.44-47: 'The one then cannot be all things, for so it would be no longer one; and it cannot be intellect, for in this way it would be all things since intellect is all things; and it cannot be being; for being is all things' (trans. Armstrong).

${ }^{94}$ Symposium 211b1.

${ }^{95}$ Enn. V.9.4.1-7.

${ }^{96}$ Given Plotinus' statement that movement and rest 'pertain to being and are what make it many', Plotinus may have in mind the five 'great kinds' from Sophist 249-256, where Motion and Rest are two of the five highest kinds of Forms ('Being', 'Sameness', and 'Difference' being the other three) characterizing the intelligible realm (cf. p. 13). Each of the five 'great kinds' imply each other: Motion characterizes the intelligible realm as implying life, while it is balanced by Rest as the principle by which Being remains eternally amidst motion; Sameness and Difference are also implied in this differentiation, insofar as each Form implies distinction from the other, while Sameness implies each Form remaining the same eternally (as also represented by Rest in contrast to Motion). Plotinus adapts the Sophist passage as characterizing Intellect's activity in terms of these five great kinds, where each facilitates and makes possible Intellect's contemplation of the Forms and itself as primary being. On this, see Enn. VI.2.7.26-31, VI.2.8.35-38, VI.2.15-12-16; cf. Crystal 194-6.
} 


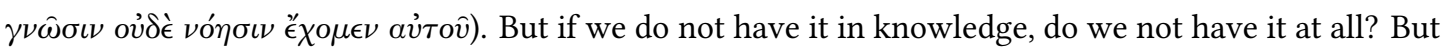

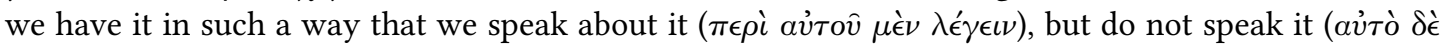
$\mu \grave{\eta} \lambda \epsilon^{\prime} \gamma \epsilon \nu$ ). For we say what it is not, but we do not say what it is: so that we speak about it from what comes after it. (Enn. V.3.14.1-7; trans. Armstrong, lightly modified)

Here Plotinus makes a twofold division with how we may speak of the One: either in literal negative terms, or in quasi-positive terms as about, or around, it ( $\tau \iota \pi \epsilon \rho \grave{\imath}$ avं $\tau o \hat{v})$. With the latter, although one is forced to speak in negative terms, Plotinus permits that one can speak about the One insofar as all things come from it. Such a way of speaking is more from the vantage point of the speaker and not so much as applied to it: thus, to speak of the One as a cause does not strictly apply to the One as to ourselves, insofar as we are causally dependent on the One. ${ }^{97}$ Plotinus speaks of this using the analogy of someone being possessed by a god: although we are aware of a greater presence, we can only speak from the effects and imperfectly reason back to the nature of the god that is prior to the possession. ${ }^{98}$ Thus, even when we speak of 'the One', this is an imprecise name insofar as it does not name the 'entity' that is prior to Intellect and the realm of being, but rather we name it relative to ourselves, insofar as we lack what it has perfectly and completely beyond ourselves. ${ }^{99}$

So far, the One has been shown to be beyond being and prior to Intellect, so that in literal terms it has no attribute that can apply proper to itself, as the principle of simplicity and cause of being by which we even speak of attributes. In this way we might talk about the One as analogous to the line and point in geometry: the line is a breadthless length which is delimited by the point which is, itself, that which has no part. The point becomes the referent from which, and/or towards which, the line is marked off and defined. In terms of an attempt at knowing the One in the way Plotinus has described it, we might describe the process as determining the asymptote for a curve from the vantage point of the curve itself: as close as we get to the asymptote, we are unable to touch it at a finite point, although we can speak as if we have reached the line and determined its coordinates.

In describing the One in these terms, this will give us a clue as to how we will eventually see Plotinus talk about the One, on the one hand, in strictly negative terms (e.g. not thinking, without life, without motion, etc.), while the possibility for speaking 'about' the One can give rise to speaking of ways of speaking positively about the One in quasi- terms. For instance, Plotinus will say that the One has a kind of thinking life, awareness, and that all things are in it, albeit in strictly conditional language that reminds us of the One's absolute simplicity. The next two sections will show how this is made possible with Plotinus' causal model with the One.

\subsection{The One's Causality of Being}

One of the great complexities that Plotinus has to explain is the production of Being from the One, where Being implies multiplicity. The paradox in this is that Plotinus subsequently has to explain how multiplicity arises from what is absolutely simple. The One stands as beyond being in its absolute simplicity, yet

\footnotetext{
${ }^{97}$ Enn. VI.9.3.49-55, esp.: 'For to say that it is the cause is not to predicate something incidental of it but of us, because we have something from it while that One is in itself....' Cf. O’Meara 56.

${ }^{98}$ Enn. VI.9.3.8-19.

${ }^{99}$ Cf. O’Meara 57.
} 
Intellect has its existence from the One thanks to the One being the source of unity. Because he holds that the One is not simply a final cause but is rather also an efficient cause of Intellect's existence, Plotinus has to explain how the One directly generates Intellect, on the one hand, while maintaining the One's continued existence as prior to being, and therefore, Intellect. ${ }^{100}$ We can consider two approaches to this question that Plotinus takes: on the one hand seeing the production of multiplicity as a deficient effect from the One, which is absolutely simple; on the other, Plotinus' approach to the One's causality in these latter terms necessitates his use of the theory of two acts, where each thing possesses an internal and corresponding external activity. By understanding these two approaches, we can see that the way Plotinus looks at the One is such that, although it precludes literal multiplicity, the One pre-contains in a completely unified way its subsequent production of Intellect which mirrors, in a multiple way, the One's being. This will eventually tie in with how Plotinus allows a form of self-constitution in the One.

\subsubsection{The One as Causing By What It Does Not Possess}

An important corollary of the One's causality is that it produces what it does not itself literally possess. As the principle of simplicity, the One can not possess multiplicity, although multiplicity comes from it. ${ }^{101}$ Plotinus comes to characterize this in terms of a gradation of deficiency of the effect from the cause, where the effect lacks in perfection what the cause contains in itself. We can see Plotinus working out the reasoning for this in his asking how multiplicity comes from the One:

(A) But how does he [the One] give them [all things]? By having them, or by not having them? But how did he give what he does not have? But if he has them, he is not simple; if he does not have them, how does the multiplicity come from him? One might perhaps grant that he gives one simple thing from himself-yet there would be room for enquiry how this could come from the absolute One; but all the same one can speak of the radiance from him, as from a light-but how can he give many things? Now what comes from him could not be the same as himself. (B) If then it is not the same, it cannot of course be better: for what could be better than the One or in any way transcend him? It must then be worse; and this means more deficient. What then is more deficient than the One? That which is not one; it is therefore many; but all the same it aspires to the one: so it is a one-many (ề $\pi$ o $\lambda \lambda \alpha \alpha^{\prime}$. (Enn. V.3.15.1-12; trans. Armstrong)

In this passage, Plotinus lays out the question of how the One produces what is not itself: the product could not possibly be the same as itself (A), so that it must be greater or lesser than itself (B). The first half (A) considers that the One might give what is identical to itself, however if the One is absolutely first, by definition what is produced from the One must be distinct from the One as the first cause. Plotinus eventually clarifies this to imply that, even if one granted the product to be an absolutely simple duplicate of the One, already this would imply multiplicity since the One is pure unity in itself: therefore such a

\footnotetext{
${ }^{100}$ A concern that is recognized in Enn. V.1.6.1-8 when Plotinus discusses the soul's attempt to determine how the One does not merely abide 'by itself' but generates from itself multiplicity. D'Ancona Costa 369 describes two possible ways one might construe an answer to this question: 'The core of the dilemma can be presented in the following alternative: either the One is not the principle of the multiplicity qua multiplicity, and consequently it is not the first and universal principle, or it actually produces the multiplicity qua multiplicity, and consequently it cannot 'remain by itself', that is, it alters its nature in the production, in order to be able to produce what is different from it. Plotinus's solution takes into account the second horn of the dilemma, in order to show that a way can be conceived in which the One gives rise to the multiplicity, without contradicting the basic tenets of the causality we must attribute to it, namely, the one in which the principle remains unalterated and undiminished.'

${ }^{101}$ Enn. V.3.15.1-8.
} 
distinction already implies multiplicity. ${ }^{102}$ This gives way to two alternatives (B): either the product is greater or lesser than the One. The former is absurd on the basis that the One is absolutely transcendent, where by definition nothing could transcend it. The remaining option left is the latter: the product must be lower and therefore a deficiency of what the One possesses completely in itself. Thus the product is characterized as a multiplicity lower than the One, yet the product also seeks its source in the One-thus it is also called a 'one-many' (ề $\pi 0 \lambda \lambda \alpha$ ).

On this count, Intellect, which is the first product from the One, functions as an imperfect realization of what the One is completely and fully-and contrariwise, the One is fully and perfectly what is not Intellect, the latter's deficiency of which the One itself does not possess. One can see this in the characterization Plotinus gives of Intellect as an image of the One, where Intellect attempts to imitate what is perfectly realized in the One. ${ }^{103}$ Intellect's closest approximation to the One lies in its self-knowledge and knowing itself, which is a result of Intellect trying to return to its source by perceiving the One as an object of knowledge. The way Plotinus portrays this is in the conceptual two-step process of (1) the production of intelligible matter-or 'inchoate Intellect'-from the One, while (2) inchoate Intellect becomes Intellect actualized when, in trying to perceive the One, it looks back to itself and thinks itself which, forthwith, produces the multiplicity of the Forms within its thinking itself. ${ }^{104}$ Intellect's attempt at seeing the One ending in its thinking itself ends up illustrating the disjunction that exists between the One and Intellect, insofar as the One produces something which is fully distinct from itself and which, as a result, returns to it only imperfectly. This contextualizes Plotinus' statement that the One produces what it does not possess, insofar as Intellect's imperfect realization of the One, via its multiplicity, is simply that which the One does not possess-since the One's perfection, which is its unity, is something that is impossible to be reproduced in Intellect. ${ }^{105}$ The next best production is one that is imperfect, which is realized in Intellect. ${ }^{106}$

Plotinus' doctrine of the One's producing by what it does not possess is linked with his understanding of the One as the 'power of all things', where Intellect is the actualization of that power by its possessing 'all things', which are the Forms it thinks:

There is One here also, but the One is the productive power of all things ( $\tau \grave{o}$ ề $\delta \dot{v} \nu \alpha \mu \iota s$ ád $\tau \tau \omega \nu)$. The things, then, of which it is the productive power are those which Intellect observes, in a way cutting

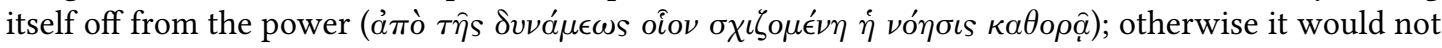
be Intellect. For Intellect also has of itself a kind of intimate perception of its power, that it has power to produce substantial reality (ov̉oíav). Intellect, certainly, by its own means even defines its being for

\footnotetext{
${ }^{102}$ Enn. V.3.15.38-45: 'Now it has been said that, if anything comes from the One, it must be something different from it; and in being different, it is not one: for if it was, it would be that One. But if it is not one, but two, it must necessarily be many' (trans. Armstrong).

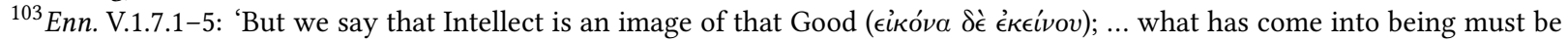
in a way that Good, and retain much of it and be a likeness of it, as light is of the sun. But Intellect is not that Good' (trans. Armstrong). Cf. Bussanich (1988) 35-6.

${ }^{104}$ Enn. V.2.1.3-15. Cf. earlier discussion in ch. 2.3.1.

${ }^{105}$ D'Ancona Costa 371: 'The multiplicity the One gives without having it in itself is therefore the multiplicity of Forms, the variety of eidê which are in turn responsible for the rational structure of the various objects of our experience. The One is the principle of the Forms precisely by its not being a Form. In its producing the intelligible multiplicity of determinations the One 'makes what it does not have' to recall the expression of the above-quoted passage from V.3.15.'

${ }^{106}$ Russi (2009) 156 characterizes this as one difference to Proclus: 'Proclus understands production, in all respects and to the very end of $\pi \rho$ óodos, as a sign of power. For Plotinus, on the contrary, production appears to be a kind of lower necessity, which serves a higher aim.'
} 


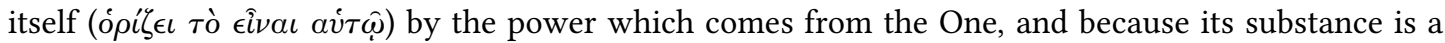
kind of single part of what belongs to the One and comes from the One, it is strengthened by the One

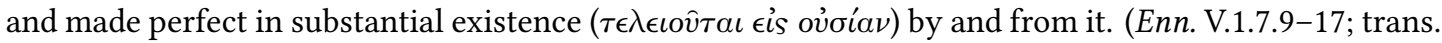
Armstrong)

Here, the One functions as the basis on which Intellect brings about being through Intellect's differentiating particular substances, or Forms, from the power provided by the One's unity. When Intellect attempts to turn back to the One, its looking back on itself as 'inchoate Intellect'-the power provided from the One-is what causes this differentiation which brings about the multiplicity of its being. ${ }^{107}$ An interesting comparison we may make here with Aristotle is that whereas the first principle for him (the unmoved mover)

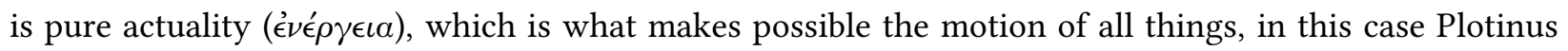

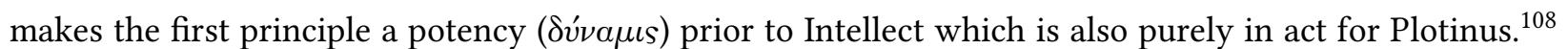
In this case, Plotinus sees that actuality pertains to the realm of being which implies multiplicity, while the One's relation to Intellect is as a power by which Intellect is able to be in act in itself. By contrast, the One's pure unity could not possibly be in the realm of being in the way that Intellect is, so that the One must stand as a power.

At the same time, however, Plotinus does take seriously Aristotle's charge from Metaphysics $\Lambda .6$ that making the first principle a potency in the way the Platonic Forms are (on Aristotle's reading) is inadequate: the first principle must act in some way, not just function as a presence by which individuals are informed. ${ }^{109}$ Plotinus' answer to this will come in the form of his theory of two acts: although the One is beyond being, and thus beyond being simply in act, the One must have something like an internal activity by which it also has a corresponding, external activity which is that from which Intellect comes about. We may then see in this way that the One acts as a power in relation to Intellect, on the one hand, while on the other it has a kind of activity in itself by which it can function as a power to Intellect. ${ }^{110}$

\subsubsection{The Two-Act Theory}

In Enn. V.4.1, after Plotinus has established the necessity and criteria for a principle of simplicity behind all things, ${ }^{111}$ Plotinus asks how the One comes to produce if it is entirely simple and is in need of nothing lower or beyond itself. The initial answer lies in a general principle Plotinus establishes that everything which is perfect by nature is also productive:

Now when anything else comes to perfection ( $\epsilon$ is $\tau \epsilon \lambda \epsilon i \omega \sigma \iota \nu$ in $)$ we see that it produces, and does not endure to remain by itself, but makes something else. This is true not only of things which have choice,

\footnotetext{
${ }^{107}$ Cf. Bussanich (1988) 48-52.

${ }^{108}$ On Intellect being completely in act for Plotinus, see Enn. V.3.5.36-49. On Aristotle's requirement that the first principle be entirely in actuality, see Metaphysics $\Lambda .6,1071 \mathrm{~b} 3-22$.

${ }^{109}$ Metaphysics 1071b12-22, esp.: 'Nothing, then, is gained even if we suppose eternal substances, as the believers in the Forms do, unless there is to be in them some principle which can cause movement; and even this is not enough, nor is another substance besides the Forms enough; for if it does not act, there will be no movement' (trans. Ross).

${ }^{110}$ Emilsson (2007) 30 also corroborates this understanding: 'The idea behind this phrase [dynamis pantôn] is of course not that the One is potentially everything in the sense in which matter may be said to be potentially everything, nor is [Plotinus] saying that the One is first actualized when it makes the things of which it is the power, as if it first then would have made itself complete. The idea is rather that the One is a kind of activity in its own right in virtue of which it is the power of producing all things, properly so called.'

${ }^{111}$ See discussion on p. 30 .
} 
but of things which grow and produce without choosing to do so, and even lifeless things, which impart themselves to others as far as they can: as fire warms, snow cools, and drugs act on something else in a way corresponding to their nature-all imitating the First Principle as far as they are able by tending to everlastingness and generosity. How then could the most perfect, the first Good, remain in itself as if it grudged to give itself or was impotent, when it is the productive power of all things? (Enn. V.4.1.27-36; trans. Armstrong)

In this basic principle, Plotinus establishes the axiom that all things which have their own perfection by nature produce an effect from themselves, whether fire having heat as its effect, or drugs healing things. We can see this as Plotinus' partial application of Aristotle's principle of the unmoved mover causing motion in moved things, ${ }^{112}$ although in Aristotle's case, the unmoved mover moves solely as a final cause. ${ }^{113}$ In this case, what is unique is that Plotinus speaks on a more broad scale with production than merely in terms of motion. With the examples cited, Plotinus outlines a direct efficient cause relationship between fire producing heat, drugs producing health, and so on-which we have also seen applied with the One's production of power that results in the generation of Intellect. Yet, of course, the balance Plotinus must achieve in this relationship of perfection and production is one where the perfection does not need the production for its being-so that the One may be entirely simple, in itself, while standing as responsible for the production of multiplicity.

We see this elucidated with Plotinus' theory of two acts in Enn. V.4.2, after the One is described as abiding in itself and separate from Intellect: ${ }^{114}$

But how, when that [Principle] abides unchanged, does Intellect come into being? (A) In each and

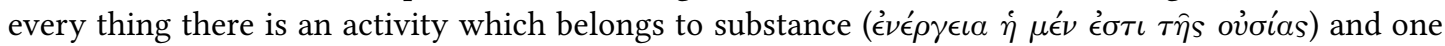

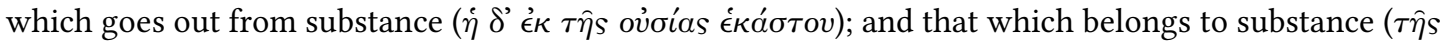

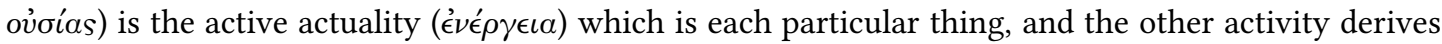
from that first one ('a $\left.\pi^{\prime} \epsilon^{\prime} \kappa \epsilon^{\prime} i v \eta s\right)$, and must in everything be a consequence of it, different from the thing itself: as in fire there is a heat which is the content of its substance, and another which comes into being from that primary heat when fire exercises the activity which is native to its substance in abiding unchanged as fire. (B) So it is in the higher world; and much more so there, while the Principle abides 'in its own proper way of life', ${ }^{115}$ the activity generated from the perfection in it and its coexistent activity acquires substantial existence, since it comes from a great power, the greatest indeed of all, and

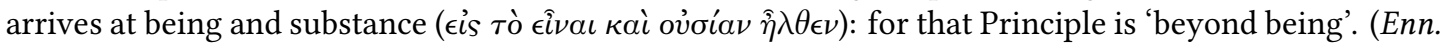
V.4.27-38; trans. Armstrong)

\footnotetext{
${ }^{112}$ Physics 257b6-14, 20-23. Cf. p. 16.

${ }^{113}$ See Metaphysics 1072a24-36, where Aristotle describes the unmoved mover as an object of desire (albeit in the context of separately-existing as the absolute first principle of motion).

${ }^{114}$ Enn. V.4.2.13-24. In this case, Plotinus ascribes a kind of life to the One in contradistinction to Intellect to illustrate the former possessing fully in unity what Intellect lacks in multiplicity (discussed in the following chapter, below). Various scholars have pointed out direct parallels with Numenius (cf. Armstrong, vol. 5, p. 146), while certain others note certain difficulties with a simple adaptation of Numenius (Bussanich (1988) 18-20, who eventually posits Plato's Timaeus (42e5-6) as a more direct influence than Numenius; Emilsson (2007) 120, n. 56, which sees the reference as too vague). Numenius posited two gods as first principles which are also by nature intellects ( $\nu$ ovs)-one which abides by itself and thinks itself, and one which thinks the Forms and is responsible for the generation of the world (see Dillon (1977) 366-72 for a thorough examination of Numenius' doctrine on this). The similarity certainly exists here, but Plotinus is markedly different in emphasizing the nature of the One as beyond intellect ( $\nu$ ovs), as Dillon (1977) 372 also notes. As we will eventually see, Plotinus does admit a kind of thinking and self-awareness in the One, but in a way which negates the One's nature as simply intellect.

${ }^{115}$ Timaeus 42e5-6 (referenced by Armstrong (trans.), vol. 5, p. 147). In this case, Plotinus is referencing from Timaeus 42d-e the god that gives over the assignments for the creation of mortal bodies to the young gods, while the former god abides by itself.
} 
In (A), Plotinus elaborates on his previous, general principle that perfection implies productivity with

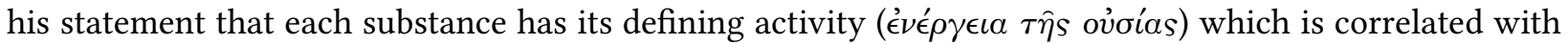

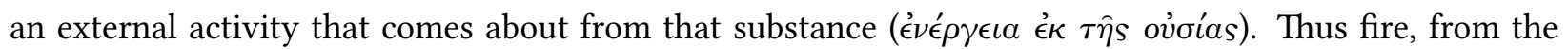
example given, has its internal activity which constitutes its being, while the external activity is a distinct manifestation of fire's being. Plotinus characterizes fire's internal, essential activity as also 'heat', so that the external manifestation of heat is something which reveals the nature of fire with its internal activity. We may note two things: Plotinus emphasizes that the external activity becomes a distinct being from the substance it comes from, so that the internal activity constituting the substance itself (fire) remains and abides by itself in relation to the external activity. Another is that the external activity (heat) is a reflection of the internal activity which Plotinus calls primary (as with 'primary heat'), constituting the substance's being. Looking back at Plotinus' description of the One as superior and productive of what is deficient, we can see this apply with the case of fire's external heat which is a deficiency of the primary heat that is constitutive of fire itself. We can see this application carried forward in the second half of the passage (B), where Plotinus applies the principle to the higher world of Intellect and the One. In this case, Plotinus does not at first directly ascribe activity to the One, but he describes it having its 'life' as abiding by itself while its 'coexistent activity' becomes a distinct substance, which is implicitly Intellect. If one follows the logic of the lower world (A) with the higher world (B), the One must then have something of an internal activity which brings about the external activity that is Intellect.

This latter might be a problem, however. In various other places like Enn. V.3.10, Plotinus directly negates the One having any activity $\left(\dot{\epsilon} \nu \epsilon^{\prime} \rho \gamma \epsilon \iota \alpha\right)$, where activity straightforwardly implies either action on something else distinct or self-action-both of which imply multiplicity. ${ }^{116}$ Thus, even internal activity would imply duality on this picture. To keep consistency, the One could not have a literal activity constituting its inner being in the same way that Intellect and Soul do, where both imply multiplicity in their internal activity. At the same time, the One's absolute perfection must be something analogous to the internal activity all things possess, since its perfection, as we have seen earlier, is what brings about the production of Intellect. Although the strict application of activity cannot apply to the One in itself, the analogy of activity carries over to the One insofar as the One's internal causal mechanism is such that its subsequent, external activity is made possible. ${ }^{117}$ We can illustrate the analogy in the following way:

internal act : external act :: fire : heat.

So also:

fire : heat :: the One : Intellect. ${ }^{118}$

\footnotetext{
${ }^{116}$ Enn. V.3.10.17-24, where Plotinus emphasizes the dual nature of Intellect's thinking, which requires the One as prior source for the possibility of such activity.

${ }^{117}$ Plotinus characterizes the One's activity as 'absolute' and not passive in any way that implies multiplicity or dependence on another in Enn. VI.8.20.4-8: 'To this we must reply that he [the One] is not at all to be classed as made, but as maker; we must posit that his making is absolute (ámó $\lambda v \tau o \nu)$, and not in order that something else should be brought toperfection by his making, since his activity ( $\left.\tau \hat{\eta} s \dot{\epsilon}^{\prime} \nu \in \rho \epsilon^{\prime} \epsilon_{\alpha}\right)$ is not directed to the perfection of something else, but is altogether this God; for there are not two, but one' (trans. Armstrong). This theme will be discussed again in more detail in the particular focus on Plotinus' doctrine of the One's self-constitution.

${ }^{118}$ Or more precisely, pre- $\nu$ ồs,
} 
Thus, even though the internal activity of the One is such that it is absolutely simple and negates all multiplicity, the One's internal activity is such that it is essentially connected with its external activity which constitutes Intellect. That is to say: although the One is beyond being, the One's causal mechanism is such that the internal activity or nature of the One can be inferred from its external activity, Intellect, which fits Plotinus' earlier statement of Intellect being an image (єiкó $\nu \alpha)$ of its paradigm in the One. ${ }^{119}$ As we will see, this implies that certain attributes of Intellect $d o$, in a certain way, apply to Intellect's source in the One.

\subsection{The oiov Principle: The One as Pre-Containing Multiplicity and Being}

Because the One has its causal mechanism such that its internal 'activity' is that by which Intellect proceeds, this gives Plotinus justification to ascribe various attributes seen in Intellect to the One-in such a way, however, that these are not literal attributes but quasi-attributes (oio $\nu){ }^{120}$ We can see this in the previous case of Enn. V.4.2, where Plotinus ascribes to the One a kind of thinking of itself ( $\kappa \alpha \tau \alpha \nu$ ó $\sigma \iota s$

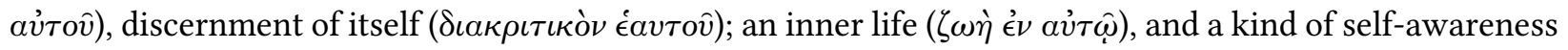

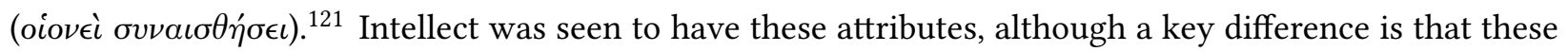
are literal attributes for Intellect, implying its multiplicity (or, more particularly, its being a 'one-many' ( $\hat{\epsilon} \nu \pi o \lambda \lambda \alpha ́$ ). One other key difference is that whereas Intellect was also characterized as being in motion in its activity, Plotinus in Enn. V.4.2 characterizes the One as being in 'everlasting rest' ( $\sigma \tau \alpha \dot{\sigma} \sigma \epsilon \iota$ ảı $\delta^{\prime} \omega$ ) even though possessing Intellect's other characteristics. Taken together, this would imply the One's mode of existence as entirely simple and united in a way distinct from Intellect's mode of multiplicity, where motion is one requisite counterpart of multiplicity in the realm of being. ${ }^{122}$ At the same time, the One's possession of attributes seen in Intellect, although in a completely unified way different from Intellect, comes before the theory of two acts is given afterward. We can then see the ascription of the latter attributes as an application of the two-acts principle to the One, with the One pre-containing what is made manifest in its external activity.

At the same time, however, is not the One supposed to be beyond being and all the attributes of Intellect? How do we not see the One's quasi-attributes as implying a contradiction with other places where he has explicitly denied the One's possession of any attributes? Although we have just seen the analogous relationship which exists between Intellect and the One through the model of internal/external activity, it may not be so clear how the One's absolute simplicity still permits this way of speaking of positive attributes. If we review Enn. V.3.15, Plotinus describes the One as possessing in a completely unified way what is distinguished in Intellect:

But how is that One the principle of all things? Is it because as principle it keeps them in being, making each one of them exist? Yes, and because it brought them into existence. But how did it do so? By

\footnotetext{
${ }^{119}$ Cf. Emilsson (2007) 41-2, which in commenting on Enn. VI.8.20.4-8 notes that Plotinus' characterization of the One's internal activity as 'absolute' implies no incompatibility between the One possessing an internal and external activity.

${ }^{120}$ Enn. VI.8.13.47-50: 'But one must go along with the words, if one in speaking of that Good uses of necessity to indicate it expressions which we do not strictly speaking allow to be used; but one should understand 'as if' (oîo ) with each of them' (trans. Armstrong).

${ }^{121}$ Enn. V.4.2.13-19.

${ }^{122}$ Cf. p. 32.
} 
possessing them beforehand. But it has been said that in this way it will be a multiplicity. But it had them in such a way as not to be distinct: they are distinguished on the second level, in the rational form. (Enn. V.3.15.28-32; trans. Armstrong)

The One in one way possesses what Intellect has realized in multiplicity but in a simplified way, standing ultimately behind Intellect as beyond being, on the one hand, while pre-possessing all of Intellect's attributes as its source, on the other. This is why literal attributes do not apply to the One, but the One still has these attributes in an analogous, conditional way. ${ }^{123}$ We might describe the double-sided nature of describing the One in this way: (1) the One, looked at from the realm of being/Intellect, has negative attributes applied to it (beyond being, activity, thought, life, cause, etc.); while (2) the One, looked at 'as if' (oîv) in itself as source of being/Intellect, has analogous attributes (being, activity, thought, life, cause, etc.) applied to it that are actualized in Intellect's activity. ${ }^{124}$ It is this latter way which, as we will see, plays the fundamental background behind which Plotinus talks about the One as the source of freedom and being for all things, and thus why Plotinus ascribes self-constitution to the One.

\subsection{Conclusion: Plotinus' Conception of Simplicity and the Implications for Self-Constitution}

So far we have seen that one way of describing the One is in terms of its absolute simplicity which negates all multiplicity, where even the activity of Intellect's self-thinking still implies multiplicity, even though the One is the most unified kind of being. The One is radically beyond all being as a consequence, and yet it is paradoxically describable in quasi-positive terms: as source of Intellect, the One pre-contains all things within itself as a single whole. This latter way of seeing the One is largely thanks to the two-act theory Plotinus develops in explaining the One's production of Intellect, which makes sense of Plotinus' description of Intellect as an image of the One. As a result, Plotinus' understanding of absolute simplicity is one which implies the negation of all literal attributes implying multiplicity, but it is a simplicity which is permissive of analogous, or metaphorical, attributes out of which Intellect comes to be actualized as the multiplicity of pure being. This comes as an immediate result of Plotinus' understanding that the One is

\footnotetext{
${ }^{123}$ The relationship between literal and analogous attributes can be seen in the way Enn. VI.7.32.6-10 characterizes the Form of Beauty to particular instances of the Beautiful in terms of the Form being 'formless' in relation to its participants. On this, see D'Ancona Costa 373: 'The production of the multiplicity of intelligible Forms by the One is not, therefore, an alternative kind of production in respect to the communication of unity, but a different analysis of the way in which suprasensible principles operate. When we consider the One as the principle of the unity of all the things which are, we are looking at the relationship of similitude which is involved in the pattern of eidetic causality. When we ask how the One can generate the multiplicity of Forms, and Plotinus answers that it occurs because of the One's being separated from all the Forms and formless in respect to them, we have before us the Plotinian answer to the paradox of self-predication, extended to the relationship between the set of the Forms and their principle'.

${ }^{124}$ Bussanich (2007) 57 proposes a slightly different two-fold distinction between 'metaphysical' and 'mystical' terms: 'The first describes the One as absent and as nothing or as present and as everything, the second incorporates metaphysical and psychological terms within a performative discourse that escapes the limitations of both affirmative and negative language in order to evoke the experience of mystical presence.' Bussanich employs this as part of his thesis that Plotinus is engaging in a higher mode of discourse about the One in mystical terms, not simply in descriptive, positive terms. Bussanich is right to critique a standard reading of Plotinus as concerned with prioritizing negative theology over and against positive language with the One, but he fails to connect the use of mystical language (i.e. talking about the One having an inner life, thought, etc.) with the causal mechanism, viz-a-viz the theory of two acts, that makes possible this transition from the non-discursive thinking of Intellect to the One's transcendence over the latter. It is likely this failure to look at the metaphysical background making possible this linguistic discourse that would explain his critique of Proclus' attack on Plotinus, where Proclus has an entirely different causal mechanism at work.
} 
a direct source of multiplicity with its generation of Intellect. Although Plotinus makes a radical jump in asserting the One's absolute simplicity beyond the divine intellect-over and against his predecessors, like Numenius and Alcinous, who asserted that the first principle is an intellect-Plotinus' principle of simplicity still has some form of multiplicity implied insofar as it is a direct source from which Intellect comes about. On Plotinus' terms, as we have seen, this does not imply a direct contradiction, but it does highlight the tension of asserting the multiplicity of Intellect's being as a direct descendant of the One. ${ }^{125}$ This will be one reason why later Neoplatonists, from Iamblichus on to Proclus, assert intermediaries between the One and intelligible being as a gradation from absolute simplicity to multiplicity-a factor that will play in to Proclus' doctrine of self-constitution and its negation from the One. ${ }^{126}$

\footnotetext{
${ }^{125}$ D'Ancona Costa 374-5 illustrates this tension well: 'The first and most obvious meaning of this idea is that analogously as we discover the Form as the separate principle of a multiplicity which shares an intelligible character, so we discover the One-Good as the separate principle of the character shared by all the Forms. Following this way of thinking, the One acts like any intelligible item whatsoever, namely, insofar as it is in itself the character-unity-that participants possess in a derived manner. There is, however, a second meaning, according to which, while an intelligible Form is responsible only for the similarity to it which is in its participants, the One-Good is responsible also for the principles of the eidetic distinctions, which are the true beings and which are to be 'referred back' to it, anagein ... pros ekeino .... Following this way of thinking, the One acts like an intelligible item insofar as this latter is conceived of as a principle which gives what it does not possess as such, but which it has the power to produce.'

${ }^{126}$ Given this fact, we may also note that where later Neoplatonists had especial concern to understand the One and all lower structures of reality in the framework of the hypotheses of the second half of Plato's Parmenides Plotinus may not necessarily show this concern in presenting a consistent picture of the One in relation to the first hypothesis. Although Plotinus defends his interpretation of the first three hypotheses in relation to the entities of the One, Intellect, and Soul in Enn. V.1.8 (esp. V.1.8.24-29), the nature of the passing reference appears to be only in regard to maintaining a general compatability between his metaphysics and what the character, Parmenides, proposes follows in the first three hypotheses of the dialog (see Vorwerk 26-31). While the first hypotheses contains only negations when speaking of the One in itself, Plotinus' One by contrast allows for a kind of implied multiplicity that preserves its simplicity. As we will see, maintaining a systematic interpretation of the first hypothesis in relation to the One will be one major concern for Proclus, especially when it comes to the reason why Proclus rejects self-constitution in the One.
} 


\section{Proclus on the One and Its Causality}

Proclus' account of the One is similar to Plotinus insofar as he also asserts the existence of a principle of absolute simplicity which is responsible for unity in all beings. An important difference from Plotinus, however, is that whereas the One was seen to be a direct cause of multiplicity, Proclus introduces intermediaries between the One and being-specifically the dyadic principles of the Limit and Unlimited-which are rather the direct cause of multiplicity. This will bear directly on the reason why Proclus denies selfconstitution to the One, since in this step, the implication of multiplicity is removed from the One, unlike the case for Plotinus. Our analysis will thus begin by looking at how Proclus talks about the existence of the One, comparing with Plotinus' approach to this question. We will then show how Proclus describes the One's causation of Being by way of negating all the positive attributes of being; connected with this will be a discussion of how the dyad of Limit and Unlimited arise from the One in this picture, out of which the first intelligible entities of Being, Life, and Intellect are generated. Describing things this way will bring us to the final chapter, where we see the specific reasons Proclus rejects self-constitution, given this background of the One's causality.

\subsection{Proclus' Proof for the One}

Proclus' proof for the One as a first principle of all unity can be found in the first six propositions of the Elements of Theology, which follow the trajectory of Plotinus' Enn. VI.9.1 that establishes the One's existence through the dependency of all things, characterized by multiplicity, on a prior source of unity. The series of proofs begins with Proclus establishing that 'every manifold ( $\pi \lambda \hat{\eta} \theta$ os) in some way participates

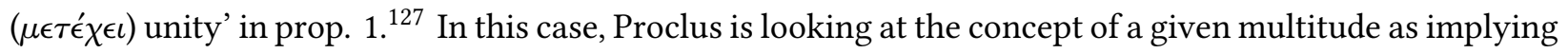
unity in some way, or participation in 'unity', whatever this unity may be. ${ }^{128}$ Proclus demonstrates this through a reductio ad absurdum of the contrary case, where the manifold neither 'as a whole nor any of its several parts will be one' (2.3-4). The result is that each part of the manifold, not being one, will go on to infinity-with each infinite part implying its own infinity of parts, as a multitude. ${ }^{129}$ Consequently the parts must be 'one' in some way which makes up the manifold, or some variation of oneness must be present-thus each manifold in some way must partake of unity in some sense.

This leads to Proclus' next steps in prop. 2-3 that all things which participate unity are both one and not-one (prop. 2), ${ }^{130}$ and by becoming one, they participate in unity (prop. 3). ${ }^{131}$ Bearing in mind the the former proposition especially, Proclus understands that each multitude has a degree of unity which is constitutive of its being, while at the same time there is a dependency on an underlying unity for its being-as seen in prop. 3. By this point, Proclus has not yet talked about the One itself as the source of

\footnotetext{
${ }^{127}$ Elem. Theol. 2.1; trans. Dodds.

${ }^{128}$ Picking up from Plotinus' examples in Enn. VI.9.1, one could not think of the manifold of an army without its units; the multitude of the parts of the house participate some form unity, which makes that house; and so on; the various, manifold of parts of a plant involves some form of unity; and so on. Cf. p. 30.

${ }^{129}$ Cf. Opsomer (2013) 628-9.

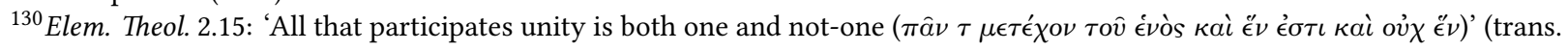
Dodds).

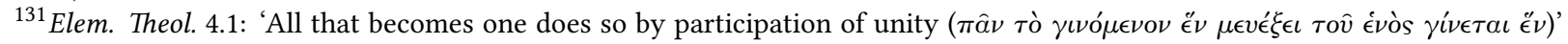
(trans. Dodds).
} 
unity, but merely that for any multitude that is 'one and not-one' and is brought into being one, there is a reliance on a participated entity which is the source of that thing's unity-even if that participated entity is itself 'one and not-one'. However the logic of prop. 1 implies that at some point we will need to posit an entity that is absolutely one in itself and sole source for all unity-which is what Proclus sets out in prop. 4-5.

Prop. 4 provides the groundwork for the One, which is prior to what is 'one and not-one' (prop. 5):

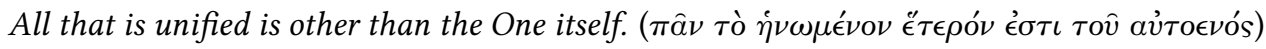

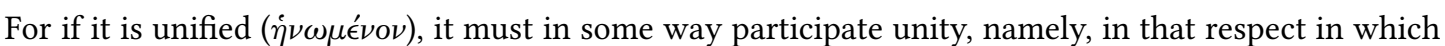
it is said to be unified; ${ }^{132}$ and what participates unity is both one and not-one. ${ }^{133}$ But the One itself is not both one and not-one: for if it also be one and not-one, then the unity which it contains will in its turn contain this pair of elements, and there will be infinite regress, since we shall find no simple unity at which our analysis can stop, but everything will be one and not-one. The unified, therefore, is something other than the One. For the One, if identical with the unified, will be infinitely manifold, as will also each of the parts which compose the unified. (Elem. Theol. 4.10-18; trans. Dodds)

Proclus' use of 'unified' ( $\dot{\nu \omega \mu \epsilon \in \nu o \nu)}$ in the proposition follows from the previous proposition, where the manifold that is both one and not-one is brought into being 'one' by its participation in unity. At this latter stage, Proclus says that eventually we must come across a participation of unity which is not a 'one and

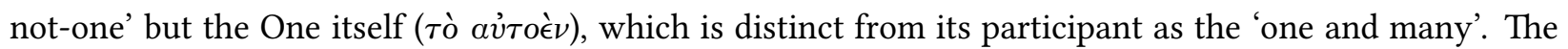
proof for this follows a similar track to prop. 1: if we do not suppose the One is distinct from being 'one and not-one', we run into the problem of infinite regress with its possessing elements that do not come to that which is not 'not-one'. Thus Proclus' statement, 'we shall find no simple unity at which our analysis can stop'-thus a 'One itself' must be posited. ${ }^{134}$

While we have established the necessity for a distinct One-itself, it may still be a question of how this One is placed in relation to the one/not-one grouping: one might think, for instance, that the relation of participation between the One-itself and the many is symmetrical. Yet we will see this is not so, as the question leads to Proclus' fifth proposition, which establishes that 'every manifold is posterior to the

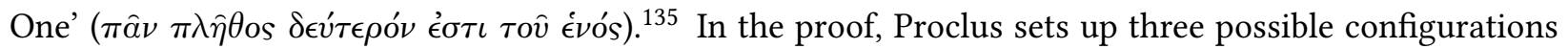
of the One-itself in relation to plurality (the 'manifold'): 1) plurality is prior to the One-itself; 2) plurality is on par with the One-itself; or 3) plurality is posterior to the One-itself. (1) is taken to be absurd, since plurality could not participate in what does not yet exist (since the One-itself is taken as posterior to

\footnotetext{
${ }^{132}$ Cf. Elem. Theol. prop. 3.

${ }^{133} \mathrm{Cf}$. Elem. Theol. prop. 2.

${ }^{134}$ Opsomer (2013) 630 breaks down the proposition into the following syllogism: i) The participant in oneness is both 'one' and not 'one' (prop. 3); ii) The One itself is not both 'one' and not 'one'; therefore, iii) the participant is not identical with the One itself. Opsomer further notes: 'There is an interesting sub-argument in support of (ii), by reductio ad impossibile: suppose the hen-itself [One-itself] is both hen [one] and not hen. Then to hen in the hen-itself is again hen and not-hen, and this ad infinitum. In other words, it is possible to analyze each hen into two components, one of which is another hen, one level deeper. Any hen is evidently different from to hen in which it is contained, as the latter is always the former plus something other. The argument further presupposes that none of the earlier hena get recycled. This gives us an allegedly vicious regress, which can be avoided only by invoking a true autohen, i.e. a one-itself which is nothing other besides that. So it turns out that the autohen which is the object of the reductio was not an autohen after all, but clearly we need one. Any plurality needs to be unified through participation in some hen and, on pain of an infinite chain, there has to be a hen that is nothing but hen, i.e. that contains nothing other and is thus free from plurality (something that does not possess the property of unity, but is unity).'

${ }^{135}$ Elem. Theol. 4.19.
} 
plurality) and the One-itself would then participate in what is not-one-itself, which implies the earlier absurdities mentioned in prop. $1-2 .{ }^{136}$ (2) is also taken to be absurd, since the plurality will have no way to participate in the One-itself (where the One-itself and plurality end up as 'contra-distinguished principles') and thus imply the absurdity of an infinity of not-ones. ${ }^{137}$. This leads to Proclus' conclusion of (3): plurality is necessarily posterior to the One-itself. ${ }^{138}$ The relation between the One and plurality is thus asymmetrical: although the manifold, or plurality, implies oneness and participation in the One, the contrary is not true-the One does not imply participation in manifoldness.

This is however not the end of the proof, intriguingly. Proclus takes (3) a step further by considering whether the One participates in another plurality higher than the One:

If on the other hand the One in like manner participates plurality ( $\pi \lambda \dot{\eta} \theta$ ovs), being indeed one in sub-

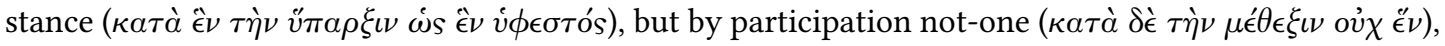
then the One will be pluralized because of the manifold as the manifold is unified ( $\dot{\eta} \nu \omega \mu \epsilon \operatorname{co} \nu$ ) because of the One. (Elem. Theol. 6.6-9; trans. Dodds)

Here, Proclus considers a possible two-fold distinction of the One as 'indeed one in substance' in relation to the manifold that is posterior to it, and yet this One might on the other hand participate in a plurality above it, so that it is 'by participation not-one'. The One, which is now a 'not-one' by participation with plurality, exists in some sense on par with the plurality which is posterior to it, so now we are left with the possibility that (3a) the One and the plurality which is a posterior participant of it come together by themselves, or (3b) another, prior principle above the One and participant-plurality bring the two together. (3a) is a problem because, as opposites, it is not in the nature of the One and plurality to come together-in fact, were this so, they would be identical to each other. ${ }^{139}$ Rather, although the One and the plurality are opposed to each other and distinct in their substance, as One and as plurality respectively, both are identical by participation. ${ }^{140}$ From this, Proclus deduces that there must be an absolute One-itself, beyond both the former One and plurality, which is responsible for bringing together the latter two, and which is itself without any plurality by participation or substance. ${ }^{141}$ Thus we are left with an absolute One itself (B1) which is responsible for both (B3) pluralities that are brought into a unified group, and (B2) relative 'Ones' that unify these pluralities, and yet participate in multiplicity in some form. ${ }^{142}$

\footnotetext{
${ }^{136}$ Elem. Theol. $4.20-26$.

${ }^{137}$ Elem. Theol. $4.27-6.3$.

${ }^{138}$ Elem. Theol. 6.4-6. Cf. Opsomer (2013) 631.

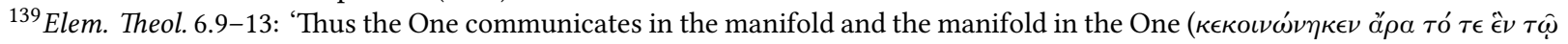

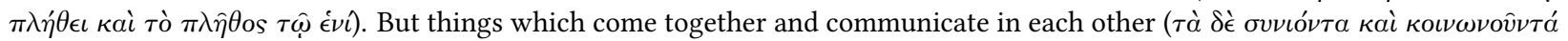

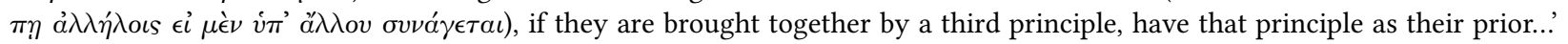
(trans. Dodds).

${ }^{140}$ Elem. Theol. 6.13-16.

${ }^{141}$ Elem. Theol. 6.16-21. Cf. Opsomer (2013) 631, particularly: '[Proclus] has not explicitly argued, however, that there is only one such autohen. One might after all think that we could invoke a different autohen each time we need to stop a regress. The problem with that, however, is that if there were two autohena, they would form a plurality and would need a higher hen to make sure they and the pluralities over which they preside would not constitute completely disjunct realities.'

${ }^{142}$ Proclus goes on to elaborate on this grouping in prop. 6 ('Every manifold is composed either of unified groups or of henads

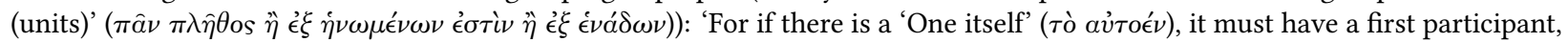
which is the first unified group (B2). And this first group is composed of henads (B3): for if it be composed of unified groups, these in turn will be composite, and so to infinity. The first unified group, then, is composed of henads; and we have found true what we enunciated' (Elem. Theol. 6.26-30; trans. Dodds).
} 
So far we should take stock: compared to Plotinus, Proclus offers a very systematic approach to proving

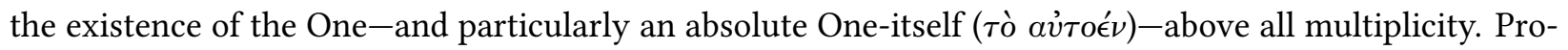
clus' approach in the Elements of Theology is to establish the One's existence from the intuition of oneness and multiplicity, where eventually we must come across a One which is absolutely prior to all multiplicity. There is one important difference from Plotinus, however. In Enn. VI.9.1, when Plotinus went through the various configurations of unity, from natural wholes containing their parts, to Soul unifying natural bodies, up to Intellect unifying Soul, each grouping was seen to have a deficient sense of unity, which only the One had in itself. While Proclus also shows that an ultimate One by itself is necessitated, by contrast he grants a level of perfection and a relatively autonomous oneness to intermediate 'Ones' (B2) that are responsible for uniting lower beings. This can be seen when Proclus talks about the case of a 'One' (B2) which is the principle of unity for the plurality that it unifies (B3), so that relative to that plurality it is a 'One'. At the same time, even that 'One' (B2), since it still has some form of multiplicity implied in it by its connection with the participant, ${ }^{143}$ depends on a higher One (B1) which unifies both it and the plurality (B3)-ultimately to the absolute One itself. ${ }^{144}$

Proclus thus has a three-term system which matches the triad of unmoved mover/self-mover/externally moved seen in Elem. Theol. prop. 14, as well as uncaused/self-caused/externally-caused that we saw described in ch. 2.4.1. Because Proclus understands that certain levels can be relatively autonomous as 'Ones', or principles of unity, in relation to their participants, this will be significant for seeing how Proclus understands the One's causality as mediated at the level of these middle terms (like (B2)), where Plotinus saw that intermediate hypostases below the One, like Intellect and Soul, had their productive power as a deficiency from the One, rather than as a distinct, separate perfection in their own domain. Bearing this in mind, our next look will be at how Proclus envisions the One's causality within this structure, particularly denominating how being is produced at the first intermediate level after the One.

\subsection{The One's Causality of Being}

As a precursor to talking about the One's causality, it will help for us to review the general structure of Proclus' causal system. We have already gone through Proclus' concept of self-constitution and its place as a middle term for entities between the One as uncaused cause and entities in the physical world which are externally caused. In Elem. Theol. prop. 20, Proclus divides reality into a series of levels behind the physical world of bodies: that of soul, first; behind soul, that of intellect; and behind intellect, ultimately that of the One. ${ }^{145}$ As has been mentioned in ch. 2.4.1, self-constitution properly applies to entities in the former two realms (intellect and soul), while the One stands as the first, uncaused cause behind these entities. This fits with Proclus' implication in Elem. Theol. prop. 5 of the existence of certain principles of unity which are relatively 'One' in relation to the plurality it unifies, while also proving the existence of a

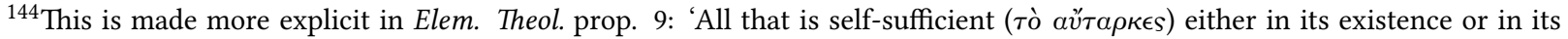
activity is superior to what is not self-sufficient but dependent upon another existence which is the cause of its completeness.' And at the same time each proportionate level of self-sufficiency is inferior to the 'unqualified Good' or the One (Elem. Theol. prop. 10).

${ }^{145}$ Elem. Theol. prop. 20.
} 
distinct, first One-itself. ${ }^{146}$ Proclus eventually goes to expand on this in Elem. Theol. prop. 101 by showing: 'Every series of wholes is referable to an unparticipated first principle and cause; and all unparticipated terms are dependent from the one First Principle of all things' (Elem. Theol. 90.1-3). Thus, in the example of the case of things which have the attribute of Life, the unparticipated entity of Life in the realm of intellect is responsible for uniting such beings. ${ }^{147}$ At the same time, since Life unites its participants and thus has multiplicity implied through the plurality participating in it, even Life itself must have prior to it the absolute One-itself as its unparticipated first cause (as seen in prop. 4-5).

Given the relationship Proclus sets up with the One as the unparticipated cause of the highest entities in the realm of intellect-Being, Life, and Intellect-a start on the question of the One's causality would then be to see how Being is generated, alongside Life and Intellect which are also causally dependent on Being. ${ }^{148}$ Underlying the production of entities from the One lie the principles of Limit and Unlimited, which we should look at more carefully in their following on the One. ${ }^{149}$ From this we should see how Proclus discusses the One's causality through negations, particularly in the case of the Limit/Unlimited pair, which are the fundamental keys behind which Proclus rejects any implication of positive attributeswhether analogical or literal-as applying to the One. The Limit and Unlimited will be instrumental in Proclus' reason for rejecting self-constitution in the One.

\subsubsection{The Principles of Limit and Unlimited}

Proclus' discussion of the Limit and Unlimited as coordinate principles can be seen in Elem. Theol. prop. 8990. In prop. 89 , Proclus establishes that all being is characterized as a composition of limit and unlimited: ${ }^{150}$

For if it have an unlimited power ( $\left.\dot{\alpha} \pi \epsilon \rho o \delta v^{\prime} \nu \alpha \mu \nu^{\prime}\right)$, it is manifestly unlimited, and in this way has the

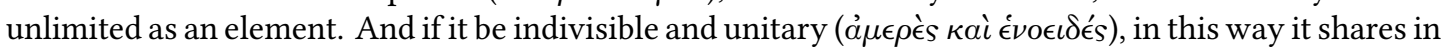
limit; for what participates unity is finite. But it is at once indivisible and of unlimited power. Therefore

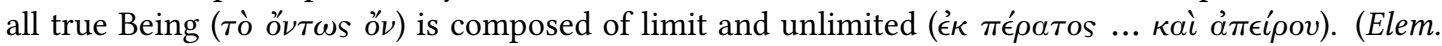
Theol. 82.2-6; trans. Dodds, lightly modified) ${ }^{151}$

In this instance, Proclus looks at Being as characterized in terms of its potency, which is the 'unlimited' element, as well as its simplicity and indivisibility, which is the 'limited' element. Because all beings partake of the entity Being itself, each being to one degree or another is characterized in terms of these two attributes. Although not mentioned here, Proclus has in mind attributes such as sameness, stability, and determination with the element of the 'limited', while otherness, motion, and indetermination is implied

\footnotetext{
${ }^{146}$ Elem. Theol. prop. 5, 6.17-21.

${ }^{147}$ Elem. Theol. prop. 101. Cf. p. 27.

${ }^{148}$ Elem. Theol. prop. 103. Cf. ch. 2.4.2.

${ }^{149}$ Another important aspect in the One's causation are the 'henads', which Proclus posits as another set of intermediaries that are participated, albeit individualized, aspects of the One in which each category of being participates. Being, Life, and Intellect, for instance, have their respective henad from which and towards which they participate in the One. On this, see appendix A. In relation to the question of self-constitution, the intermediary principles of the Limit and Unlimited are more significant for our current discussion inasmuch as they are participated and directly incorporated into the first, highest entity of Being-unlike the henads.

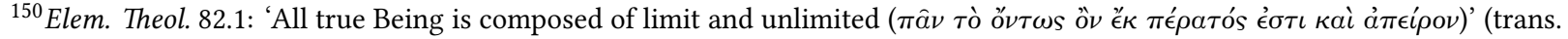
Dodds, lightly modified).

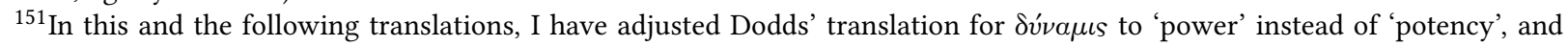

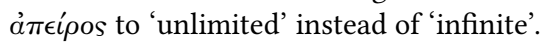


with the 'unlimited'. ${ }^{152}$ Proclus lists certain examples such as Intellect's sameness, eternity, and possessing a single life in its activity as the attributes arising from the character of the 'limited' in it; ${ }^{153}$ on the flip side, the 'unlimited' can be seen in Intellect's power which is infinite in terms of having an eternal motion and continuity, making possible Intellect having an 'unsleeping life' and being the cause for the motion of things which always move. ${ }^{154}$ This can also be seen at the lowest level with matter, insofar as on the one hand, matter in itself is purely undetermined, formless, and shapeless, which are all representative of the 'unlimited' aspect; at the same time matter is shaped and formed through the 'forms-in-matter', which are representative of the 'limited' aspect. ${ }^{155}$ Just as with Intellect, matter also does not exist purely in itself in one aspect or another of limited or unlimited, but it has both elements together. ${ }^{156}$

While the elements of the 'limit' and 'unlimited' are seen as components of all beings, Proclus does not simply leave these as aspects at the highest intelligible entity, Being, but rather locates them as distinct, separate principles out of which Being, and all subsequent entities in being, are generated:

Prior to all that is composed of limit and unlimited there exist substantially and independently the first

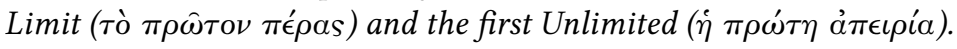

For if prior to the characters of individuals there subsist these characters in themselves as universal and originative causes, belonging not to some but to all without restriction, ${ }^{157}$ then before their common product there must exist the first Limit and the primitively Unlimited. For the limit contained in the mixture has a share of unlimitedness, and the unlimited of limit; but the first manifestation of any principle is free from alien elements, and hence the primitively Infinite can have no infusion of limit, nor the first Limit of unlimitedness: therefore these characters exist primitively prior to the mixture. (Elem. Theol. prop. 90, 82.7-16; trans. Dodds, lightly modified)

Here, Proclus follows the logic that we had seen earlier in prop. $4-5^{158}$ that the aspect of unity seen in participating individuals must go back to a source of that unity with a participated entity providing that aspect. This can be seen here with the aspect of the 'limited' found in Being going back to a prior principle of the Limited itself-and similarly for the aspect of unlimited going back to the principle of the Unlimited. In saying that each aspect must have a separate origin, Proclus appears to be implicitly disagreeing with Plotinus, where the latter recognized the 'unlimited' and 'limited' as aspects of Intellect's procession and self-constitution from the One-the 'unlimited' as Intellect's procession from the One, with

\footnotetext{
${ }^{152}$ D’Ancona Costa 377.

${ }^{153}$ In Parm. 1122.9-13.

${ }^{154}$ In Parm. 1120.5-11: 'But indeed, even prior to Time, behold the unlimited ( $\tau \grave{o}$ ă $\pi \epsilon \rho o \nu$ ) in Intellect itself and intellectual life; for this is non-transient and always a totality and present as a whole, and eternal and unlimited in power; its eternal motion and unfailing continuity is a mark of an essence and power which does not give out, but always preserves unsleeping life, through which also everything that is in motion is able to move, participating through its motion in stable infinity' (trans. Morrow/Dillon, lightly modified).

${ }^{155}$ In Parm. 1119.5-9; 1123.9-14.

${ }^{156}$ This can be seen Proclus' example of the generation of forms in matter in In Parm. 1123.1-5, esp.: 'All this shows in this realm the opposition of limit and unlimitedness; for although generated things alter in unlimited ways, nevertheless their forms are limited and persist the same, becoming neither more nor less.'

${ }^{157} \mathrm{Cf}$. Elem. Theol. prop. 23 ('All that is unparticipated produces out of itself the participated; and all participated substances are linked by upward tension to existences not participated'), esp. 26.30-35: 'Every participated term, on the other hand, becoming a property of that particular by which it is participated, is secondary to that which in all is equally present and has filled them all out of its own being. That which is in one is not in the others; while that which is present to all alike, that it may illuminate all, is not in any one, but is prior to them all' (trans. Dodds).

${ }^{158}$ And further elaborated in Elem. Theol. prop. 23; cf. n. 157.
} 
Intellect's indefinite 'sight', which becomes simultaneously limited by Intellect's turn back on itself and thinking itself. ${ }^{159}$ By contrast, Proclus takes the Limit and Unlimited as distinct first principles prior to all beings, and specifically the hypostasis of Being, in the intelligible and lower realms below the One.

At the same time, the ontological status of the Limit and Unlimited must be distinct from both the 'henads' and the entities of being. The henads stand as the first set of entities next to the One and function as participated aspects of the One in relation to the highest entities in the intelligible realm, while being at once wholly separate from all being. ${ }^{160}$ The Limit and Unlimited, by contrast, are also found in all beings through the highest principle, Being, which is the combination of these latter two, as Elem. Theol. prop. 102 also implies: 'All that in any sense exists is composite of limit and infinite because of the primal Being $\ldots{ }^{161}$ If we recall our discussion of self-constitution in ch. 2.4.1, we can see the discussion applying here with the hypostasis of Being, where the latter's self-constitution is a result of realizing its prior causes of the Limit and the Unlimited brought together in the causal process of its constituting its own being. As a consequence, the Limit and Unlimited stand as the first, non-self-constituted principles from which Being and all subsequent intelligible entities are derived. ${ }^{162}$ In this sense, the Limit and Unlimited can be called the proper first causes of all being and multiplicity, since they form the basis on which the elements of the 'unlimited' and 'limit' can be found in all beings, being traced back to the first product of the two found in the entity of Being. ${ }^{163}$

\subsubsection{The One's Causality via Negation}

To begin describing the One's causality of the Limit and Unlimited, we should start with seeing how the One is described as productive by its nature as the Good. This will then be connected with Proclus' description of the One causing by way of negating the positive aspects of being, which is rather an indication of the One's superiority over all things. From this basis we can then see how the Limit and Unlimited proceed from the One as mirroring the One's simplicity.

A beginning into seeing how the One produces can be seen in Elem. Theol. prop. 25, where Proclus links productivity with a thing's perfection, which is analogous to the One:

Whatever is complete proceeds to generate those things which it is capable of producing, imitating in its

\footnotetext{
${ }^{159}$ See Enn. VI.2.22, esp. VI.2.22.7-19, where Plotinus connects the Limit and Unlimited of the Philebus with Intellect's apprehension of the Forms (as limit), while prior to its apprehension, Intellect is unlimited, like the apprehension of a genus before the species have been apprehended. (Plotinus also says that the apprehension of an individual or 'one' as that individual is impossible-signifying the unlimited-without applying and apprehending the form of the individual-which is the limit.) Although he does not explicitly bring out the connection in this passage, this is analogous to the stage of Intellect's procession from the One, before its turning and looking towards the One, which is where it starts thinking on itself-and thus how it thinks the Forms in thinking itself. On Proclus' use of the Limit and Unlimited as separate principles, cf. D’Ancona Costa 377.

${ }^{160}$ See n. 149 and appendix A.

${ }^{161}$ Elem. Theol. prop. 102 continues further: '...all that lives has self-movement because of the primal Life; and all that is cognitive participates knowledge because of the primal Intelligence' (trans. Dodds). Gersh (1973) 78-80 links the three hypostases of Being,

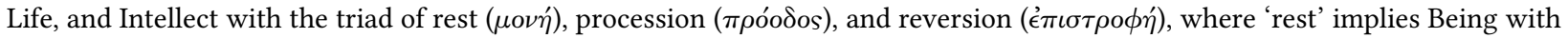
the basic mixture of Limit and Unlimited; procession implies motion from Being, which is hypostasized in Life; and reversion from Life, as well as Being, implies Intellect, which thinks the first intelligible, Being, where its thinking implies the motion that is hypostasized in Life. The highest entities of Being, Life, and Intellect thus represent the highest paradigm against which triad of rest, procession, and reversion.

${ }^{162}$ Gersh (1973) 32, 37.

${ }^{163}$ For a discussion of Proclus' sources behind the Limit and Unlimited and his use of those sources, see appendix B.
} 


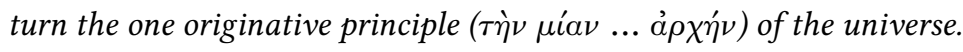

(A) For that principle because of its own goodness is by a unitary act (evvaíws) constitutive of all that is: for the Good being identical with the One, ${ }^{164}$ action which has the form of Goodness ( $\alpha \gamma_{\alpha} \theta 0 \epsilon i \delta \omega s$ ) is identical with unitary action. (B) In like manner the principles consequent upon it are impelled because of their proper completeness to generate further principles inferior to their own being. ${ }^{165}$ (C)

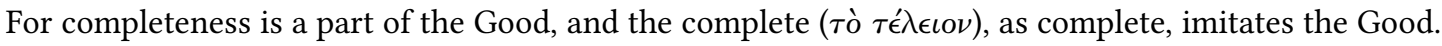
Now we saw that the Good was constitutive of all things. Accordingly the complete is by nature productive within the limits of its power. The more complete is the cause of more, in proportion to the degree of its completeness: for the more complete participates the Good more fully; that is, it is nearer to the Good; that is, it is more nearly akin to the cause of all; that is, it is the cause of more. (Elem. Theol. 28.21-34; trans. Dodds)

It is worth noting the first few lines of (A) link the One/Good with the productivity of all beings, so that the One's production through a 'unitary act' is also linked with acting with 'the form of Goodness' ( $\dot{\alpha} \gamma \alpha \theta 0 \epsilon \iota \delta \hat{\omega} s)$. In this, Proclus is referencing Elem. Theol. prop. 13, where he links the One with being the Good, with 'the Good' implying the provision of unity which keeps all things in existence. ${ }^{166}$ Since goodness implies unity, we can see this idea applied here with the One, as Good, constituting all things. In (B) Proclus applies this principle to entities below the One which are productive of lower beings, so that the productive power of these principles is proportional to the level of 'completeness' each has in proportion to its distance from the One: that is, for instance Being has more productive power compared to Life, since it is the most unified and, in this sense, closest to the One. Of primary interest here is Proclus ascribing productivity to the 'completeness' each principle possesses, where the paradigm of 'completeness' is best seen in the One. The higher an entity's completeness is, the more 'one' it is in its being and activity. In this, Proclus establishes a connection between productivity and perfection, or 'completeness', where production is always a sign of a thing possessing its perfection or unity. In one sense this is similar to Plotinus' approach of seeing a gradation of perfection implying productivity, going from Soul and Intellect to the One, albeit the emphasis for Plotinus lay on each level's imperfect, deficient realization of attaining to the One's being. Given Proclus' linking between the One and productivity, we should next see how Proclus conceives of the 'completeness' that is implied in the One.

As a proviso, we should remember that Proclus' concern from Elem. Theol. prop. 1-5 is that the One, as the absolute first principle of all unity, is removed from all participation with plurality, so that it is the absolutely unparticipated term in relation to multiplicity as participating in the One's unity through the henads-the participated terms, posterior to the One as unparticipated. Proclus has this in mind when he interprets the first hypothesis of Plato's Parmenides in his Commentary, where all positive attributes are negated from the hypothesized One. This elaboration is seen in In Parm. when Proclus comments on Parmenides $137 \mathrm{c}$ with the One being shown not to be many:

Everything then, which is negated of the One proceeds from it. For it itself must be no one of all other things, in order that all things may derive from it. For this reason, it seems to me that often Parmenides denies opposite attributes of it, for instance when he says that it is neither whole nor part, neither

\footnotetext{
${ }^{164}$ Cf. Elem. Theol. prop. 13.

${ }^{165}$ Cf. Elem. Theol. prop. 7.

${ }^{166}$ Elem. Theol. prop. 13, 14.24-25: 'Every good tends to unify what participates it; and all unification is a good; and the Good is identical to the One.' See esp. 16.1-8.
} 
same nor different, neither static nor in motion; for the One transcends all antithesis, rises above all relation, is pure from all duality, being itself the cause of all multiplicity and of co-ordinate pairs of opposites and of the primal dyad and of all relation and of all antithesis. (In Parm. 1076.23-1077.3; trans. Morrow/Dillon)

Proclus underlines the fact that, since the One stands as cause of all multiplicity and dualities, up to the principles of Limit and Unlimited by implication, it must be negated from the things it causes since it is prior to them.

At the same time, one might ask how those negations can imply that the One is a cause. Proclus argues earlier that the negations applied to the One can rather imply the One's superiority over all things, where the negation implies its corresponding assertion:

Indeed, if I may state my view in summary, I would say that even as the One is the cause of all things,

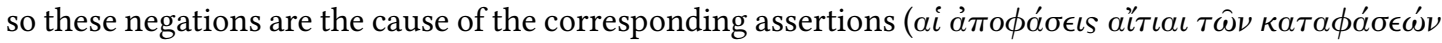
$\epsilon i \sigma \iota \nu)$. For this reason, all that the Second Hypothesis, as we have said previously, asserts, is denied by the First; for all those positive assertions proceed from these negations, and the cause of these is the One, as being prior to all other things. For even as the soul, being incorporeal, has produced the body, and as the intellect, even though unsouled (because after all it is not a soul) has given substance to the soul, even so the One, while not being itself pluralised, has given substance to all multiplicity, and although it does not possess number, to number, and not possessing shape, to shape, and similarly in the case of everything else; for it is none of the things to which it gives substance. For, after all, no other cause is the same as its own products. (In Parm. 1075.13-24; trans. Morrow/Dillon)

Here, just as in Plotinus' Enn. V.3.15, the One is described as a cause of all things by being beyond all the effects of which it is a cause-hence, negations are appropriate to the One. But in this case, Proclus is more emphatic about the nature of the One's productivity through the negation of all positive attributes that are seen in the realm of being. Proclus' reference to the second hypothesis of the Parmenides refers to the positive attributes ascribed to the One, which Proclus takes to imply the realm of being. ${ }^{167}$ Proclus has in mind the negations from the first hypothesis of the Parmenides, such as the One being without part and whole, both of which are equally asserted of the One in the second hypothesis (that is, that the One is a whole and also possesses parts). ${ }^{168}$ The idea is expanded with the example of soul being the productive cause of body, while soul itself is without body, and so on for the other examples. In this same sense, the One is understood as being the cause of multiplicity without being multiple itself. Given the example of soul as higher over body, while it has 'body' negated of it, one sees implied that the cause, in spite of the negation of its effect, is productive of its effect, even when the cause itself has the essential attribute of its effect negated from it. Proclus appears to have this in mind here with the One, even when every attribute of being and multiplicity is denied of the One, so that the One is productive through the negation of the effect it brings about. ${ }^{169}$

\footnotetext{
${ }^{167}$ In Parm. 1068.20-21: 'And if in fact we have the whole level of gods and all the One which is participated in by Being presented to us in the Second Hypothesis.... On the second hypothesis, see Parmenides 142b-155e.

${ }^{168}$ Parmenides $137 \mathrm{c} 3-\mathrm{d} 3$; $142 \mathrm{~d} 1-8$.

${ }^{169}$ It should be noted at this point that Proclus' argument here builds on a more basic question, addressed in In Parm. 1072.141074.17 of whether negation can indicate superiority: 'It is generally felt that an assertion is a more worthy thing than a negation. A negation, after all, is a deprivation of something; whereas an assertion, they say, involves the presence, and, as it were, the possession, of Form' (In Parm. 1072.14-17; trans. Morrow/Dillon). Proclus may have in mind Aristotle here, who critiques negations being used as definitions for forms in Topics VI.6, 143b11-34, and Parts of Animals I.3, 642b22-643a6, so that by implication
} 
Seeing that the One causes by way of its negations, we should next look more specifically at the One having 'limit' and 'unlimited' negated from it, from which the principles of the Limit and Unlimited come about. Commenting on where Parmenides $137 \mathrm{~d}$ says that the the One is 'unlimited', Proclus responds that the One could not be 'unlimited' in the way that is seen in existent things, as is summed up in the principle of the Unlimited: since the 'unlimited' ultimately represents infinity of power, the One must be beyond this sense of 'unlimited' implying multiplicity in some form. ${ }^{170}$ Another reason that the One is not called 'unlimited' in the latter sense is that the Unlimited is, in a certain sense, inferior in nature to the Limit, so that the Limit comes before the Unlimited. ${ }^{171}$ Proclus may implicitly have in mind his doctrine from Elem.

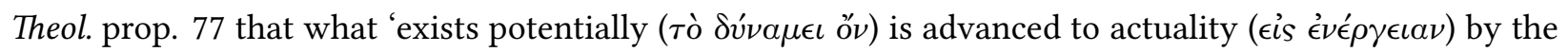
agency of something which is actually what the other is potentially' (72.20-21). From this, the Unlimited has infinite potentiality which is only realized through the application of Limit, which is analogous to actuality ( $\left.\epsilon^{\prime} \nu \epsilon^{\prime} \rho \gamma \epsilon \iota \alpha\right)$ - the combination of which brings about the entity of Being, as we saw earlier. Because of this structure, the Unlimited has a secondary priority in relation to the Limit-and so likewise the One is also beyond being 'unlimited' in this sense. Proclus thus takes the One being 'unlimited' in the sense of being strictly beyond all 'limit', including the principle of the Limit. ${ }^{172}$ Of course, one might ask why this would be the case: it would seem that the One is the first limit against which all things are measured. Yet for Proclus, the problem is that relating all things to the One as a limit would imply that the One is conditioned by its relation to all things as a limit-going back to the problem of a 'One' participated by multiplicity implying that it could not be the One itself. Thus the One must necessarily be beyond the Limit, as well as the Unlimited. ${ }^{173}$

At this point we may summarize the One's production of the Limit and the Unlimited. On looking back, the Limit was described as communicating unity and form to things, while the Unlimited was that by which power, or potency, is realized in things. Insofar as the Limit is that which limits or unifies something, it is a mirror of the One's unity, only insofar as it is communicated in all things, beginning with Being. ${ }^{174}$ Likewise, the Unlimited also loosely mirrors the One, albeit secondarily after the Limit, insofar as it is most unitary as the highest power, as following on the One. ${ }^{175}$ In this sense, the Limit and the Unlimited

negation does not imply superiority (as indicative of a genus, for instance; Aristotle's point is that negation only indicates either a privation of the proper function of a nature-e.g. being blind-or a difference indicating a species of a genus-length indicating what is without breadth, which is a difference from length with breadth, which both fall under a higher genus of 'length'); see Deslauriers 27-9 for further discussion of this in Aristotle. Porphyry also mentions 'some people' who hold that the Aristotelian category of $\epsilon^{\prime} \xi$ s ('state') 'had to be discussed in positive terms, and privations in negative terms' in On Aristotle's Categories 134.25ff, which is also likely a reference back to Aristotle. Syrianus in On Aristotle's Metaphysics 34.32ff provides a more positive account of privations, which may be one source for Proclus' approach here on describing negations as a 'positive' account indicating superiority. Many thanks to Gary Gabor for these references.

${ }^{170}$ In Parm. 1123.15-24.

${ }^{171}$ In Parm. 1123.24-1124.2.

${ }^{172}$ In Parm. 1124.5-12.

${ }^{173}$ In Parm. 1124.18-28.

${ }^{174}$ Chlup 77-8: 'For Proclus, Limit and the Unlimited represent a sort of a basic 'interface' between the One and the lower levels. In the One as such they are not yet distinguished, being pre-embraced in it in a unitary manner; but when a lower level attempts to relate to the One, it can only do so through their prism. According to Proclus the One is altogether incomprehensible and transcendent in itself, and if we do speak about it, we do not really talk about that first unfathomable principle, but about its first relatively comprehensible image which is already delimited in some way.'

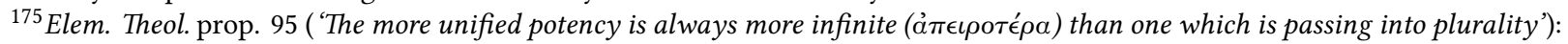
'For if the first Unlimited ( $\left.\dot{\eta} \pi \rho \omega^{\prime} \tau \eta \dot{\alpha} \pi \epsilon \iota \iota^{\prime} \alpha\right)$ is nearest to the One, then of two potencies that which is more akin to the One is 
can be described as positive dual aspects of the One's being and productivity, where the One is unitarily what is expressed at the level of the Limit, as the source of unity for all things, and the Unlimited, as the source of productivity for all things. In other words, in one sense the One is the Limit and the Unlimited, but in an absolutely simple way which denies even the distinction of the aspects of oneness and power as represented in the two entities. ${ }^{176}$ We can see this going back to Proclus' description of the One as the Good, where the One's unity implied its goodness as producing and keeping all things them in existence as the source of unity. ${ }^{177}$ But since it is properly prior to all multiplicity, the One must be stripped of all aspects implying multiplicity, where all participated entities, even the Limit and Unlimited as the highest entities, imply multiplicity in their communication with plurality. ${ }^{178}$ Thus, one might say that the One has a 'hidden' kind of power and unity by which it produces the Limit and the Unlimited, but in itself the One has these two aspects denied of it, since it is superior and prior to any implication of multiplicity. ${ }^{179}$ In this sense the analogy from soul as productive of body, while itself being without body, also applies to the One, except in a radical way in being prior to any positive, identifiable aspect of being.

\subsection{Conclusion: The One as Uncaused and Cause of Self-Constitution}

Going back to Plotinus and comparing with his conception of the One, Proclus' One is similar in being the cause of all things by having the attributes of being, implying multiplicity, denied of it. The process by which the One is identified as a first cause is also similar for both Proclus and Plotinus, although Proclus' consideration of certain 'Ones' that are participated below the absolute, unparticipated 'One' (the Limit/Unlimited pair as a specific example we have just seen) is an additional step over Plotinus. For the latter, Soul is a more unified source in relation to body, but in itself Soul is insufficient compared to its higher source of unity-Intellect-which ultimately leads up to the One as the sole, perfect source of unity. This constitutes one subtle but essential difference from Proclus, where Proclus allows that there are gradations of perfection in the causal chain from the One: Intellect has its own, autonomous perfection as cause of all intellectual knowledge in things, but this autonomy is relative to its higher causes of unity, which are found in Being and Life. ${ }^{180}$ By contrast, Plotinus characterizes Intellect as a deficient realization of the One's unity, with Soul as a further deficient realization coming from Intellect, while the One, although beyond being, is the perfect paradigm for all lower beings. Because of this, Plotinus conceives of the One

infinite in a greater degree than that which falls away from it...' (Elem. Theol. 84.30-32; trans. Dodds, lightly modified).

${ }^{176}$ See Platonic Theology III.9, 36.10-16, where Proclus also implies that the Limit and Unlimited are henads: 'That is why Socrates, wishing to show how the mode of generation is different in the case of two principles and the case of mixed says that God 'has revealed' the Limit and Unlimited (

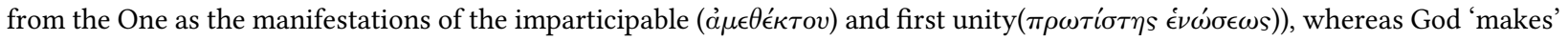
the mixed and produces it as mixing through first principles ( $\tau \hat{\omega} \nu \pi \rho \omega \dot{\tau} \omega \nu \dot{\alpha} \rho \chi \hat{\omega} \nu$ )' (trans. Lankila). See Lankila 68-70, which offers an in-depth analysis of the Limit and Unlimited as quasi-henads according to the Platonic Theology. Cf. Chlup 78.

${ }^{177}$ Elem. Theol. prop. 13. Cf. n. 166.

${ }^{178}$ Going back to the basic stricture of an absolute, unparticipated One from Elem. Theol. prop. 5.

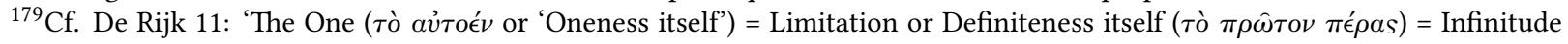
itself ( $\dot{\eta} \pi \rho \omega^{\prime} \tau \eta \dot{\alpha} \pi \epsilon \iota \iota^{\prime} \alpha$ ); see Elem. prop. 90. The First Principle’s Infinitude is nothing but superabundant Power whose activity

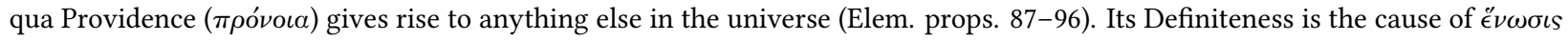
or 'unific power' which constitutes the unity of an entity of lower rank and unifies it in counter balancing as it were its selfdestructive manifoldness.'

${ }^{180} \mathrm{Cf}$. earlier discussion in ch. 2.4.2. 
containing all multiplicity within itself in a unified, simple way.

This is where Proclus' understanding of the One as productive of being through the Limit and Unlimited is ultimately significant, since the latter are the proper causes of multiplicity-albeit at different stages, beginning with the simplest first production of Being. The One stands as cause of multiplicity only insofar as it has all attributes of multiplicity, up to the Limit and Unlimited, denied of it, while the Limit and Unlimited proceed from the One as positive reflections of the One's nature. However, is this not another version of Plotinus' One pre-containing multiplicity, albeit at a much simpler level in the opposed relation of the Limit and Unlimited? Proclus would say no: as Elem. Theol. prop. 13 showed, the One is linked with the Good, insofar as goodness implies the preservation of all things, while unity is a concomitant part of this definition. The Unlimited implies power and production, while the Limit implies unity-both attributes of which, for the One as Good, are definitionally equivalent, albeit in a negative form in the One. This is unlike Plotinus, where in the procession of Intellect from the One, its first turn in the direction of the One towards itself already implies the distinction of subject and object-which are definitionally opposed. Plotinus' One has to pre-contain this distinction of opposition within itself, whereas Proclus' One pre-contains by negation the positive expression of itself, the dyad of the Limit and Unlimited, which rather definitionally imply each other. Thus, Proclus would say that the One certainly does not pre-contain multiplicity, except insofar as it is by its being that the Limit and Unlimited come about, from which all lower, self-constituted entities like Being, Life, and Intellect bring about the production of multiplicity. This ultimately plays into how Proclus sees the One as a prior cause for self-constitution, via the first mixture of the Limit and Unlimited with Being's self-constitution, in contrast to Plotinus' One anticipating in a hidden way Intellect's self-constituting activity. 


\section{The One and Self-Constitution}

At this point we may now return to the main question we have been seeking to answer: whether Proclus' charge against Plotinus is justified that self-constitution in the One, however this concept is understood, is contrary to the One's simplicity. Having looked at the general concept of self-constitution in Plotinus and Proclus, as well as both of their concepts of the One, we should now bring our findings together by reviewing in more detail Plotinus' and Proclus' discussion on self-constitution in relation to the One. In looking at Plotinus, we should see how his argument for the One's self-constitution is conditioned by his general discussion of the One as the source of freedom in action, as found in the lower levels of Intellect and Soul. Proclus' critique should then be weighed against Plotinus' careful use of speech about the One's positive attributes, including self-constitution, with non-literal, quasi- (oio $\nu$ ) terms. But as we will see, Plotinus' talk of self-constitution in the One is conditioned by his causal model of the One, which we saw in ch. 3, and supported by his view of self-constitution at lower levels as deficient realizations of the One's being in ch. 2.4.1. It is with this underlying causal model in mind that Proclus' critique ultimately considers, and which points to a real tension in Plotinus' understanding of the One's simplicity which Proclus is actively trying to avoid with his own causal model.

\subsection{Enn. VI.8.13-14: Plotinus' Argument for the One as Cause of Its Own Being}

In Enn. VI.8.13.50-59, Plotinus brings up the One bringing itself into existence from choice and will:

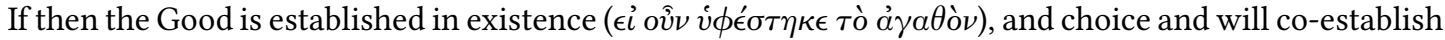

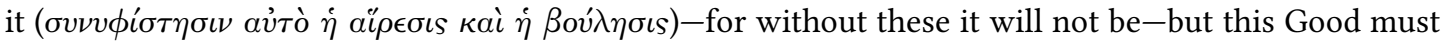

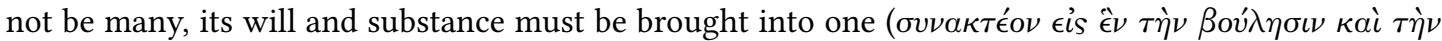

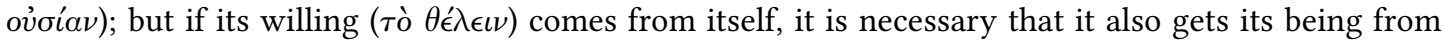

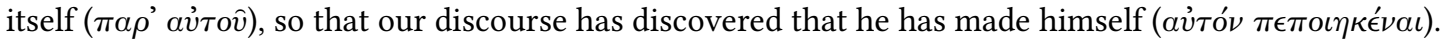
(Enn. VI.8.13.50-55; trans. Armstrong, lightly modified)

We should note the structure of the argument Plotinus provides: (A) given that the One exists, or is 'established in existence', choice and will are involved in the One's existence, where choice and will play a constitutive part of the One's existence. (B) At the same time, implicitly as the first cause, choice and will also come from the One. (C) If choice and will are involved in establishing something in existence, and if it is the One that is established in existence, then the One establishes itself in existence-(D) thus it 'makes' itself. (A) appears to be premised on a pre-supposition that every entity's existence is dependent on a prior will, whether from itself, from another, or by 'chance'-something which will be considered shortly. With (B), Plotinus established earlier in the chapter that the nature of the One (or also the Good) is the 'will of himself', where the Good, as such, has nothing else but itself to will. ${ }^{181}$ This is built on a consideration that, if the One has activities, those activities must necessarily come from a will-and given that those activities are identical to the One, as absolutely simple, the One will be identical to its will. ${ }^{182}$ A further reason to see

\footnotetext{
${ }^{181}$ Enn. VI.8.13.38-41.

${ }^{182}$ Enn. VI.8.13.5-8: 'For if we were to grant activities to him, and ascribe his activities to what we might call his will-for he does not act without willing-and his activities are what we might call his substance, his will and his substance will be the same thing' (trans. Armstrong).
} 
why Plotinus posits (B) is that all things desire the Good: '...every being in its desire for the Good wants to be that Good rather than what it is, and thinks that it is in the highest degree when it participates in the Good' (Enn. VI.8.13.12-14). ${ }^{183}$ Thus if willing by definition desires the Good, while the Good has a will, then the Good has nothing else to desire and will but itself as a result. (C) then follows on this: the One brings itself into being since it wills itself.

\subsubsection{Contextualizing Plotinus' Argument for the One's Self-Constitution}

However with (A), it would be worth asking why Plotinus appears to assume that all things are caused by the will of something, rather than, for instance, assume an uncaused cause in the manner of Aristotle's unmoved mover. This question is wrapped with the general context of Enn. VI.8, where Plotinus is inquiring into the nature of human freedom as it leads up to its source in the first cause. ${ }^{184}$ Plotinus' concern is firstly to track down a sufficient definition of freedom, and secondly to locate the source of that freedom ultimately found in the One. Starting at the human level, Plotinus says that what is truly free and in our power' is not what typically masters us with 'opposing chances and compulsions and strong passions possessing our souls' but rather that which '...we do without being forced to and with knowledge [of what we are doing], and in our power which we are also competent to do'. ${ }^{185}$ Thus freedom for Plotinus implies not just acting without compulsion but also action according to knowledge, 'which we are also competent to do'. Sense perception, on this count, is not sufficient as the source of this freedom, since it only perceives without knowledge. Even knowledge in relation to external action, involving sense perception, does not necessarily imply freedom of action, since such action can be 'mixed'-whether by other desires or circumstances. ${ }^{186}$ Ultimately the realm of Intellect is where one finds freedom, for Plotinus, since Intellect's activity is free from association with the body, implying external impediments and constraints, and its activity is within itself and not compelled by anything outside it. ${ }^{187}$

While this latter consideration makes sense, Plotinus still wishes to continue on to the source of freedom with his enquiry. Although it is in the realm of Intellect that one finds what is truly in one's power, or what is entirely voluntary, Intellect's being is contingent on the One as its prior source of unity and perfect goodness. Thus Plotinus' statement:

The soul, then, becomes free when it presses on without hindrance to the Good by means of Intellect, and what it does through this is in its power; but Intellect is free through itself; but the nature of the Good is the very goal of the striving and that through which the others have what is in their power, when one is able to attain it without hindrance and the other to have it. (Enn. VI.8.7.1-6; trans. Armstrong)

Thus in human acting, insofar as the soul is ordered according to Intellect is freedom found in a derivative way, while freedom itself is found in Intellect. So far this matches Plotinus' description of Intellect as being

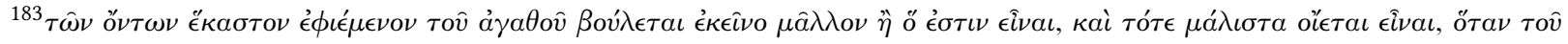
ả $\gamma \alpha \theta$ ov̂ $\mu \epsilon \tau \alpha \lambda \alpha \dot{\beta} \eta$.

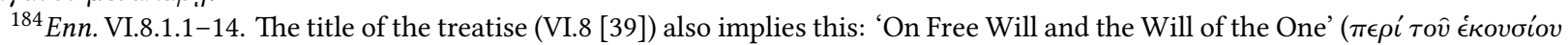

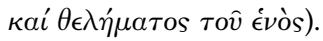

${ }^{185}$ Enn. VI.8.1.21-34.

${ }^{186}$ Enn. VI.8.2.28-37.

${ }^{187}$ Enn. VI.8.3.20-26.
} 
completely in act as the highest being, so that it is also equally the most free in its activity as the highest being. And yet since the One is the source for Intellect's being as the perfect Good, freedom must also properly be found in the One. One difficulty to this is that, if the One is beyond being, freedom does not literally apply to it. ${ }^{188}$ Thus the following problem could be put forward to the One:

Unless some rash statement starting from a different way of thinking says that since [the nature of the Good] happens to be as it is, and does not have the mastery of what it is, and is what it is not from itself, it would not have freedom, and its doing or not doing what it is necessitated to do or not to do is not in its power. This statement is indeed contrary and absurd and would altogether do away with the nature of free will and self-determination and our idea of what is in our power, as if this was empty talk and names for non-existent things. (Enn. VI.8.7.11-20; trans. Armstrong)

The objection Plotinus considers is that the One, since it 'happens to be as it is'-which also implies that it exists by chance-does not appear to have mastery over itself, and is thus not free in its acting. ${ }^{189}$ Although it might seem somewhat strange why Plotinus would be worried about the charge that the One is by chance, assuming the One is established as the first principle beyond being and thus any need for justification, this objection has a particular place in the treatise for the One as a source of freedom. Plotinus' concern is that if the One's freedom is put in question, then there is no grounding for free will or self-determination as we see it in Intellect, if the One is the source for Intellect and thus Intellect's freedom.

Although the One is beyond being, and so beyond literal description, Plotinus sees that one needs to give an explanation of the One as the source of freedom for the sake of 'persuasion':

But if one must bring in these names of what we are looking for, let it be said again that it was not correct to use them, because one must not make [the One] two even for the sake of forming an idea of it; but now we must depart a little from correct thinking in our discourse for the sake of persuasion ( $\tau \hat{\eta} s, \pi \epsilon$ ov̂s). (Enn. VI.8.13.1-5; trans. Armstrong)

In referencing 'these names', Plotinus is referring to the possibility of calling the One 'master of himself' (avi ô кúpıos), which he earlier showed to be technically improper when applied to the One. This is so since the phrase properly applies to 'substance', or Intellect, while the One, as above Intellect, is also above being 'master of himself' alongside every other attribute applying to being. ${ }^{190}$ Because such terminology

\footnotetext{
${ }^{188}$ Cf. Eliasson 211-2.

${ }^{189}$ See Enn. VI.8.7.24-36 on the implication of the objector's view implying the One exists by chance. On the origin of this objection posed, see Narbonne (2007) 190-1, esp.: 'On the question of the origin of this position that is 'different', or maintained 'from another side', we have not yet got beyond the stage of conjectures, which can be summed up under four headings: the objection comes either from materialists who attribute everything to chance-someone like Strato of Lampsacus, for example, or Epicureans; or it is of Gnostic origin (Bréhier, Cilento); or it stems from an experiment or a (dialectical) thought-exercise (Gedankenexperiment) undertaken by Plotinus himself (Harder, Theiler, Leroux); or it is of Christian origin (Armstrong, Whittaker). The Gnostic hypothesis lacks any solid foundation, as Leroux has effectively shown, and the Christian hypothesis, while more believable a priori, in the end rests on no precise textual evidence, even if it is true that at this period Christian authors are to be found who stress the free and voluntary nature of God's act of creation-authors such as Methodius of Olympus or Hippolytus of Rome. In the absence of any concrete testimony one way or the other, hypothesis for hypothesis, it is only the idea of an objection raised by a materialist, as relentlessly determined as he is subtle, that seems probable enough to be worth considering for an instant.' Narbonne (2007) 191-3 goes on to argue that Plotinus is following a perennial concern in the Platonic tradition to refute materialism in proving wrong the charge that the One's nature is determined by chance instead of by itself.

${ }^{190}$ Enn. VI.8.12.28-38, esp.: 'What then is that which is in a more honourable position than being its own master? It is because since substance and activity there are in a way two and gave, from the point of view of activity, the idea of mastery, but this was the same thing as substance, for this reason mastery came to be separated, and it was said to be master of itself. But where there

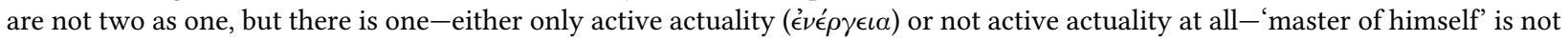
correct.'
} 
implies duality (even implied in the language with the distinction between the subject and the possessive genitive), Plotinus says that the term is not 'correct' in forming the proper, right idea of the One, which is why the phrase properly shifts down to Intellect instead. At the same time, Plotinus sees the need to correct the mistake given by the objection in suggesting that the One is not otherwise 'master of himself'. In this sense, Plotinus admits there is a second form of discourse about the One, implied in the departure from 'correct thinking': on the literal level, the objection that the One is 'master of himself' simply does not apply in the sense that such a statement is true or false; on another, non-literal level, the objection is something which is true or false. It is in this latter realm that Plotinus seeks to address the objection of the One being determined by chance by answering that the One is truly 'master of himself'. Thus in Enn. VI.8.13.50-55, Plotinus constructs in 'as if' (oio $)$ phrases-safeguarding the One's absolute simplicity ${ }^{191}-$ a way to understand the One being master of itself, instead of having its being determined by chance, through talking about the One constituting its own being.

\subsubsection{Plotinus' Analogical Language as Corresponding with the One’s Being}

Given this two-tiered discourse about the One, one should ask how Plotinus understands the 'as if' language of the second, non-literal tier: in relation to self-constitution, does such language correspond to an aspect of the One's being in some real way, or is this language metaphorical and without any real referent? For instance, with the latter option, one might say that a non-existent square-circle has the property of squareness, which is applied from an abstraction of square objections in common experience to a concept of square-circle that that person has in mind. In this case, the property of squareness has absolutely no referent, even analogous, since the square-circle does not exist beyond being a mental concept-in fact, even the concept is irrational, insofar as the concept, 'square-circle', involves a contradiction between the two definitions of a square and circle. ${ }^{192}$ With the former option, on the other hand, someone of Plotinus' view (or Proclus' view) might say that the attribute of life does not strictly or properly apply to the physical body of an animal except in an analogous, derived way insofar as it does have a proper application to its source in the soul. ${ }^{193}$ In this sense, although the property is not literally in the thing itself, the property lies in the thing in an analogous, if derived, way. In the real-referent view, the property has a kind of existence in the subject, although it has no literal existence, while in the non-existent view, the property has no existence in the subject since the subject is absolutely non-existent.

Given our analysis of the One's causality in ch. 3, the first, real-referent view would appear to be the one Plotinus has in mind. Recalling our look at the way the One generates Intellect, Plotinus' two-act theory is significant insofar as Plotinus claims that all things possess an external act which comes from and manifests a thing's internal act. It is from this that we saw the One's generation of Intellect being an image (єikóva) of the One. ${ }^{194}$ Because of the One's direct generation of Intellect, which is an image of the One, the One pre-contains within itself all attributes implying multiplicity which are manifested in Intellect, but

\footnotetext{
${ }^{191}$ Enn. VI.8.47-50.

${ }^{192}$ See Euclid's Elements, Book 1, def. 15, 22.

${ }^{193} \mathrm{Cf}$. Enn. VI.9.1.17-23, which is analogous insofar as the soul is more 'one', relatively speaking to body, while body is in a lesser sense to soul 'one'.

${ }^{194}$ Cf. pp. 36-39.
} 
in an absolutely unified way in which each is not distinct from the other in the One. ${ }^{195}$ Because the One pre-contains these attributes within itself, it must contain all the effects it has to a supreme degree that is higher than Intellect-and thus beyond the literal level of language, which applies up to Intellect. What we can see in Intellect then applies in a higher, superior way to the One, which fits the way Plotinus has been speaking about the One making itself and bringing itself into being. So in relation to the question of how Plotinus understands the non-literal discourse that is used for 'persuasion', there is a correlation of the property in question which does apply to the One, however the language would necessarily not be literal but analogical.

The correlation between the non-literal, analogical language of the One and the One implicitly precontaining its effects can be seen in the context of VI.8.14, after Plotinus has laid out his argument for the One's self-constitution in 'as if' language:

(A) But these came in this way from a single source which did not reason (ov $\lambda \epsilon \lambda o \gamma \iota \sigma \mu \epsilon \operatorname{v\eta }$ ) but gave

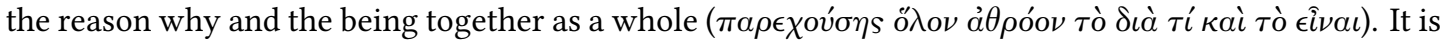
the source therefore of being and the why of being ( $\tau$ ôे $\delta \iota \grave{\alpha} \tau i \in \hat{\imath} \nu \alpha u$ ), giving both at once; but that from which these came is like the things which have come to be much more originally ( $\dot{\alpha} \rho \chi \epsilon \tau v \pi \omega \dot{\omega} \epsilon \rho o \nu)$ and more truly and more than as it is on their level in that it is better. (B) If then there is nothing random or by chance and no 'it happened to be like this' ( $\sigma v v \epsilon \hat{\epsilon} \beta \eta \gamma \grave{\alpha} \rho$ oṽ $\tau \omega s)$ with the things which have their cause in themselves, and all things which come from him do have it, for he is the father of reason and cause and causative substance ( all far from chance, he would be the principle ( $\alpha \dot{\alpha} \chi \grave{\eta})$ and in a way the exemplar (oîo $\pi \alpha \rho a ́ \delta \epsilon \iota \gamma \mu \alpha)$ of all things which have no part in chance, truly and primarily, uncontaminated by chances and coincidence

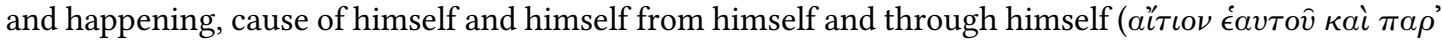

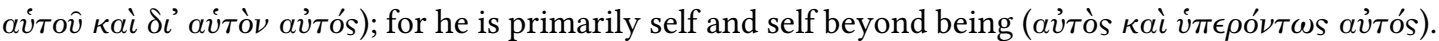
(Enn. VI.8.14.30-42; trans. Armstrong)

Plotinus' emphasis on the One being the source of being, where chance is posterior to the level of primary being as seen in Intellect, ${ }^{196}$ is what drives his argument that it is a patently mistaken view to attribute chance to the One's being, as seen in (A). The One is not simply beyond being in a way where one's attributes to it have no application, but as the source of Intellect it must pre-contain what is manifested in Intellect. Thus Plotinus directly draws out this principle in (B), where if chance is not manifested in Intellect, which is one of 'the things which have their cause in themselves', certainly much more so must this be the case in the One. The language Plotinus uses is telling, insofar as he speaks literally in saying the One is a principle ( $\dot{\alpha} \rho \chi \dot{\eta})$ of Intellect, while he speaks non-literally with the One as 'in a way the exemplar' (oio $\pi \alpha \rho \alpha \dot{\delta} \epsilon \iota \gamma \mu \alpha$ ) of Intellect. Once again this points back to the double-sided literal/analogical language Plotinus allows of the One, where here this is also matched with the causal model of the One as, on the one hand, principle of Intellect and superior by being absolutely simple, and on the other hand, as directly pre-containing attributes manifested in Intellect. Because Intellect constitutes itself in its attempt to turn back towards the One and imitate it, as we saw in ch. 2.3.1, the One must also contain this self-constitution in a more perfect way, only in its being absolutely one and the same with itself-thus Plotinus' statement of the One as 'primarily self and self beyond self'. 197

${ }^{195}$ Cf. pp. 39-40; Enn. V.3.15.28-32.

${ }^{196}$ Enn. VI.8.10.11-18.

${ }^{197}$ Although we should note here that, where Plotinus often speaks of Intellect's activity towards itself in terms of motion, as 
Given that Plotinus backs up his language of the One being self-constituted by looking at the One as the source of Intellect, we can see this fits with our analysis of the One pre-containing the attributes of Intellect which imply multiplicity in ch. 3.3. However, as was seen in Enn. V.3.15.28-32, the One contains these in a mode appropriate to itself as absolutely simple. This double-sided aspect also reflects what we saw with Plotinus' understanding of self-constitution at the lower levels of Intellect and Soul where Intellect in relation to Soul stands unmoved in its production of Soul, while in itself Intellect has motion connected with its internal act which constitutes its being. ${ }^{198}$ Although activity normally implies duality in each entity, like Intellect, constituting itself, when brought to the One this literal duality is erased for Plotinus, according to Enn. V.3.15.28-32, even though the language used of self-constitution and activity attributed to the One still implies duality. Thus, in Plotinus, the One's simplicity is such that it pre-contains the attributes of multiplicity, albeit in a transcendent, unified way, since Intellect is directly produced from the One. This is something we should keep in mind as the essential reason Plotinus asserts self-constitution to the One, since this will play one underlying reason for Proclus' critique of the assertion of self-constitution in the One, even if such an assertion is by analogy instead of literal.

\subsection{Reviewing Proclus' Critique of Self-Constitution in the One}

Here we may go back to the critique Proclus offered in the Commentary on Parmenides against selfconstitution in the One and see how Proclus has Plotinus in mind, given our previous discussion. Starting with Proclus' reconstruction of the argument for self-constitution in the One:

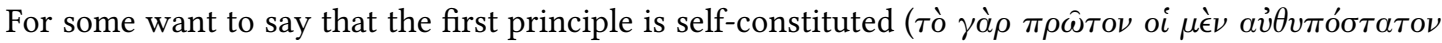
$\left.\lambda \epsilon^{\prime} \gamma \epsilon \nu \dot{\alpha} \xi \iota v \hat{\sigma} \sigma \nu\right)$, arguing that even as the first principle of moving things is the self-moved, even so the first principle of all those things which have any sort of existence is self-constituted; for all things subsequent to the first principle also derive from the first principle. This first principle, then, is self-constituted in the proper sense, as deriving its substance from nothing else, whereas as they say, everything must either be created by itself or, inevitably, by something else. (In Parm. 1149.24-1150.2; trans. Morrow/Dillon)

So far we should note the parallelism of Proclus' reconstructed argument with that which Plotinus gave in Enn. VI.8.14: as the One is the 'father of reason and cause and causative substance'-out of which the One is a paradigm of Intellect by being self-constituted-so also here Proclus summarizes this when he says that the first principle is self-constituted as a result of all things deriving their existence from the One. Proclus thinks that the argument for the One's self-constitution follows the same logic of positing self-motion as the principle for all moved things, which hearkens back to Plato's argument for self-motion, as we saw in ch. 2.1. The mention of those who hold that 'everything must either be created by itself or, inevitably, by something else' is also directly referencing Plotinus' line of thought in Enn. VI.8.7-21, where Plotinus is trying to circumvent the objector's implication of the One's being as coming from chance rather than from itself. Interestingly, Proclus also mentions the view of Plotinus' objector before this passage and classes it

we saw earlier (see p. 21), he does not explicitly attribute motion to the One. In this case, motion may perhaps be a sign of a kind of incompleteness in Intellect's self-constitution, where the One's lack of even a quasi-motion implies that its self-constitution is perfect.

${ }^{198}$ See p. 22. 
under the view that the One is, in some sense, self-constituted, albeit from chance instead of from itself. ${ }^{199}$ Other than disagreeing with the objector's position when he mentions this view, Proclus seems to think the objector's view falls under the same problem of ascribing self-constitution to the One, and that the answer to this, as well as Plotinus' position, comes in rejecting the premise that the One is self-constituted, as we next see:

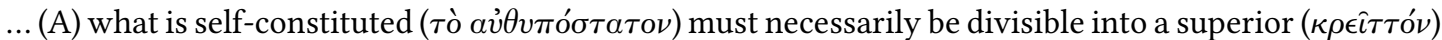
and an inferior ( $\chi \epsilon \hat{\imath} \rho \circ \nu)$ element; for it is superior in so far as it constitutes ( $\alpha \alpha \hat{o} v \dot{v} \phi i \sigma \tau \eta \sigma \iota \nu$ ), and it is in-

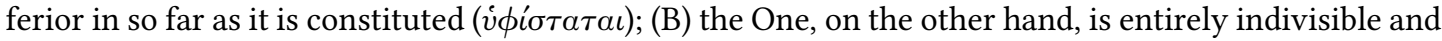

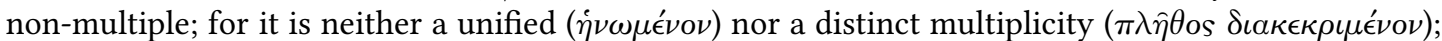
for if it were distinct, it would be in many places and not one, whereas if it were unified there would have to be something else prior to it which unified it; for what is unified is something which has unity as an attribute, but is not itself unity, as the Eleatic Stranger says. (C) If, then, the self-constituted is in any way divisible, while the One is not divisible, the One would not be self-constituted, but rather the cause of all self-constituted entities, by virtue of the fact that all things are preserved by the agency of the One, both such things as are generated by themselves and such things as are generated by others. (In Parm. 1150.6-17; trans. Morrow/Dillon, lightly modified)

Proclus' response to the position of the One's self-constituted starts out with an analysis (A) of the basic mechanism of self-constitution into a superior, constituting element, and an inferior, constituted element. Although the same entity is one with itself, there is still the basic division that Proclus points out in the process which implies duality. At the same time we should remember from the Elements of Theology that Proclus classed self-constituted entities as simple, ${ }^{200}$ so here in one, relative sense self-constitution implies simplicity, while on the other hand there is still the duality of cause and caused implied in an entity constituting itself. This goes against the One's absolute simplicity which negates all implication of duality, even where the latter implies relative simplicity, as we next see in (B). The way Proclus goes on to refute the attribution of divisibility to the One is in terms of either distinct or unified multiplicity, which is also how Elem. Theol. prop. 4 went on to show the existence of the One as distinct from unified and distinct pluralities. ${ }^{201}$ While distinct multiplicity implies that the One would be divided in place, unified multiplicity would imply that the One has unity as an attribute-both of which necessitate the One as a source of pure unity. It seems that Proclus may have the latter category of 'unified multiplicity' in mind with self-constitution, where unity is an attribute that results from an entity constituting itself. This would fit our earlier description of self-constitution for Proclus implying dependency on higher causes: Being, for instance, constitutes itself, while it relies on its prior sources of the Limit and Unlimited-both of which communicate unity as an attribute to all things and which constitute all existent things. ${ }^{202}$ This dependency would fit the relative 'Ones' Proclus spoke about in Elem. Theol. prop. 4 which unify their participants, so that they are unified but require a prior 'One', or the absolute One itself, as the unparticipated source of unity. ${ }^{203}$ Ultimately, because of this understanding of self-constitution implying unity as an attribute,

\footnotetext{
${ }^{199}$ In Parm. 1146.6-10: 'For I class as self-constitutive ( $a \dot{\theta} \theta v \pi$ ó $\tau \alpha \tau \tau o \nu$ ) not that which nothing produces (in view of which some authorities have declared that the First Principle is self-constitutive as having no cause of itself; and then, as having no cause, they

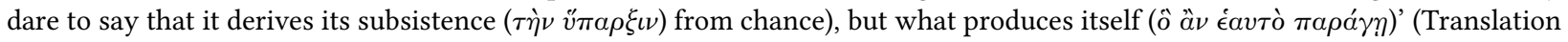
slightly modified).

${ }^{200}$ Cf. pp. $24-26$.

${ }^{201}$ Cf. p. 43.

${ }^{202}$ See ch. 2.4.2, 4.2.1.

${ }^{203}$ Cf. pp. $43-4.1$.
} 
implicitly fitting under the 'unified' category, Proclus goes on to refute the One as self-constituted and rather hold the One as prior cause of self-constitution and the externally caused.

So far we should compare this approach with Plotinus' own argument for the One's self-constitution. Proclus does not address, for instance, the distinction of literal/analogical language about the One which Plotinus used with his positive descriptions of the One, particularly in regard to self-constitution. Rather, Proclus seems to read Plotinus' argument as a literal one, or as one which necessitates a literal read: although the One for Plotinus is absolutely simple and beyond being, the One as self-constituted in its inner being falls into the domain of having unity as an attribute with self-constitution as necessitating duality. At the same time, Plotinus does seem to follow Proclus' train of thought on the argument for the first principle's self-constitution following on self-motion as the first cause of all moved things. We saw this in some form described at the end of ch. 2.3, where Plotinus appears to merge Plato's concept of self-motion with Aristotle's concept of the unmoved mover with the two-act theory: while Intellect remains unmoved in relation to its external activity constituting Soul, Intellect's internal act is also a kind of motion which is constitutive of its own being; by analogy, although Plotinus does not ascribe motion to the One, this fits with Plotinus' description of the One as self-constituted in its being, while relative to Intellect the One is uncaused and beyond the literal status of cause. However we should also recall Proclus' requirement that there should be an uncaused cause in the chain of causality with the self-constituted and externally caused. To one degree Plotinus also holds to this with his view of the One as beyond being and source of unity for Intellect and the lower entities, but ultimately Plotinus, as we have seen, holds to an understanding of the One as a paradigm for Intellect, of which the latter is a multiple manifestation of the One. It is precisely this underlying view that Proclus criticizes which plays a part of Proclus' reason to reject self-constitution in the One.

\subsection{Objection: Is Proclus' Critique fustified?}

At this point we should ask, given Proclus' critique and our matching of Proclus with Plotinus, is Proclus' critique justified? A major weak point in Proclus' critique is his lack of addressing the two-sided distinction of language that Plotinus applied to the One. Plotinus' One is such that its absolute simplicity is not threatened at first glance, since it does not have any attribute implying multiplicity applied to it at the literal level. One might think that Proclus' critique has no ground because, at base, Plotinus is holding the same view and concern of the One's simplicity as Proclus. This is a critique that John Dillon also holds, as we saw in the Introduction (ch. 1) when commenting on the In Parm. passage of Proclus' critique:

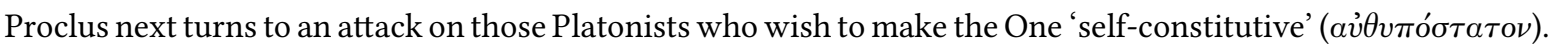

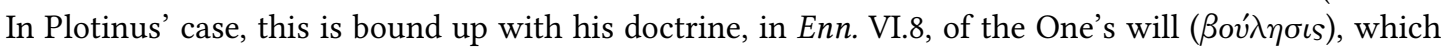
brings about its self-generation. For Proclus, self-constitution seems inevitably to involve a duality of creating and created aspects. Plotinus, however, is second to no man in his insistence on the complete simplicity of the One, so the dispute here is really a matter of semantics, with, if anything, Proclus not appreciating the subtlety of Plotinus' reasoning. ${ }^{204}$

Dillon's interpretation of the dispute between Plotinus and Proclus as being one of semantics rests on the assumption that both hold essentially the same model of the One's simplicity, and second, following on

${ }^{204}$ Morrow/Dillon (trans.) 477. 
this previous assumption, that Proclus is not addressing Plotinus' careful use of 'as if' language in relation to the One's self-constitution-implying that speaking about the One in literal or metaphorical terms is otherwise inconsequential. Both assumptions, however, do not hold up on our analysis so far.

The problem with the first assumption is that we have seen Plotinus' conception of the One's simplicity stand differently to Proclus based on the One's causality. Because Plotinus' One directly produces Intellect, it must pre-contain within itself Intellect's multiplicity in a hidden, unified way that is ineffable-in the same way that the Form of Beauty stands as 'formless' in relation to beautiful things. ${ }^{205}$ Although the One is absolutely simple, looked at from one side, looked at from another side 'as if' in itself, the One anticipates the attributes of multiplicity which are manifested in Intellect's generation and consequent self-constitution. On this count, the One's quasi-self-constitution is a consequence of this. Proclus' One, on the other hand, merely produces the Limit and Unlimited as the positive dual aspects of itself, where it is the latter two that are the first causes of multiplicity. All the attributes of the intelligible realm implying multiplicity reduce back to the pair of Limit and Unlimited, which in themselves end up reflecting positive dual aspects of the One. In this sense, Proclus' One is entirely negative in being absolutely simple and pure unity, so that it does not directly anticipate the multiplicity of the realm of being in the way Plotinus' One does.

The response to the second assumption ends up following from this latter understanding. Although Proclus does not explicitly address Plotinus' use of 'as if' (oiov) language as applied to the One in the passage, Proclus has Plotinus' causal model in mind which implies and justifies Plotinus' analogical language. Our earlier analysis showed that Plotinus speaking of the One's implicit, positive attributes in 'as if' terms, including its self-constitution, indicates real aspects about the One's being, although in purely metaphorical terms which are improper and technically incorrect when applied literally. This follows on seeing the One like the Form of Beauty in relation to beautiful particulars, so that one can ascribe qualities from those particulars to the Form, but in a way that is inferior to the Form in itself in relation to the particulars. Proclus attacks this approach to the One when he critiques those who hold to the One having 'models before models'. ${ }^{206}$ This is connected with seeing Intellect and Soul in Plotinus' system as imperfect realizations of what the One is ineffably but perfectly, including in terms of self-constitution. It is this understanding of the One's causality that is tied to the language that Plotinus allows-not literal but analogical, in respecting the nature of the 'models before models'. With this in mind, Proclus is indirectly addressing Plotinus' 'as if' language in this critique, which underlies his particular his particular critique of the One's quasi-self-constitution in Plotinus.

${ }^{206}$ In Parm. 1107.8-17, in commenting on Parmenides 137c-d, when the One is denied having parts or being a whole: 'There are other authorities, however, who have said that since the first principle is cause of all things, situated above Life, above Intellect, above Being itself, it possesses within itself in some way the causes of all these things unutterably and unimaginably and in the most unified way, and in a way unknowable to us but knowable to itself; and the hidden causes of all things in it are paradigms prior to paradigms [or 'paradigms of paradigms'] ( $\pi \alpha \rho \alpha \delta \epsilon i \gamma \mu \alpha \tau \alpha \pi \alpha \rho \alpha \delta \epsilon \iota \gamma \mu \alpha ́ \tau \omega \nu)$, and the primal entity itself is a whole prior to wholes, not having need of parts. A whole prior to parts has in some way need of the parts, and it is this that Plato has denied of it here, whereas a whole prior to wholes has no need of parts' (trans. Morrow/Dillon). Cf. D’Ancona Costa 376-7. Proclus goes on to say that such authorities fail to notice Plato's emphasis that one should only speak in negations in relation to the One. Thus we also see here that Proclus is motivated by a more strict exegesis of the Parmenides in relation to speaking of the One in itself.
} 
In Proclus' view, the ultimate problem for allowing this analogical language of the One is that it fails to describe the One as a purely negative cause. On Proclus' causal model, the One must function as the negative counterpart to the Limit and Unlimited, out of which the various structures of being and multiplicity come about. To speak any other way about the One than in negative terms would imply that the One has 'models before models', which both puts into question the One being a source of pure unity, only understood in negative terms, and fails to look at the Limit and the Unlimited as the positive manifestations of the One. ${ }^{207}$ Thus, although both Plotinus and Proclus agree on the One's absolute simplicity in applying negations at the literal level, for Proclus this means a denial even of metaphorical terms-ultimately the ground on which he refutes Plotinus' arguing for self-constitution in the One.

\subsection{Conclusion: Proclus' Causal Model as a Response to Plotinus}

Proclus' critique of Plotinus ultimately holds depending on how strongly one pushes the One's absolute simplicity in the direction of negating any relation to all multiplicity. And yet, however one sees the requirement for the first principle's simplicity, Plotinus' understanding of the One exposes a basic tension with the One's simplicity pre-containing the attributes of multiplicity as a direct cause of Intellect. ${ }^{208}$ Although Plotinus attempts to hedge his language of the One constituting itself in qualified terms, the very notion of self-constitution implies distinction, which Proclus outlines in his critique. It appears that Proclus wants to take seriously the implication of the One's simplicity implying pure negation, which is one reason he moves self-constitution strictly to the realm of intellect and soul, where the various attributes of being are produced with each entity constituting itself (Being, for instance, constituting itself from the Limit/Unlimited, while Life constitutes itself from Being, etc.). In doing this, Proclus leaves the One as an unparticipated cause of pure unity that is mediated through the Limit and Unlimited. ${ }^{209}$

One can see from this how Proclus is attempting to side-step the problem of the One being a cause of multiplicity without also having that multiplicity implied in itself by its causal association. This is ultimately what plays into Proclus' rejection of self-constitution in the One. On the flip side, one difficulty of Proclus' system is that, by de-emphasizing any direct tie to being and multiplicity, it is hard to see how the One functions as a meaningful cause of all things. ${ }^{210}$ Proclus' description of the One causing by way of negation could still end up facing the same difficulty to the question that Plotinus asks of how the One produces that which it does not have. ${ }^{211}$ At least what we see in Proclus is an attempt to provide a more systematic answer to Plotinus' own question by externalizing the One's production of being through selfconstituted entities coming from the One by means of the Limit and Unlimited. To this extent, Proclus' system is an improvement on the idea of holding that the first principle is absolutely simple and, at once,

${ }^{210}$ A critique Damascius may also implicitly have in mind in his re-appropriation of Proclus' system, where he ends up positing the 'Ineffable' prior to the One, in order to balance the One having some causal connection to all things as their principle, while safeguarding the notion of absolute simplicity implying absolutely no relation to anything, even with the negation of 'cause' applied to the One (it is on this account that Damascius speaks of a 'negation of negation' in relation to the Ineffable). On this, see Opsomer (2013) 638ff.

${ }^{211}$ Cf. p. 34.
} 
responsible for the production of the multiplicity that is being. 


\section{Appendices}

\section{A The One and the Henads in Proclus}

If we return to Elem. Theol. prop. 6, an important insight offered is that the One must have a first participant, the first 'unified group', immediately after it:

For if there is a 'One itself', it must have a first participant, which is the first unified group. And this first group is composed of henads: for if it be composed of unified groups, these in turn will be composite, and so to infinity. The first unified group, then, is composed of henads; and we have found true what we enunciated. (Elem. Theol. 6.26-30; trans. Dodds)

The introduction of this proof is, in a sense, a corollary to prop. 5, where there was a hypothetical 'One' that itself implied multiplicity while acting as a participated principle for a given plurality (B2 and B3, from earlier). ${ }^{212}$ This is part of Proclus' general proposition that, 'every manifold is composed either of

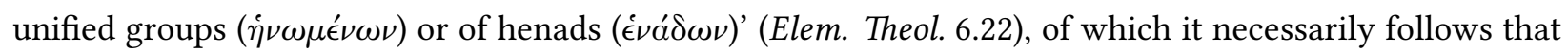
the One itself must have a participant and a 'unified group'. Proclus' statement that there must be a first participant and unified group following on the One becomes foundational for the introduction of a quasilevel of 'henads' between the One and the realm of intellect (specifically Being, Life, and Intellect) in Elem. Theol. prop. 113-115. The henads exist as principles of unity for the entities of Being, Life, and Intellect, where each latter is a participated principle (B2) of their respective unified group (B3); following the logic of a need for an unparticipated principle above (B3) and (B2), each henad is then a higher principle of unity (B1) for each of Being, Life, and Intellect with its corresponding participants. ${ }^{213}$

The henads stand uniquely as intermediaries between the One and the intelligible realm. Because they are prior to the entities of Being, Life, and Intellect, the henads are beyond being, just like the One, and thus beyond knowledge. ${ }^{214}$ What makes the henads akin to the One, and therefore in the same ranking as the One, is their character as in being a oneness, reflecting their name (év̀), and as self-complete ( $\alpha \dot{\tau} \tau o \tau \epsilon \lambda \grave{\eta} s$ ) implying commonality with the Good as One. ${ }^{215}$ As a result, they are what make possible the One's communication of unity to beings through all beings' participation in the henads (at least in the case of Being, Life and Intellect), while they also guarantee the One's status as the absolute unparticipated entity in the causal chain. ${ }^{216}$ One could perhaps ask, however: if the One, as unparticipated relative to the entities of being, guarantees the unity of the henads as participated entities and the henads' participants

\footnotetext{
${ }^{212} \mathrm{Cf}$. discussion of B1/B2/B3 in pp. 44-45.

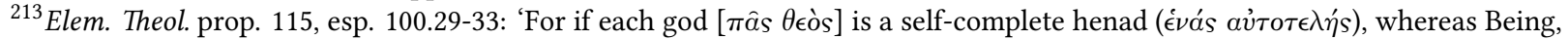
Life, and [Intellect] are not henads but unified groups, then it is plain that every god transcends all the three principles in question. For if these three, though mutually distinct, are each implicit in the other two, then no one of them can be a pure unity, since each contains all' (trans. Dodds). In this case, Proclus calls the henads 'gods' insofar as each partakes of its 'originative cause', which is the One (Elem. Theol. prop. 113, 100.13-15). Since the One is identified as God, insofar as the One is the Good (Elem. Theol. prop. 13) and Proclus has identified the Good with being God (Elem. Theol. prop. 112; 113, 100.10-12), it follows the henads are gods by being participants of the One.

${ }^{214}$ Elem. Theol. 100.34-102.12.

${ }^{215}$ Elem. Theol. prop. 114.

${ }^{216}$ Elem. Theol.. 116, esp. 102.14-16: 'For in the first place it is clear that the One is imparticipable: were it participated, it would thereby become the unity of a particular and cease to be the cause both of existent things and of the principles prior to existence' (trans. Dodds).
} 
(like Being, Life, and Intellect), why should the One not be itself subject to the same necessity of another unparticipated unity which unites both it and the apparent multiplicity of henads it stands over? However, we should take note that the way the One is related to the henads is distinct to the way Being, for instance, is related to its participants of particular beings: as sharing the same attribute of unity that the One has, ${ }^{217}$ the henads are equally absolutely simple as the One, which is in contrast to the relationship between the participated principle of Being in relation to its participants, where there is a gradation of unity between the latter two. ${ }^{218}$

The result of seeing the henads as the first participated entities below the One is that they are that by which the One communicates unity to all lower entities, where we might say that the henads are participated aspects of the One. ${ }^{219}$ Thus, the henad of Being is one aspect of unity which is participated by Being itself, while the henad of Life is another, distinct aspect of unity which participated by Life itself. Each henad thus communicates an aspect of unity which is unfolded in each entity's self-constituted being. ${ }^{220}$ This is one way in which the One is absolutely removed from any implication or connection with multiplicity, where the henads become the intermediaries of the One as the direct participated entities, and by implication causes, of entities in the intelligible realm which involve multiplicity. At the same time, the One can function as a cause in such a way that it is not implicated in multiplicity through its causing unity by the henads. ${ }^{221}$

Although the henads are the intermediary causes of being, one might ask how the henads come about as distinct 'self-complete' entities from the One, although identical to the One in the character of unity. On this, a look at Elem. Theol. prop. 159 mentions: 'Every order of gods is from the two initial principles

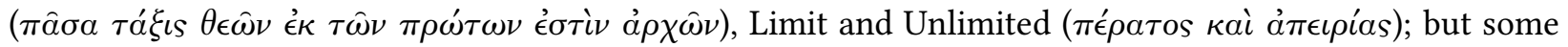
manifest predominantly the causality of the Limit, others that of the Unlimited' (trans. Dodds, lightly modified). In this, Proclus notes that two principles, the Limit and Unlimited, lie in some way at the basis of the existence of the henads. ${ }^{222}$ So even here with the henads as intermediate entities, the two principles of Limit and Unlimited are in some sense essentially connected with the henads and their production for

\footnotetext{
${ }^{217}$ Elem. Theol. prop. 113.

${ }^{218}$ Although because the henads are participated by entities which are characterized by plurality, they are technically not as simple as the One in itself. Cf. Opsomer (2013) 13.

${ }^{219}$ Opsomer (2013) 13: 'As [the henads] are that in which Being participates, they are themselves above Being. Accordingly they are characterized by perfect simplicity, just like to hen. They differ from to hen, however, not only by there being more than just one of them, but also by being participated tokens of unity'

${ }^{220}$ Elem. Theol. prop. 118

${ }^{221}$ Elem. Theol. prop. 137, 120.31: 'Every henad is co-operative with the One in producing the real-existent which participates

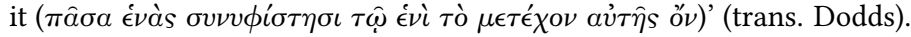

${ }^{222}$ Implied in the 'order of gods', where the henads were shown to be gods earlier.
} 


\section{Proclus. ${ }^{223} 224$}

\footnotetext{
${ }^{223}$ Exactly how Proclus understands this proposition to be understood is somewhat ambiguous, however: in saying that the Limit and the Unlimited are those from which the 'order of gods' (or, that is, henads) are derived, does Proclus mean the henads themselves are composed of Limit/Unlimited? Or is he implying the order that proceeds from the henads? This would throw into question the henads' simplicity, if they are supposed to inherit the same character from the One. In his commentary on prop. 159,

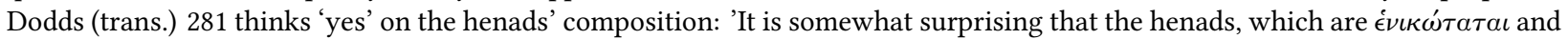

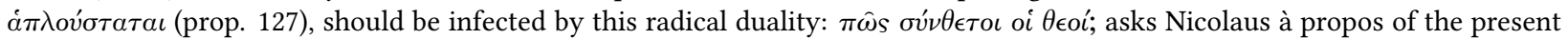
passage, and I confess I do not know the answer.' Butler 391-2 answers in the negative: 'But on what basis are we supposed to assume that principles of classification precede the Gods? What manner of entity are Limit and Infinity supposed to be? Proclus does not simply posit entities out of the ether without grounding their manner of existence. He posits the Gods, and all agency in the universe is reducible to their activity, the highest schematization of which consists in the contrast between each God's limit-aspect and their infinity-aspect. This does not impart a 'radical duality' into the henad for the very reason that Limit and Infinity, as the highest of forms, are instruments of the divine illumination of Being, and are relevant for us and to us. They are arise from an analysis of the nature of the Gods the ground of which is no real composition.' On this, Butler appears to offer a safer analysis of this question. For our present purposes, we may note this question in passing, but focus on the fact that Proclus' principles of Limit and Unlimited, although different kinds of principles in his system compared to the entities of the One, henads, and those of the intelligible realm, are the proper 'instruments' by which the One brings about being.

${ }^{224}$ In passing, we should also note that it is a question why Proclus has to posit two intermediary principles-the henads, and the Limit/Unlimited-in the One's production of multiplicity. D'Ancona Costa (1996) 379 characterizes the need for these two principle sets this way: 'One may ask if the two accounts are inconsistent or, rather, complementary, and this question might be answered only by means of an analysis which lies beyond the scope of this paper. What is important to emphasize here is the fact that Proclus feels compelled to provide two explanations for the origin of multiplicity, the one pivoting on the idea that if the intelligible realm has an intrinsic variety, this is owing to the presence of a hypostasis-the Unlimited-which intermingles with the Limit; and the other which tries to explain how it is possible that the variety of the Ideas comes from the One, without being beforehand 'in' the One.'
} 


\section{B Some Conceptual Background on the Limit and Unlimited in Proclus}

Proclus' discussion of the Limit and Unlimited as constituent principles of Being is drawing from Plato's Philebus, where Plato employs these this pair as distinct principles from which all being is created. ${ }^{225}$ This is also a part of later developments in the Old Academy and middle Platonism, including especially neoPythagoreanism, which Proclus explicitly draws in his interpretation and application of Plato's principles in the dialogue. In Plato's Philebus the Limit/Unlimited distinction is brought up in reference to Socrates' attempt in the dialogue to answer whether the intellectual life or the life of pleasure is the Good. When Socrates first brings up the two elements, he references 'people of old' who say that the 'limit' and 'unlimited' are found in all things. ${ }^{226}$ Eventually in Philebus $25 \mathrm{~b}-27 \mathrm{c}$, Socrates expands the analysis of Limit and Unlimited in themselves to a four-part distinction of Limit, Unlimited, mixture, and cause, ${ }^{227}$ where the cause, as the 'craftsman' who mixes the combination of Limit and Unlimited, is 'always leading in the order of nature, while the thing made follows since it comes into being through it...' (Philebus 27a4; trans. Frede).

This four-part set of principles that Plato discusses is applied in the Old Academy doctrines, as reported by Aristotle, to the first principles of the One and the Indefinite Dyad, where the One acts on the Indefinite Dyad by imposing 'limit' ( $\pi \epsilon \rho \alpha s)$ to form a system of natural numbers, which appear to form the basis for the creation of Forms (although characterized as 'Form-numbers', where the Forms now appear to be thought of as numbers). ${ }^{228}$ In this case, the 'limit' and the craftsman/cause of Philebus appear to be molded together into the 'One' of the Old Academy view, where the One imposes itself, which is the 'limit', onto the Indefinite Dyad as a separate principle from the One but also co-existing with the One. While Proclus in some sense will note a connection between the 'limit' and the craftsman as described in the Old Academy 'One', he also wants to assert the distinction between the craftsman as first cause over the 'limit' and corresponding 'unlimited' (as represented with the Indefinite Dyad), where the latter two end up as derivations from the transcendent One. On this, Proclus has as his precedent the middle Platonist and Neopythagorean Eudorus of Alexandria, who posits the transcendent One as a supreme first principle over the 'monad' and 'dyad' (in functionally similar roles to the 'limit' and 'unlimited') in his interpretation of the Pythagoreans. Eudorus, in holding to the transcendent One, sees that positing the opposed principles of the monad and dyad as absolute first principles is insufficient if they are also causes of each other, where he instead holds that there must be a prior first principle which is common to the

\footnotetext{
${ }^{225}$ Proclus explicitly cites this connection in In Parm. 938.5-6, 1122.7-9.

${ }^{226}$ Philebus 16c5-d5, esp.: 'And the people of old, superior to us and living in closer proximity to the gods, have bequeathed us this tale, that whatever is said to be consists of one and many, having in its nature limit and unlimitedness. Since this is the structure of things, we have to assume that there is in each case always one form for every one of them, and we must search for it, as we will indeed find it there' (trans. Frede).

${ }^{227}$ Plato, via Socrates, introduces mixture as third component in Philebus 25b-26d, where the mix of Limit and Unlimited brings about certain, specific generations. One example is the right mixture which brings health out of sickness: 'Socrates: Is it not true that in sickness the right combination of the opposites establishes the state of health? Protarchus: Certainly. Socrates: And does not the same thing happen in the case of the high and the low, the fast and the slow, which belongs to the unlimited? Is it not the presence of these factors in them which forges a limit and thereby creates the different kinds of music in their perfection? Protarchus: Beautiful!' (Philebus 25e8-26a4; trans. Frede). The final, fourth category of 'cause' is mentioned in Philebus 26e1-27b3 as the 'craftsman' who mixes together the kinds to create the specific generations and mixes.

${ }^{228}$ Metaphysics 987a29ff. See Dillon (2003) 18-21 for further background of this view.
} 
pair. $^{229}$ Given this, it is interesting to see that Eudorus also refers to the monad and dyad as 'elements' ( $\sigma \tau \circ \iota \chi \epsilon \hat{\imath} \alpha$ ), while the transcendent One is ultimately a principle ( $\left.\dot{\alpha} \rho \chi \eta^{\prime}\right)$ over the two. ${ }^{230}$

Given this background, especially with Eudorus' innovations, Proclus on the one hand recognizes that all things derive from the combination of the Limit and the Unlimited, where the element of the limit is applied to the unlimited to create the various mixtures of being, as implied in Plato's Philebus. At the same time, Proclus incorporates the Old Academy insights in seeing the Limit as a 'One' in imposing unity on things, where the Limit mirrors the One in directly being the cause of unity for all things. Balancing with this, Eudorus' insights are also incorporated by making the One transcendent over the Limit and Unlimited, instead of holding to a dualistic set of principles with the One and Indefinite Dyad of the Old Academy doctrines, where the Limit and Unlimited are derived from the One. By combining these two insights, Proclus wants to derive all real multiplicity from two, basic elements which arise from the One, which would make possible a way in which the One can be described as absolutely simple and cause of unity, on the one hand, while the derivation of multiplicity from it is proportionate to its simplicity.

\footnotetext{
${ }^{229}$ Dillon (1977) 126-127. Dillon also notes on 127: 'The Old Pythagoreans, on the other hand, do not seem to have postulated a single supreme principle, but rather a pair, Limit and Unlimited, which for Eudorus is only secondary.' Dillon notes from this that Eudorus may be original with positing a supreme One above the monad/limit and dyad/unlimited.

${ }^{230}$ Dillon (2014) 261. Dillon further notes on 261-2: 'Now there can be no question of this system corresponding to anything in ancient Pythagoreanism, but it is nonetheless interesting for that. It would seem to be an extrapolation, either by Eudorus himself or some pseudo-Pythagorean text, of the system of Limit and Unlimited propounded by Plato in the Philebus (16c-30e), together with the Good, and/or the One of the Parmenides. The 'cause of the mixture' of Philebus 27c may also be in play here, regarded as a separate principle superior to the other two.
} 


\section{Bibliography}

\section{Primary Sources}

Aristotle. 1984a. 'Metaphysics'. In The Complete Works of Aristotle, ed. by Jonathan Barnes, trans. by W.D. Ross. Princeton: Princeton University Press.

- . 1984b. 'On the Soul'. In The Complete Works of Aristotle, ed. by Jonathan Barnes, trans. by J.A. Smith. Princeton: Princeton University Press.

- . 1984c. 'Parts of Animals'. In The Complete Works of Aristotle, ed. by Jonathan Barnes, trans. by W. Ogle. Princeton: Princeton University Press.

- . 1984d. 'Physics'. In The Complete Works of Aristotle, ed. by Jonathan Barnes, trans. by R.P. Hardie and R.K. Gaye. Princeton: Princeton University Press.

- . 1984e. 'Topics'. In The Complete Works of Aristotle, ed. by Jonathan Barnes, trans. by W.A. PickardCambridge. Princeton: Princeton University Press.

Plato. 1997a. 'Parmenides'. In Plato: Complete Works, ed. by John M. Cooper, trans. by Mary Louise Gill and Paul Ryan. Indianapolis: Hackett Publishing.

— . 1975. 'Phaedrus'. In Plato in Twelve Volumes, ed. by John M. Cooper, trans. by Harold N. Fowler, vol. 9. Harvard: Harvard University Press.

- . 1997b. 'Philebus'. In Plato: Complete Works, ed. by John M. Cooper, trans. by Dorothea Frede. Indianapolis: Hackett Publishing.

- . 2008. Plato: Laws 10. Trans. and comm. by Robert Mayhew. Oxford: Oxford University Press.

- . 1997c. 'Republic'. In Plato: Complete Works, ed. by John M. Cooper, trans. by G.M.A. Grube. Revised trans. by C.D.C. Reeve. Indianapolis: Hackett Publishing.

- . 1997d. 'Sophist'. In Plato: Complete Works, ed. by John M. Cooper, trans. by Nicholas P. White. Indianapolis: Hackett Publishing.

- . 1997e. 'Symposium'. In Plato: Complete Works, ed. by John M. Cooper, trans. by Alexander Nehamas and Paul Woodruff. Indianapolis: Hackett Publishing.

- . 1997f. 'Timaeus'. In Plato: Complete Works, ed. by John M. Cooper, trans. by Donald J. Zeyl. Indianapolis: Hackett Publishing.

Plotinus. 1966-88. Enneads. Ed. and trans. by A.H. Armstrong. 7 vols. Cambridge: Harvard University Press. Porphyry. 1992. On Aristotle's Categories. Trans. by Steven K. Strange. Ithaca: Cornell University Press.

Proclus. 2009. Procli in Platonis Parmenidem commentaria. Ed. by Carlos Steel. Vol. 3. Critical edition by Carlos Steel and Leen van Campe. Oxford: Oxford University Press.

- . 1987. Proclus' Commentary on Plato's Parmenides. Trans. by Glenn R. Morrow and John M. Dillon. With a comment. by John M. Dillon. Princeton: Princeton University Press.

- . 1963. The Elements of Theology. Trans. and comm. by E.R. Dodds. Oxford: Clarendon Press.

Syrianus. 2006. On Aristotle Metaphysics 3-4. Trans. by Dominic O’Meara and John Dillon. Ithaca: Cornell University Press.

\section{Secondary Sources}

Barnes, Jonathan. 1983. 'Immaterial Causes'. Oxford Studies in Ancient Philosophy 1:169-92. 
Bierwaltes, W. 1999. 'Causa sui. Plotinus Begriff des Einen als Ursprung des Gedankens der Selbstursächlichkeit'. In Traditions of platonism: essays in honour of John Dillon, ed. by John J. Cleary, 191-226. Aldershot: Ashgate.

Bussanich, John. 2007. 'Plotinus on the Being of the One'. In Metaphysical Patterns in Platonism: Ancient, Medieval, Renaissance, and Modern, ed. by John Finamore and Robert Berchman, 57-72. New Orleans: University Press of the South.

- . 1988. The One and its Relation to Intellect in Plotinus. Leiden: Brill.

Butler, Edward P. 2003. 'The Metaphysics of Polytheism in Proclus'. PhD thesis, New School University.

Chiaradonna, R. 2002. Sostanza, movimento, analogia: Plotino critico di Arisotele. Naples: Bibliopolis.

Chlup, Radek. 2012. Proclus: An Introduction. Cambridge University Press.

Crystal, Ian M. 2002. Self-Intellection and Its Epistemological Origins in Ancient Greek Thought. Burlington: Ashgate Publishing Company.

D'Ancona Costa, Cristina. 1996. 'Plotinus and later Platonic philosophers on the causality of the First Principle'. In The Cambridge Companion to Plotinus, ed. by Lloyd P. Gerson, 356-85. Cambridge: Cambridge University Press.

De Rijk, LM. 1992. 'Causation and Participation in Proclus: The Pivotal Role of Scope Distinction in his Metaphysics'. In On Proclus and his Influence in Medieval Philosophy, ed. by E.P. Bos and P.A. Meijer, 1-34. Leiden: Brill.

Deslauriers, Marguerite. 2007. Aristotle on Definition. Leiden: Brill.

Dillon, John. 1988. 'Porphyry and Iamblichus in Proclus: Commentary on the Parmenides'. In Gonimos: Neoplatonic and Byzantine Studies Presented to Leendert G. Westerink at 75, 21-48. Buffalo: Arethusa.

- . 1992. 'Porphyry's Doctrine of the One'. In Sophies Maietores, ed. by M.-O. Goulet-Cazé, G. Madec and D. O’Brien, 356-366. Paris: Institut d'Etudes Augustiniennes.

- . 2014. 'Pythagoreanism in the Academic tradition: the Early Academy to Numenius'. In A History of Pythagoreanism, ed. by Carl A. Huffman, 250-273. Cambridge: Cambridge University Press.

- . 2003. The Heirs of Plato: A Study of the Old Academy (347-274 BC). Oxford: Clarendon Press.

- . 1977. The Middle Platonists, 80 B.C. to A.D. 220. Ithaca: Cornell University Press.

Eliasson, Erik. 2008. The Notion of That Which Depends On Us in Plotinus and Its Background. Leiden: Brill.

Emilsson, Eyjólfur Kjalar. 2007. Plotinus on Intellect. Oxford: Clarendon Press.

Furley, David. 1994. 'Self-Movers'. In Self-Motion: From Aristotle to Newton, ed. by Mary Louise Gill and James G. Lennox, 3-14. Princeton: Princeton University Press.

Gersh, Stephen. 1978. From Iamblichus to Eriugena: An Investigation of the Prehistory and Evolution of the Pseudo-Dionysian Tradition. Leiden: Brill.

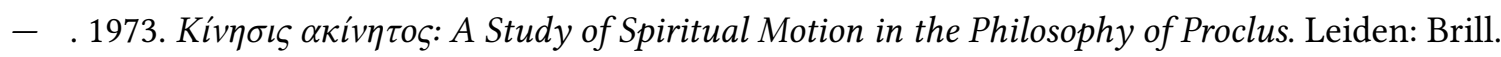

Graeser, Andreas. 1972. Plotinus and the Stoics: A Preliminary Study. Leiden: Brill.

Horn, Christoph. 2007. 'The Concept of Will in Plotinus'. In Reading Ancient Texts. Volume II: Aristotle and Neoplatonism, ed. by Suzanne Stern-Gillet and Kevin Corrigan, 153-78. Leiden: Brill.

Lankila, Tuomo. 2010. 'Henadology in the Two Theologies of Proclus'. Dionysius 28:63-76.

Lloyd, A.C. 1990. The Anatomy of Neoplatonism. Oxford: Clarendon Press. 
Menn, Stephen. 2002. 'Aristotle's Definition of Soul and the Programme of the De Anima'. Oxford Studies in Ancient Philosophy 22:83-139.

— . 2012a. 'Aristotle's Theology'. In The Oxford Handbook of Aristotle, ed. by Christopher Shields, 422-64. Oxford: Oxford University Press.

- . 2012b. 'Self-motion and reflection: Hermeias and Proclus on the harmony of Plato and Aristotle on the soul'. In Neoplatonism and the Philosophy of Nature, ed. by James Wilberding and Christoph Horn, 44-67. Oxford: Oxford University Press.

Narbonne, Jean-Marc. 2007. 'Divine Freedom In Plotinus and Iamblichus (Tractate VI.8 (39) 7, 11-15 and De Mysteriis III, 17-20)'. In Reading Ancient Texts. Volume II: Aristotle and Neoplatonism, ed. by Suzanne Stern-Gillet and Kevin Corrigan, 179-97. Leiden: Brill.

O'Meara, Dominic. 1993. Plotinus: An Introduction to the Enneads. Oxford: Clarendon Press.

Opsomer, Jan. 2012. 'Self-Motion According to Iamblichus'. Elenchos 33 (2): 259-90.

- . 2013. 'Syrianus, Proclus, and Damascius'. In Routledge Companion to Ancient Philosophy, ed. by J. Warren and F. Sheffield, 626-42. New York and London: Routledge.

- . 2009. 'The integration of Aristotelian physics in a Neoplatonic context: Proclus on movers and divisibility'. In Physics and Philosophy of Nature in Greek Neoplatonism, ed. by Riccardo Chiaradonna and Franco Trabattoni, 189-229. Leiden: Brill.

Russi, Chiara. 2009. 'Causality and Sensible Objects: A Comparison Between Plotinus and Proclus'. In Physics and Philosophy of Nature in Greek Neoplatonism, ed. by Riccardo Chiaradonna and Franco Trabattoni, 145-71. Leiden: Brill.

Steel, Carlos. 1994. "Y $\pi \alpha \rho \xi ı \varsigma$ chez Proclus'. In Hyparxis e hypostasis nel neoplatonismo, Atti del I Colloquio Internazionale del Centro di Ricerca sul Neoplatonismo, Università degli studi di Catania, 1-3 ottobre 1992, ed. by F. Romano and D.P. Taormina, 79-100. Firenze: L.S. Olschki.

Vorwerk, Matthias. 2010. 'Plotinus and the Parmenides: Problems of Interpretation'. In Plato's Parmenides and Its Heritage, ed. by John Turner and Kevin Corrigan, 2:23-33. Atlanta: Society of Biblical Literature.

Whittaker, J. 1975. 'The Historical Background of Proclus' Doctrine of the $\alpha \dot{\theta} \theta v \pi$ ó $\tau \alpha \tau \alpha$ '. In De Famblique à Proclus. Entretiens sur l'Antiquité classique XXI, 193-230. Vandoeuvres-Geneva: Foundation Hardt. 